\title{
NOVEL GREEN BIODEGRADABLE POLYLACTIDE BASED POLYURETHANE TRIBLOCK COPOLYMERS REINFORCED WITH CELLULOSE NANOWHISKERS
}

\author{
NOHA ALI ABDEL HADY
}

B.Sc. in Chemistry, Cairo University, Egypt, 1993

\author{
A thesis \\ presented to Ryerson University \\ in partial fulfillment of the requirements for the degree of \\ Master of Applied Science \\ in the program of \\ Chemical Engineering
}

Toronto, Ontario, Canada, 2017

(C) Noha A. Abdelhady, 2017 


\section{AUTHOR'S DECLARATION}

I hereby declare that I am the sole author of this thesis. This is a true copy of the thesis, including any required final revisions, as accepted by my examiners.

I authorize Ryerson University to lend this thesis to other institutions or individuals for the purpose of scholarly research.

I further authorize Ryerson University to reproduce this thesis by photocopying or by other means, in total or in part, at the request of other institutions or individuals for the purpose of scholarly research.

I understand that my thesis may be made electronically available to the public. 


\title{
ABSTRACT \\ Novel Green Biodegradable Polylactide Based Polyurethane Triblock Copolymers Reinforced With Cellulose Nanowhiskers
}

\author{
MASc, 2017 \\ Noha Ali Abdel Hady \\ Department of Chemical Engineering, Ryerson University
}

Novel green classes of biodegradable polylactide-based triblock polyurethane (TBPU) polymers were synthesized. Owing to their tailored mechanical properties, improved degradation rates, and the enhance cell attachment potential compared with polylactide-homopolymer, they tested for biomedical applications. Triblock copolymers (TB) of different lactide and polyethylene glycol composition were first fabricated by ring-opening polymerization using tin octoate as catalyst. Afterwich polycaprolactone diole (PCL-diole) is reacted with TB copolymers using 1,4-butane diisocyanate (BDI) as nontoxic chain extender to form the final TBPUs. Final composition, molecular weight, thermal properties, hydrophilicity and biodegradation of the obtained TB and TBPU were studied and characterized using ${ }^{1} \mathrm{H}-\mathrm{NMR}$, GPC, FTIR, DSC, SEM and contact angle measurements. Results obtained from the high molecular weight members of TBPUs showed improved hydrophilicity and degradation rates along with tailored mechanical properties. Nanocomposites obtained by reinforcing TBPU3 with 7\% (w/w) BCNW showed $~ 16 \%$ increase in tensile strength and 330\% in \% elongation compared with PL-homopolymer. Those polymers and their nanocomposites demonstrated promising potential to be used as bone cement, and in regenerative medicin. 


\section{ACKNOWLEDGEMENTS}

This work was carried out between 2015 and 2017 in the Nanocomposites and Biomaterials Engineering Laboratory, Chemical Engineering Department, Ryerson University, Toronto, Canada. The research was part of my MASc study.

I wish to express my gratitude to Professor Yaser Dahman for his good advice and interest in my work, and for providing the opportunity to work in his research group.

In particular, I want to acknowledge my co-worker Dr. Mohamed Khattab for his invaluable contribution, advantageous comments, and encouragement during this work, as well as his fruitful co-operation in many areas.

Further, I would like to thank, Dr. Russell Viirre from the Department of Chemistry and Biology at Ryerson University, for allowing me to conduct NMR analyses.

I would also like to acknowledge Shawn McFadden for allowing me to used FTIR, DSC, and GPC instruments.

I would also thank Ali Hemmati and Daniel Boothe for all the technical assistance including making the molds.

Many thanks for the help received from Mr. Qiang Li, from the Department of Mechanical Engineering at Ryerson University, who conducted SEM analyses.

All the staff in the Chemical Engineering department who helped during this work is sincerely thanked.

\section{Noha Abdel Hady}




\section{TABLE OF CONTENTS}

Author's Declaration $\quad$ ii

Abstract iii

Acknowledgements $\quad$ iv

List of Tables $\quad$ viii

List of Figures $\quad$ ix

List of Schemes $\quad$ x

List of Appendices $\quad$ xi

CHAPTER 1 - INTRODUCTION 1

1.1 Overview and Background 1

1.2 Problem Statement $\quad 4$

1.3 Objectives and Specific Aims $\quad 4$

1.4 Research Plan $\quad 6$

CHAPTER 2 - LITERATURE REVIEW

$\begin{array}{lr}\text { 2.1 Polymerization Methods of Lactic Acid } & 8\end{array}$

2.2 Chemical Modification of PLA through Copolymerization with PEG: A 12 Review

2.3 Chemical Modification of PLA through Chain Extention/Chain Linker Using 14 Urethane Reactions: A Review

2.4 Synthesis of Poly(ester-urethane) 16

2.5 Hydrolytic Degradation of Poly(ester-urethane) 17

$\begin{array}{ll}2.6 \text { Bacterial Cellulose Nanowhiskers } & 18\end{array}$

2.6.1 Tensile Properties of BCNW and their Reinforcement Potentials 19

2.6.2 Nanocomposites of BCNW with Biodegradable Polymers $\quad 20$

2.6.3 Micromechanical Modeling for Predicting and Investigating the Reinforcing 21

Potential of BCNW in Nanocomposites

2.7 Mechanical Properties of PL Based Poly(ester-urethane) 22

2.8 Mechanical Properties of PL Based Cellulose Nanocomposites 23 
2.9 Biomedical Applications of PLA-PEG copolymers

2.9.1 Tissue engineering (TE)

2.9.2 Wound management 25

2.9.3 Drug Delivery Systems (DDS) $\quad \mathbf{2 5}$

2.9.4 Orthopedic devices $\quad 27$

CHAPTER 3 - EXPERIMENTAL 28

3.1 Materials 28

3.2 Culture Growth Medium 28

3.3 Preparations $\quad 29$

3.3.1 Bacterial Strain and Culture Growth Conditions 29

3.3.2 Production of BC Nanofibers 29

3.3.3 Preparation of Bacterial Cellulose Nanowhiskers (BCNW) 30

3.3.4 Suspension of BCNW in Organic Solvent 30

3.3.5 Synthesis of PL-PEG-PL Triblock Copolymer (TB) 31

3.3.6 Separation and Purification of TB copolymers $\quad 31$

3.3.7 Synthesis of TB-BDI Pre-polymer $\quad 32$

3.3.8 Synthesis of Triblock Polyurethane Polymers (TBPUs) 32

3.3.9 Preparation of Polymer Films $\quad 33$

3.3.10 Preparation of TBPU/BCNW Composites $\quad 33$

3.4 Characterization Techniques and Analysis Procedure $\quad 34$

3.4.1 Fourier Transform Infra-red Spectroscopy (FTIR/ATR) 34

3.4.2 ${ }^{1} \mathrm{H}$-NMR spectra $\quad 34$

3.4.3 Calculation of Molecular Weight of Copolymer Using ${ }^{1} \mathrm{H}-\mathrm{NMR} \quad 34$

3.4.3.1 Determination of the DP and Molecular Weight 34

3.4.3.2 Copolymer Composition Characterization $\quad 35$

3.4.4 Gel Permeation Chromatography (GPC) 36

3.4.5 Differential Scanning Calorimetry (DSC) 36

3.4.6 Water Content Measurements $\quad 36$

3.4.7 Contact Angle Measurements $\quad 37$

3.4.8 Biodegradation $\quad \mathbf{3 7}$

3.4.9 Field Emission Scanning Electron Microscopy (FE-SEM) 37 
4.2 Characterization of The Synthesized PL-PEG-PL and TBPUs 40

4.2.1 ATR-FTIR Spectra $\quad \mathbf{4 0}$

4.2.2 ${ }^{1} \mathrm{H}-\mathrm{NMR}$

4.3 Water Absorption and Contact Angle Testing of TB Copolymer and their TBPUs 48

4.4 Degradation and Morphological Changes $\quad 51$

4.5 Thermal Properties of TBPUs Copolymers $\quad 56$

4.6 Mechanical Properties of TB and TBPUs $\quad 58$

4.7 Satistical Analysis and Error Calculations $\quad 64$

CHAPTER 5- CONCLUSION AND PROSPECTS

5.1 Conclusion $\quad 65$

5.2 Future prospects $\quad 66$

$\begin{array}{lr}\text { APPENDICES } & 67\end{array}$

$\begin{array}{ll}\text { Appendix A. Gluconacetobacter xylinus (ATCC } ® 700178^{\mathrm{TM}} \text { ) } & \mathbf{6 7}\end{array}$

$\begin{array}{ll}\text { Appendix B. }{ }^{1} \text { H-NMR Spectra } & 68\end{array}$

$\begin{array}{ll}\text { Appendix C. Row data of some replicated experiments } & \mathbf{7 3}\end{array}$

Appendix D. Mechanical Testing $\quad 75$

$\begin{array}{ll}\text { REFERENCES } & 77\end{array}$ 


\section{LIST OF TABLES}

Table 2.1 A selective summary of studies on PLA polymerization using tin compounds as catalyst

Table 2.2 Polylactic acid (PLA)-based structures applied in biomedical and tissue engineering applications.

Table 2.3 Investigations on PLA-PEG copolymers as drug delivery systems............ 26

Table 4.1 Feed composition used in preparing PL-PEG-PL triblock copolymer.......... 40

Table 4.2 ${ }^{1} \mathrm{H}$-NMR $\left(\mathrm{CDCl}_{3}\right)$ chemical shift of (PL-PEG-PL) triblock copolymer......... 43

Table 4.3 $\mathrm{PL}_{\mathrm{x}} / \mathrm{PEG}_{\mathrm{y}} / \mathrm{PL}_{\mathrm{x}}$ triblock copolymers obtained from polymerization of lactide and PEG of different feed ratios........................................ $\quad 45$

Table 4.4 ${ }^{1} \mathrm{H}$-NMR $\left(\mathrm{CDCl}_{3}\right)$ chemical shift of TBPU............................ 46

Table 4.5 Feed ratios, number average molecular weights and thermal properties of the different polyurethanes synthesized in this study........................ 47

Table 4.6 Contact angles of TB copolymers and TBPUs synthesized using different LA/PEG feed ratios ..................................................

Table 4.7 Tensile properties of the different polymer films and their nanocomposites with BCNW

Table 4.8 Mechanical properties of biodegradable polyesters, few tissues and commercially available biomaterials 


\section{LIST OF FIGURES}

Figure 2.1 Methods of obtaining high molecular weight PLA.................... 8

Figure 2.2 Lactide stereoisomers: from left to right: L-lactide, meso-lactide and Dlactide.

Figure 2.3 Cationic octanoic acid co-initiated mechanism of lactide polymerization in presence of stannous octoate.

Figure 2.4 Reaction of isocyanate with (A) alcohol, (B) carboxylic acid, (C) urethane, and (D) amide.

Figure 2.5 (A) Schematic illustration for BC biosynthesis and nanofibers production; (B) cellulose-producing bacteria, G. Xylinus during production.

Figure 2.6 Schematic presentation for acid hydrolysis of amorphous regions and the formation of BCNW along with AFM images of cellulose nanowhiskers produced from $\mathrm{BC}$ by $\mathrm{H}_{2} \mathrm{SO}_{4}$ hydrolysis

Figure 2.7 Di- and triblock copolymers and their association to form nanoparticles that can contain noscapine. (A) Polymeric nanoparticles of triblock PLA-PEGPLA. (B) Polymeric nanoparticles of diblock PEG-PLA....................

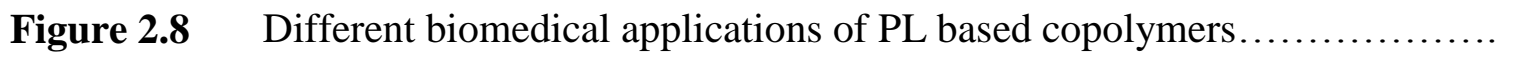
Lab photo showing BC pellicles during their production from shake culture.

Figure 4.2 ATR-FTIR spectra of PCL-diole, triblock copolymer conjugated with BDI (TB-BDI) and TBPU-1

Figure 4.3 Detailed ${ }^{1} \mathrm{H}-\mathrm{NMR}$ band assignment of the TB( PL-PEG-PL) copolymer in $\mathrm{CDCl}_{3}$

Figure 4.4

Detailed ${ }^{1} \mathrm{H}-\mathrm{NMR}$ band assignment of the TBPU copolymer in $\mathrm{CDCl}_{3}$

Figure 4.6 Water absorption vs. time for PL, TBPU-1, TBPU-2 and TBPU-3 at room temperature................................................... 50

Figure 4.7 Comparison between the variation of the water contact angles with time for PL-homopolymer, TBPU-1, TBPU-2, and TBPU-3 at room temperature......

Figure 4.8 Enzymatic degradation profiles of various molecular weights TBPUs and PL homopolymer. Error bars represent standard deviation for three trials.....

Figure 4.9 Degradation profiles of TBPUs and PL in PBS at (pH 7.4). Error bars represent standard deviation for three trials.

Figure 4.10 Comparison between the weight loss by degradation of TBPUs and PL in 


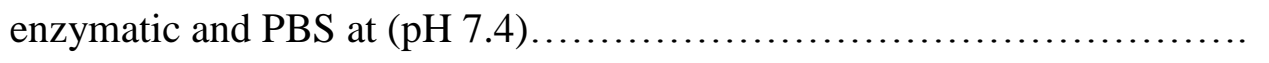

Figure 4.11 SEM images of TBPU-3 films showing the morphological changes after hydrolytic and enzymatic degradation for 5 days $(120 \mathrm{~h})$.

Figure 4.12 Degradation profiles of TBPU-3 in PBS at various pH values $(7.4,6.0$ and 5.0). Error bars represent standard deviation for three trials.

Figure 4.13 The change in $\mathrm{pH}$ values of the degradation media with time during degradation of TBPU-3 and PL in PBS at various $\mathrm{pH}$ values (7.4, 6.0 and 5.0)

Figure 4.14 DSC thermograms of PEG (4000), PL-homopolymer and TBPUs samples....

Figure 4.15 Stress-strain curves of PL, TB3, and TBPU-3 .........................

Figure 4.16 Comparison between tensile strength and \% elongation of the PL, TB3 and

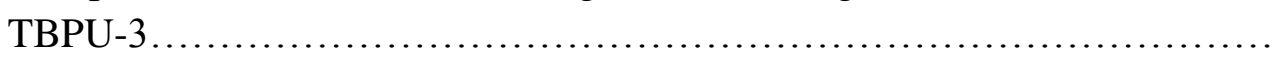

Figure 4.17 Trabecular and cancellous bones in human body....................... 60

Figure 4.18 Stress-strain curves of the nanocomposites PL/7\%w BCNW, TB3/7\%w

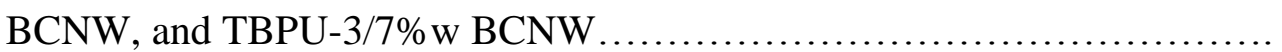

Figure 4.19 Comparison between tensile strength and $\%$ elongation of the nanocomposites of PL, TB3 and TBPU-3 with 7\%w of BCNW ............

Figure 4.20 Effect of the different BCNW content on mechanical properties of the TBPU-3 nanocomposite.

\section{LIST OF SCHEMES}

Scheme 1.1 The proposed structure of TBPUs................................. 5

Scheme 1.2 Schematic presentation showing the entire project...................... 7

Scheme 4.1 Synthesis route s and structures of PL-PEG-PL triblock copolymer, triblock copolymer-BDI and triblock copolymer urethane. 


\section{LIST OF APPENDICES}

Appendix A. Gluconacetobacter xylinus (ATCC $\left(700178^{\mathrm{TM}}\right) \ldots \ldots \ldots \ldots \ldots \ldots \ldots \ldots \ldots \ldots$

Appendix B. $\quad{ }^{1} \mathrm{H}-\mathrm{NMR}$ Spectra......................................... 68

Figure B1 $\quad{ }^{1} \mathrm{H}-\mathrm{NMR}$ spectrum of the triblock copolymer $\mathrm{TB} 1$ in $\mathrm{CDCl}_{3} \ldots \ldots \ldots \ldots \ldots \quad \mathbf{6 8}$

Figure B2 $\quad{ }^{1} \mathrm{H}-\mathrm{NMR}$ spectrum of the triblock polyurethane TBPU-1 in $\mathrm{CDCl}_{3} \ldots \ldots \ldots \ldots . \quad 68$

Figure B3 $\quad{ }^{1} \mathrm{H}-\mathrm{NMR}$ spectrum of the triblock copolymer $\mathrm{TB} 2$ in $\mathrm{CDCl}_{3} \ldots \ldots \ldots \ldots .69$

Figure B4 $\quad{ }^{1} \mathrm{H}-\mathrm{NMR}$ spectrum of triblock polyurethane TBPU-2 in $\mathrm{CDCl}_{3} \ldots \ldots \ldots . \quad 69$

Figure B5 $\quad{ }^{1} \mathrm{H}-\mathrm{NMR}$ spectrum of the triblock copolymer $\mathrm{TB} 3$ in $\mathrm{CDCl}_{3} \ldots \ldots \ldots \ldots \ldots \ldots \ldots . .70$

Figure B6 $\quad{ }^{1} \mathrm{H}-\mathrm{NMR}$ spectrum of the triblock polyurethane TBPU-3 in $\mathrm{CDCl}_{3} \ldots \ldots . \quad 70$

Figure B7 $\quad{ }^{1} \mathrm{H}-\mathrm{NMR}$ spectrum of the triblockpolyurethane TBPU-4 in $\mathrm{CDCl}_{3} \ldots \ldots \ldots .71$

Figure B8 $\quad{ }^{1} \mathrm{H}-\mathrm{NMR}$ spectrum of the triblock polyurethane TBPU-5 in $\mathrm{CDCl}_{3} \ldots \ldots \ldots . \quad 71$

Figure B9 $\quad{ }^{1} \mathrm{H}-\mathrm{NMR}$ spectrum of the triblock polyurethane TBPU-6 in $\mathrm{CDCl}_{3} \ldots \ldots \ldots .72$

Appendix C. Row data of some replicated experiments...................... 73

Appendix D. Mechanical Testing ........................................ 75

Figure D1 A typical stress-strain curve..................................... 76 


\section{CHAPTER 1 - INTRODUCTION}

\subsection{Overview and Background}

Biodegradable polymers are used in an increasingly large number of biomedical applications. This includes drug-releasing implants, bioresorbable surgical sutures, biodegradable vascular grafts, as well as in sustained drug delivery applications [1]. Most crucial attribute of biodegradable polymeric material is its biocompatibility at implantation time and products of its degradation process. Additional parameters that play important roles include mechanical properties of the material and matching of the polymer biodegradation with the rate of healing process. Lack of polymers that meet these rather demanding requirements has continuously prompted a continuous research for new improved biodegradable polymers.

Among the different synthetic polymers are the aliphatic polyesters, such as poly(lactic acid) (PLA) [2], poly(glycolic acid) (PGA) [3], poly(lactic-co-glycolide) (PLGA) [4], and poly(orthoesters) (POE) [5]. They have been widely utilized due to their known degradation by the hydrolysis of ester bonds to form resorbable nontoxic degradation products [6]. However, some biocompatibility concerns of these materials have been raised in recent years. For instance, the acidic degradation by-products would cause a decrease in the $\mathrm{pH}$ value of the surrounding tissues [7], the small particles released during degradation might trigger an inflammatory response [8], and the lack of cell attachment due to their high hydrophobicity [9]. With the current development in biomedical field, there is a necessity to design and synthesize new nontoxic biodegradable polymers that could overcome most of the drawbacks confronting their wider use in many of the current applications.

Segmented polyurethanes (SPU) is one of the emerging solutions, they have been used extensively in fabrication of biomedical devices due to their good biocompatibility as well as their excellent physical and mechanical properties [10]. The structure of polyurethane can be easily tailored to meet specific needs such as obtaining materials of certain range of physical, chemical properties, and also controllable degradation rates [11,12]. However, the major problem in those materials is the release of toxic and carcinogenic byproducts after their degradation due to the harmful diisocyanates that commonly utilized as chain linkers in those reactions, such as 4,4-diphenylmethane isocyanate (MDI) and 2,4-toluene diisocyanate (TDI) $[13,14]$. Accordingly, many researchers have been using L-lysine derived diisocyanate (LDI) to 
produce nontoxic degradation products [15]. Skarja and Woodhouse [16,17] have developed a family of novel biodegradable segmented polyurethanes which are suitable for use in soft tissue applications. The hard segments of these materials were LDI and a phenylalanine diester chain extender, and the soft segments were poly(caprolactone) (PCL) or poly(ethylene oxide) (PEO). Hilborn and co-workers [18,19] synthesized highly elastic biodegradable polyurethanes using LDI and biodegradable macrodiols (copolymers of trimethylene carbonate, 3-caprolactone, and D,L-lactic acid) with low degradation rates for long-term tissue engineering scaffolds. Other kinds of biodegradable polyurethanes were also developed using LDI and glycerol for the controlled release of camptothecin [20,21].

Nowadays, the current studies on these biodegradable polyurethanes are focused on both longterm degradation applications, such as tissue engineering scaffolds and long-term drug delivery devices, and also the rapid degradable polymer due to their clinical importance in rapid drug delivery system [22] and magnetic resonance contrast agent in biomedical imaging (MRI) [23]. Amphiphilic block copolymer of polyurethanes is special class of biodegradable materials that is capable to form core-shell micelles structure, which in tern could encapsulate varieties of drug molecules or magnetic nanoparticles inside their core cavities to enhance their biostability in vivo. Moreover, they can be easily eliminated from the body due to their rapid degradation.

To overcome the current limitations that confront the use of the previously mentioned biodegradable homopolymers, the current project focus on the synthesis of wide range of molecular weights of green nontoxic biodegradable triblock polyurethanes (TBPUs) that have improved hydrophilicity, degradation rate and cell attachment abilities over the pure homopolymers PLA and PCL. Those newly designed polyurethane can be used either for rapid drug delivery system and MRI contrast agent, as well as in tissue engineering scaffolds. The structures of those designated polyurethanes based on the triblock copolymer PL-PEG-PL as hard segment and PCL as soft segment. In triblock copolymer (TB), PEG was introduced in different ratios during polymerization reaction to enhance the hydrophilicity and degradability of PL segments [24], whereas PCL segments are used to improve flexibility and \% elongation. In addition, the nontoxic 1,4-butane diisocyanate (BDI) was used as chain linker in an attempt to avoid the release of toxic and carcinogenic byproduct after degradation. The use of BDI is of special interest since, upon degradation, it yields 1,4-butane diamine, also known as putrescine, which is already present in mammalian cells [25,26]. This would be highly beneficial if 
considering the biocompatibility of the prepared poly(ester-urethanes) for biomedical applications.

Polymer nanocomposites based on nanofibers have attracted tremendous attention in recent years from both the scientific and academic communities as a result of the substantial property enhancements obtained from relatively low nanofiller loadings [27]. Nanocomposites of polyester urethanes of biodegradable polymer with various nano-reinforcement fillers, such as layered silicate, carbon nanotubes and layered double hydroxide are being developed and extensively studied [28]. However, the discovery of new green based nano-material excited worldwide interest among researchers.

Bacterial cellulose (BC) is one of the most abundant natural biomaterial that is synthesized in the interior of the bacterial cell such as "Acetobacter xylinum". BC is a biocompatible biopolymer, displaying non-toxic effects to endothelial cells and has little effect on blood profiles. It has been approved by FDA and extensively used as a starting material for many biomedical applications such as wound dressings, biomimetic scaffolds, and drug delivery devices [29]. In the current study, BC is used as natural source for obtaining green reinforcing nanofibers called bacterial cellulose nanowhiskers (BCNW), by controlled acidic hydrolysis of BC nanofibers. Due to its high aspect ratio; (length/diameter) of 30 to150, hydrophilicity, high crystallinity and excellent thermo-mechanical properties; (stiffer than aluminum and steel) [30], BCNW will be considered as excellent candidate for reinforcing polyurethane matrix even if it used in small loading amounts. The new BCNW/TBPUs nanocomposite will be envisioned, from one side, to show improved interfacial adhesion with the newly generated cells due to the presence of hydrophilic PEG and BCNW in the hydrophobic polymer matrix, and from the other side to improve the mechanical strength and biodegradation rate.

This project is a multifaceted challenge, since obtaining a new group of materials with a given set of mechanical and physical properties, to be used in biomedical applications, is conditional upon being biocompatible and biodegradable. 


\subsection{Problem Statement}

Although biodegradable polyesters based on PLA have found important and high volume uses in packaging applications, however, they lack certain optimum properties and the failure to meet many requirements such as brittleness, small ultimate elongation strain of nearly $10 \%$, high hydrophobicity, low cell attachment ability and low drug loading and stability. The later drawbaks imit its usefulness in biomedical applications [31,32]. In addition, PLA homopolymer has slow biodegradation rate and its degradation products in the body decreases the $\mathrm{pH}$ of surrounding tissues substantially. This may cause clinical complications such as necrosis and delayed healing. Therefore, considerable efforts have been directed towards improving the properties of PLA to maximize its utilization in biomedical field. One possible approach, which is simple and inexpensive, is to blend the hydrophobic PLA with another hydrophilic polymer. However, the expected significant improvements have not been observed in PLA-based polymer blends due to the high immiscibility between the two different polymers as observed in previous studies [33,34]. Another approach was to produce PLA-based copolymers with other flexible hydrophilic segments [35,36]. However the copolymerization approach gave more promising results rather than blend, it was difficult to produce high molecular weight polymers with the same approach [37,38], which is a prerequisite for PLA-based polymers to show high mechanical properties. The chain linking/chain-extension methods facilitates the development of high molecular weight PLA-based polyurethane (PLA-PU) with tailored properties and now considered as one of the promising solutions and proven tool for modifying polymer properties to meet special requirements for specific applications $[39,40]$.

\subsection{Objectives and Specific Aims}

This research project aimed to develop new polylacide based biodegradable polymers with tailored properties to meet specific requirements-application relationship. The main objective of his project is to design, synthesize, and characterize a series of polylactide-based triblock polyurethane (TBPU) polymers of different segments and molecular weights in order to modify the properties of polylactide homopolymer through (a) enhancing its hydrophilic properties; (b) increasing the ultimate elongation strain; (c) avoiding the formation of highly acidic biodegradation products; (d) improving the bioactivity; (e) and also increasing the number of cell motif sites within its structure. Thus, the "multicomponent" nature of the intended series of the 
segmented copolymer might afford the required versatility, in terms of the high mechanical properties, fast and complete biodegradation, hydrophilic properties, as well as the nontoxic nature of entire components or their biodegradation products. This approach will allow one to vary, quite independently, various parameters in the system by choosing different types of polymers and consequently the desired properties.

To achieve this goal, new types of triblock polyurethane copolymers based on polylactide (PL), PEG and PCL were polymerized. These TBPUs are designed to be green and completely degradable resulting into non-toxic products. PL segments will support the structure by their known high mechanical strength. The incorporation of PEG in the structure of the hard segment of the proposed polyurethane will help to reduce the hydrophobicity and brittleness of PL. In addition, the elastic response of the system will mainly be improved by addition of the flexible PCL as soft segment. The short PEG chains (4000 g/mol) can be readily excreted through the kidney, PL and PCL are broken down into monomeric acids by hydrolysis and can be eliminated through normal excretory routes. Nevertheless, the utilization of BDI as a green and nontoxic linker is considered another plus addition in the proposed polyurethane structure, and upon degradation it yields nontoxic products. Therefore, these components have special interest especially for biomedical applications. The proposed polyurethane structure is presented in Scheme 1.

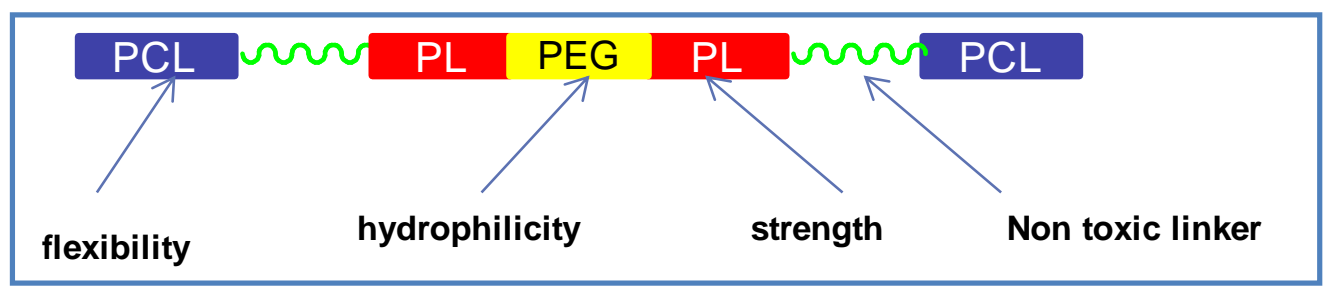

Scheme 1.1 Proposed structure of TBPUs.

The TBPUs of low molecular weight can be utilized as drug delivery carriers and implantable membranes where fast degradation and drug stability are required, whereas the TBPUs of higher molecular weights can be used in fabrication of porous scaffold that are used in tissue engineering scaffolds. 


\subsection{Research Plan}

Based on the comprehensive review of previous studies, encountered review challenges and the objectives of the thesis, the research design is formulated as follow:

\section{Part 1: Synthesis of polymers}

This part includes the following;

1- Synthesis of PL-PEG-PL triblock copolymers of different molecular weight, block length and PL/PEG segment ratios via ring opening polymerization of lactide in the presence of PEG as a macroinitiator and $\mathrm{Sn}(\mathrm{Oct})_{2}$ as catalysts. Six samples were obtained from six different $\mathrm{LA} / \mathrm{PEG}$ feed ratios at the same reaction conditions.

2- TB-BDI pre-polymers were synthesized by the reaction of the previously synthesized triblock copolymers with BDI in 1:2 molar ratios, respectively.

3- Six different TBPUs samples were obtained from the urethane reaction between TB-BDI and PCL-diole in 1:2 molar ratio, respectively.

4- Structure characterization and molecular weight determination were done by using FTIR/ATR, ${ }^{1} \mathrm{H}-\mathrm{NMR}, \mathrm{DSC}$, and GPC.

5- Studying the hydrophilicity of the surface and the bulk by contact angle and water uptake measurements.

6- Studying the degradation profile of polymers in phosphate buffer (PBS) and enzymatic solutions at different $\mathrm{pH}$ values.

\section{Part 2: Reinforcing BCNW in TBPU Matrix}

This part includes the following steps;

1- Biosynthesis of bacterial cellulose nanofibers.

2- Preparation of BCNW following harsh acid hydrolysis method.

3- Morphological determination of BCNW by FE-SEM.

4- Solvent exchange of $\mathrm{BCNW}$ to the polymer casting solvent. 


\section{Part 3: Testing the mechanical properties and fabrication of TBPUs/BCNW scaffold}

This part includes the following;

1- Testing the mechanical properties of the prepared polymers.

2- Reinforcing the polymers with $\mathrm{BCNW}$, and then retesting their mechanical properties.

3- Reinforcing of TBPUs (matrix) with different ratios of BCNW and testing the mechanical properties of the obtained nanocomposites.

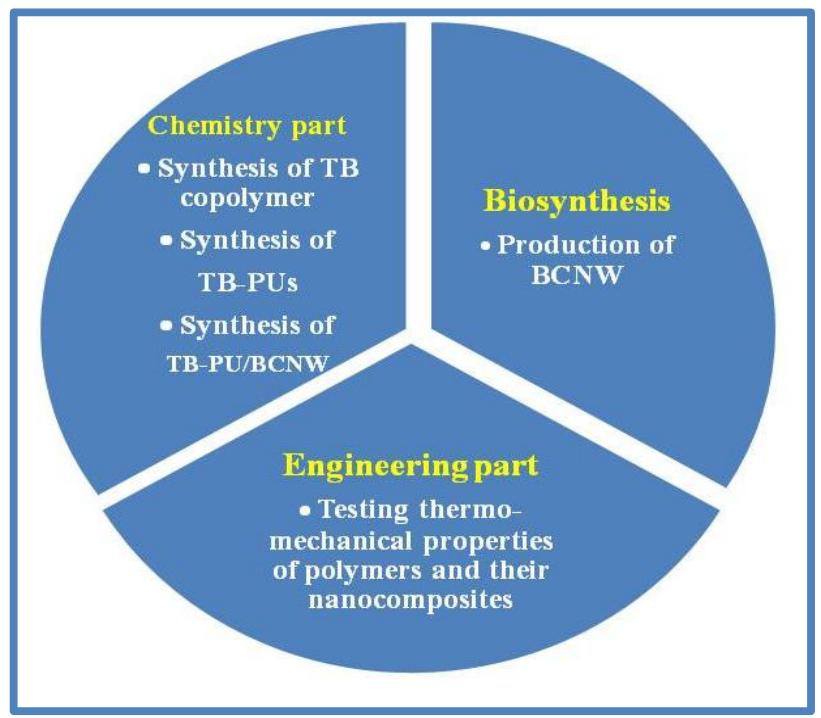

Scheme 1.2 Schematic presentation showing the entire project. 


\section{CHAPTER 2 - LITERATURE REVIEW}

\subsection{Polymerization Methods of Lactic Acid}

The existence of both a hydroxyl and a carboxyl group in lactic acid molecule enabled it to be converted directly into polyester via polycondensation reactions. However, the conventional condensation polymerization of lactic acid does not increase the molecular weight sufficiently unless organic solvents are used for azeotropic distillation of condensation water and the polymerization time is very long. Conventional polycondensation of lactic acid yields a brittle glassy polymer, which is unusable for most applications [42,42].

The most common way to obtain high-molecular-weight poly(lactic acid) is through ring opening polymerization (ROP) of lactide [43-46], which has been introduced after the pioneering research of Carothers's [47], where two-step method that yielded high-molecular-weight PLA polymer has been carried out. In the first step, water is removed from lactic acid molecules under mild conditions, without a solvent, to produce poly(lactic acid) oligomer, which is in then catalytically depolymerized through an internal transesterification, i.e., by back-biting reaction to form cyclic intermediate referred as lactide or cyclic lactic acid dimmer, see Fig. 2.1.

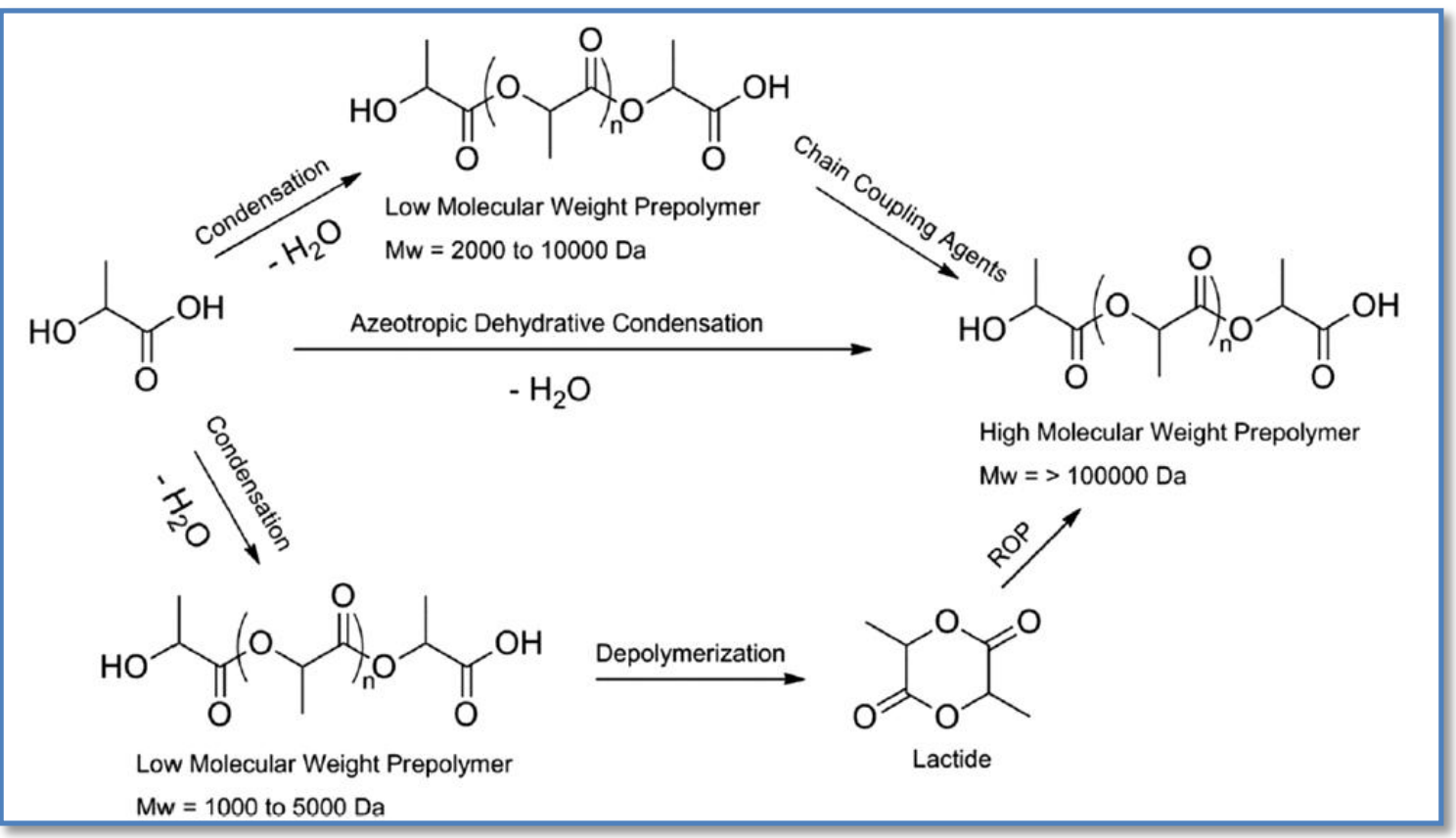

Fig. 2.1. Methods of obtaining high molecular weight PLA [44]. 
Lactide formed during depolymerization in three stereo forms: L-lactide, D-lactide, and mesolactide. In the second step, purified L-lactide, D-lactide or DL-lactide meso-lactide monomer is converted into the corresponding high-molecular weight polyester by catalytic ROP. Ring-opening polymerization of lactide can be carried out in melt, bulk, or in solution and by cationic, anionic, and coordination-insertion mechanisms depending on the catalyst $(48,49)$. The choice of initiator system, co-initiator as chain control agent, catalyst concentration, monomer-to-initiator ratio, and polymerization temperature and time significantly affect the polymer properties. These properties, such as the molecular weight, degree of crystallinity and residual monomer content, in turn affect the physical-mechanical properties and range of temperature for use of the polylactide and its copolymers (50-53).

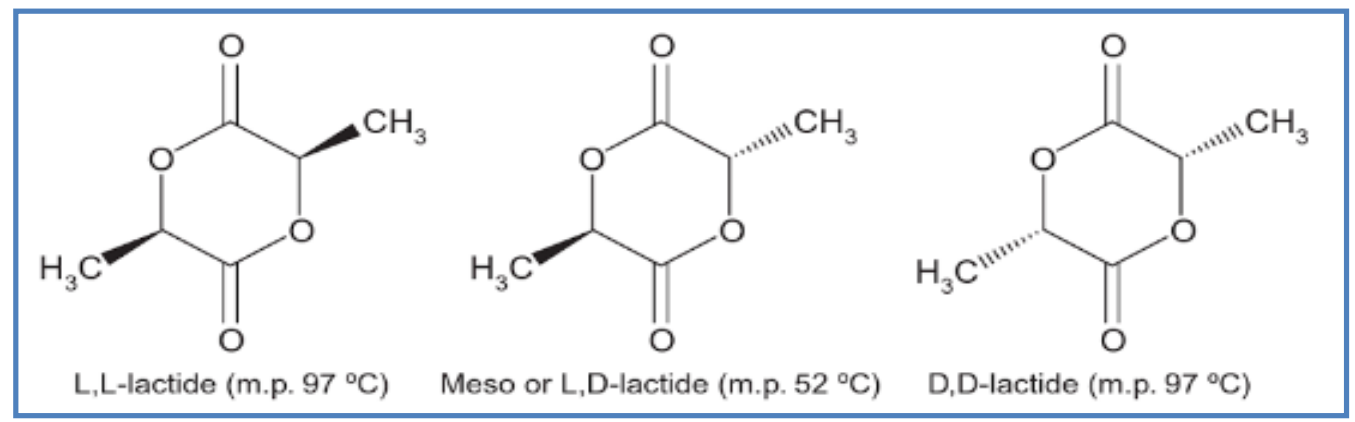

Fig. 2.2 Lactide stereoisomers: from left to right: L-lactide, meso-lactide and D-lactide.

Many current PLA polymerization methods employ stannous octoate as the catalyst. It has been shown to be very effective, causes a low degree of racemization at high temperature [54], has low toxicity, and is accepted by the US Food and Drug Administration. A selective summary of literature on PLA synthesis using stannous octoate as the catalyst is given in Table 2.1.

Schwach et al. [55] reexamined the ring-opening polymerization of PLA in the presence of stannous octoate under conditions allowing for the end-group characterization of growing chains by high-resolution ${ }^{1} \mathrm{H}-\mathrm{NMR}$. For low values of monomer to initiator ratios, the DL-lactide ring was opened to yield lactyl octoate-terminated short chains. A cationic-type mechanism involving co-ordination by octanoic acid was proposed to account for experimental findings, see Fig.2.3. 
Table 2.1. A selective summary of studies on PLA polymerization used tin compounds as catalyst.

\begin{tabular}{|c|c|c|c|c|c|c|}
\hline Polymer & Catalyst & Solvent(s) & $\begin{array}{c}\text { Reaction } \\
\text { Temperature, }{ }^{\circ} \mathrm{C}\end{array}$ & Reaction time & Mlecular weights & Reference \\
\hline L-PLA & $\mathrm{Sn}(\mathrm{Oct})_{2}$ & Glycerol & 130 & $6 \mathrm{hrs}$ & $\mathrm{M}_{\mathrm{n}}=3,000-12,800$ & {$[56]$} \\
\hline DL- PLA & $\mathrm{Sn}(\mathrm{Oct})_{2}$ & NA & 160 & $23 \mathrm{hrs}$ & $\mathrm{M}_{\mathrm{w}}=82,000$ & {$[57]$} \\
\hline DL- PLA & $\mathrm{Sn}(\mathrm{Oct})_{2}$ & Alcohols & 200 & $60-75 \mathrm{~min}$ & $\mathrm{M}_{\mathrm{w}}=35,000$ & [58] \\
\hline L-PLA & $\mathrm{Sn}(\mathrm{Oct})_{2}$ & $\begin{array}{c}\text { Alcohols, } \\
\text { carboxylic acid }\end{array}$ & 130 & $2-72 \mathrm{hrs}$ & $\mathrm{M}_{\mathrm{n}}=250,000$ & [59] \\
\hline L-PLA & $\mathrm{Sn}(\mathrm{Oct})_{2}$ & No solvent & 130 & $72 \mathrm{hrs}$ & $\mathrm{M}_{\mathrm{v}}=20,000-680,000$ & {$[60]$} \\
\hline L-PLA & $\mathrm{Sn}(\mathrm{Oct})_{2}$ and triphenylamine & No solvent & $180-185$ & $7 \mathrm{~min}$ & $\mathrm{M}_{\mathrm{n}}=91,000$ & {$[61]$} \\
\hline L-PLA & $\begin{array}{l}\text { Sn }(\mathrm{Oct})_{2} \text { and compounds of } \\
\text { titanium and zirconium }\end{array}$ & Toluene & $180-235$ & $15-180 \mathrm{~min}$ & $\mathrm{M}_{\mathrm{n}}=40,000-100,000$ & {$[62]$} \\
\hline D-PLA & $\begin{array}{l}\text { Stannous trifluoromethane } \\
\text { sulphonate, Scandium(III) } \\
\text { trifluoromethane sulfonate }\end{array}$ & Ethanol & $40-65$ & $50-100 \mathrm{hrs}$. & $\mathrm{M}_{\mathrm{n}}=1,080-2,162$ & {$[63]$} \\
\hline L-PLA & $\mathrm{SnCl}_{2} / \mathrm{p}-\mathrm{TSA}$ & NA & 180 & $12 \mathrm{hrs}$ & $\mathrm{M}_{\mathrm{w}}=30,000$ & [64] \\
\hline L-PLA & $\begin{array}{l}\text { Sn substituted mesoporous } \\
\text { silica molecular sieve }\end{array}$ & No solvent & 130 & $72 \mathrm{hrs}$ & $\mathrm{M}_{\mathrm{n}}=36,000$ & [65] \\
\hline L-PLA & Sn powder & NA & 140 & $20-40$ hrs & $\mathrm{M}_{\mathrm{w}}=140,000$ & [66] \\
\hline
\end{tabular}




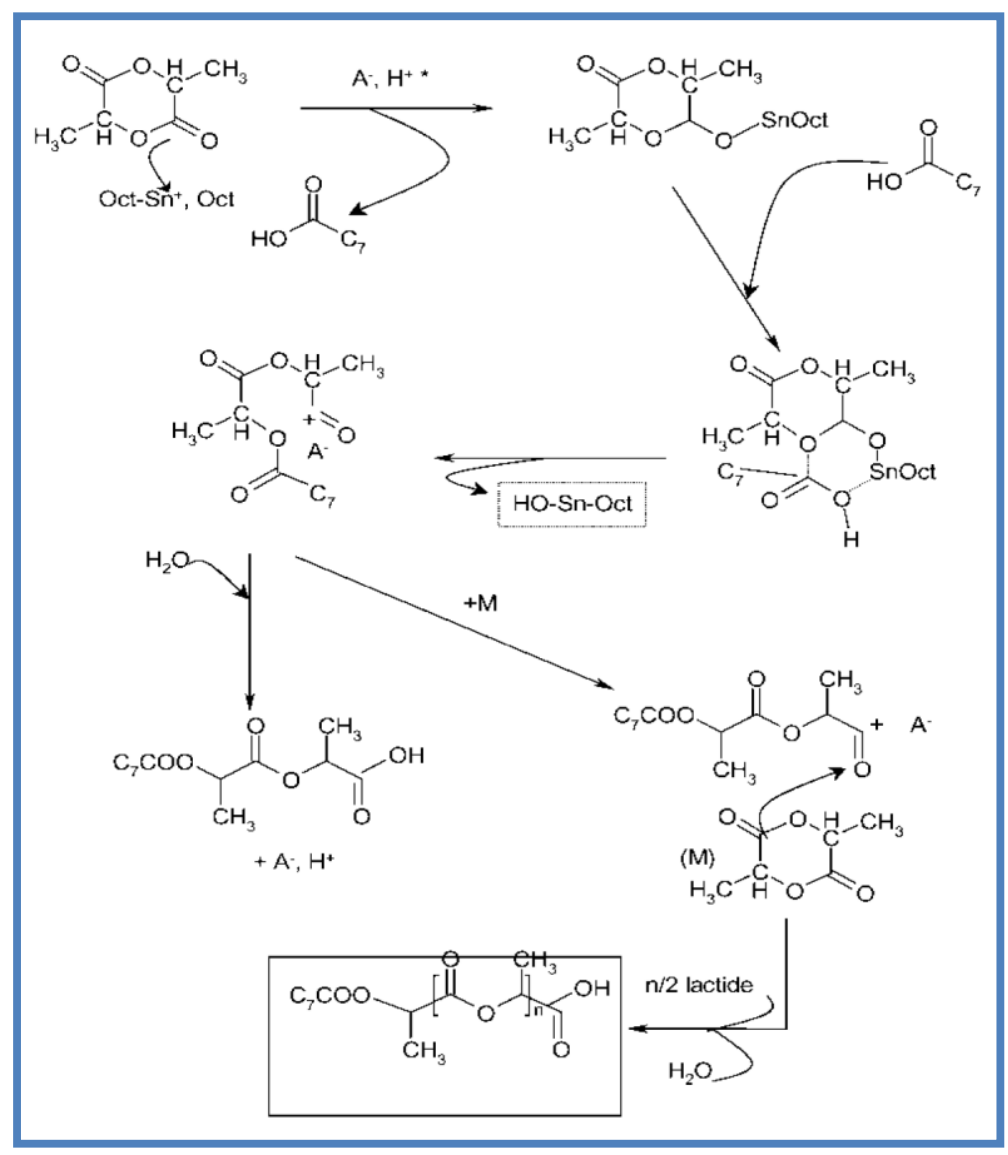

Fig. 2.3 Cationic octanoic acid co-initiated mechanism of lactide polymerization in presence of stannous octoate [55]. 


\subsection{Chemical Modification of PLA through Copolymerization with PEG: A Review}

The carboxyl and hydroxyl groups of LA make it possible to copolymerize it with other monomers through polycondensation with lactone-type monomers such as $\varepsilon$-caprolactone. This generally leads to low molecular weight copolymers. Alternately, it can be through ring-opening copolymerization of lactide with other cyclic monomers such as glycolide, $\delta$-valerolactone, and trimethylene carbonate, and ethylene oxide (EO) to produce high molecular weight copolymers. The hydrophobicity and crystallinity of the copolymers can be increased for low to moderate comonomer contents. Besides, poly(ethylene oxide) (PEO) and PEG have been most commonly copolymerized with PLA to prepare copolymers on account that it is highly biocompatible, hydrophilic and non-toxic, non-immunogenic and non-antigenic [67]. Such properties reduce protein adsorption and enhance resistance to bacterial and animal cell adhesion. Block copolymers are composed of long sequences (blocks) of the same monomer unit, covalently bound to sequences of a different type. The blocks can be connected in a variety of ways for examples diblock PLA-PEG copolymers and triblock PLA-PEG-PLA copolymers allow modulation of the biodegradation rate, the hydrophilicity, and the mechanical properties of the copolymers, while phase separation can be tailored with PLA-PEG multi-block copolymers of predetermined block lengths [68]. Star and dendrimer-like PLA-PEG copolymers have also been synthesized to lower the $T_{g}, T_{m}$, and the crystallinity of the materials [69].

Riley et al. [70] prepared a range of PLA-PEG copolymers incorporating a PEG block of constant molecular weight $(\mathrm{Mn}=5,000)$ and varying PLA segment lengths $(\mathrm{Mn}=2,000$ $110,000)$ by ROP of D,L-lactide catalyzed by stannous octoate; all the dispersions were stable under physiological conditions. In 2003, Li and Vert [71] prepared series of diblock and triblock copolymers by ring-opening polymerization of L(D)-lactide from mono- and dihydroxyl PEO, using zinc metal as a catalyst under vacuum. The copolymers were semicrystalline, their composition and molar mass being determining factors affecting their solubility in water. Fu et al. [72] prepared series of LA-based polyurethanes modified by castor oil with controllable mechanical properties. In this work, hydroxyl terminated pre-polymers were synthesized by copolymerization of L-LA and 1, 4-butanediol.

Matsumoto et al. [73] prepared biodegradable poly(L-lactide)-poly(ethylene glycol)-poly(Llactide) copolymer (PLA-PEG-PLA) nanoparticles containing progesterone as a model drug. PEG with weight-average molecular weight $\left(\mathrm{M}_{\mathrm{w}}\right)$ of 6600 or 20,000 was introduced as a 
hydrophilic segment into a hydrophobic PLA homopolymer. PLA-PEG-PLA copolymers, whose PEG content ranged from 5.2 to $25.8 \%$ (w\%), were showed drug trapping efficiencies around $70 \%$ and the weight-averaged mean diameters of the nanoparticles were less than 335 nm. The amount of drug released increased as the PEG content and Mw of PLA-PEG-PLA copolymers increased and the total Mw of copolymers of nanoparticles decreased.

In another study, PCL/PEO/PLA tri-component copolymers with different compositions were synthesized and characterized by means of GPC, FT-IR, ${ }^{1} \mathrm{H}-\mathrm{NMR},{ }^{13} \mathrm{C}$ NMR, DSC, and X-ray diffractometry. The mechanical properties and biodegradation behavior were also studied [74]. Biodegradable and amphiphilic diblock copolymers [polylactide-block-poly-(ethylene glycol)] and triblock copolymers [polylactide-block-poly(ethylene glycol)-block-polylactide] were synthesized by the anionic ring-opening polymerization of lactides in the presence of poly(ethylene glycol) methyl ether or poly(ethylene glycol) and potassium hexamethyldisilazide as a catalyst. The polymerization in toluene at room temperature was very fast, yielding copolymers of controlled molecular weights and tailored molecular architectures [75].

A series of poly(l-lactide)-poly(ethylene glycol) multiblock copolymers (Multi-PLE) with high molecular weight were synthesized and successfully used to fabricate three-dimensional scaffolds. The cell affinity of various Multi-PLE copolymers was evaluated using mouse NIH $3 \mathrm{~T} 3$ fibroblasts as model cells, and compared with that of poly(l-lactide) (PLLA). The results showed that the cell attachment efficiency on Multi-PLE 4/1(4/1 refers to the molar ratio of lactidyl units to ethylene oxide units) films was close to that on PLLA film, while the cell proliferation on Multi-PLE4/1 and Multi-PLE2/1 scaffolds was better than that on PLLA scaffold, which was closely related to the improved hydrophilicity of Multi-PLE copolymers due to the incorporation of PEG in comparison with pure PLLA [76].

A novel one-step method as alternative route to synthesis hydrophilic drug delivery carrier PLEG was studied by Wang et al. [77] instead of the traditional two-step method using lactide as intermediate. Directly starting from lactic acid (LA) and poly(ethylene glycol) (PEG), biodegradable material polylactic acid-polyethylene glycol (PLEG) was synthesized via melt copolycondensation. The optimal synthetic conditions, including prepolymerization method, catalyst kinds and quantity, copolymerization temperature and time, LA stereochemical configuration, feed weight ratio $\mathrm{mLA} / \mathrm{mPEG}$ and $\mathrm{Mn}$ of PEG, were all studied in detail. When d,1-LA and PEG $\left(\mathrm{M}_{\mathrm{n}}=1000 \mathrm{Da}\right)$ prepolymerized together as feed weight ratio md,1-LA/mPEG 
90/10, $15 \mathrm{~h}$ copolycondensation under $165^{\circ} \mathrm{C}$ and $70 \mathrm{~Pa}$, and $0.5 \mathrm{wt} \% \mathrm{SnO}$ as catalyst, gave d,1PLEG1000 with the highest $[\mu]$ of $0.40 \mathrm{dL} / \mathrm{g}$, and the corresponding MW was 41,700 Da. Using 1-LA instead of d,1-LA, $10 \mathrm{~h}$ polymerization under $165^{\circ} \mathrm{C}$ and $70 \mathrm{~Pa}$, and $0.5 \mathrm{wt} \% \mathrm{SnO}$ as catalyst, gave 1-PLEG1000 with the highest $[\mu]$ of $0.21 \mathrm{dL} / \mathrm{g}$ and MW of 15,600 Da. Contact angle testing showed that d,1-PELG not only had higher MW than PDLLA, PLLA and 1-PELG, but also better hydrophilicity than PDLLA.

Thermoplastic hydrogels of alternating multiblock copolymers, consisting of poly(ethylene glycol) (PEG) and poly(l-lactic acid) (PLLA), were studied by Huh et al. [78]. Where dicarboxylated oligomeric PLLAs were synthesized by the condensation reaction of 1-lactic acid in the presence of succinic acid. Changing the feed ratio of 1-lactic acid to succinic acid controlled PLLA molecular weights. Alternating multiblock copolymers with different block lengths of PEG and PLLA were obtained from the polycondensation reaction between PEG and dicarboxylated-PLLA in the presence of dicyclohexyl carbodiimide and N-dimethyl aminopyridine as catalysts.

Poly(ethylene glycol)-poly(D,L-lactide) block copolymers (PEG-PLA) with varying composition were prepared through successive ring-opening polymerization of ethylene oxide and D,L-lactide using an anionic initiator, and their property of multimolecular micellization in aqueous medium was examined in detail from the standpoint of designing carriers for hydrophobic drugs. The heterogeneity of PEG-PLA was found to crucially affect the size and distribution of micelles, and narrowly-distributed micelles with sizes of $30 \mathrm{~nm}$ in diameter were formed only from PEGPLA with a substantially narrow molecular weight distribution and an appropriate balance in the length ratio of the PEG and PLA segments in PEG-PLA block copolymers [79].

\subsection{Chemical Modification of PLA through Chain Extension/Chain Linker Using Urethane Reactions: A Review}

Due to the relatively complicated and expensive ring-opening polymerization of lactide, and the need for the modification of the polymer properties of poly(lactic acid) for different types of applications, alternative polymerization routes for lactic acid are considered to achieve highmolecular-weight polyesters. One of the highly interested routes is to treat condensation polymers with chain extenders [80]. Chain extenders are usually bifunctional low-molecular weight compounds that will increase the molecular weight of polymers in a fast reaction without 
causing contamination of the resulting polymer [81]. The chain extending of polyesters can be conveniently and economically performed in an extruder if the reaction rate is high enough [82]. Inata and Matsumura studied extensively carboxyl [83] and hydroxyl-reactive [84] addition-type chain extenders for polyesters. In the polyester chains, the hydroxyl end-group usually coexists with the carboxyl end-group. Carboxyl-reactive chain extender seems to be more advantageous, since the reduction of the acid value, resulting in improved thermal stability, is accompanied with the increase in molecular weight. However, hydroxyl end-groups are usually predominant over the carboxyl end-groups in the relatively low-molecular-weight polyesters prepared by the melt polycondensation procedure. Thus, hydroxyl-reactive chain extenders can be more effective in increasing the molecular weight [85]. Suitable chain extenders for polyesters are bis(2oxazolines), diisocyanates, bisepoxides, bis(ketene acetals), dianhydrides, bis[5(4H)oxazolones], bis(5,6-dihydro-4H-1,3-oxazines) [86-88] and Joncryl-ADR(styrene- glycidyl acrylate copolymer) [89-91].

The two-step polymerization of lactic acid to high-molecular-weight thermoplastic poly(esterurethanes) has been extensively studied $[92,93]$. Seppälä and coworkers introduced a poly(esterurethane) process consisting of polycondensation of lactic acid to low-molecular-weight hydroxylterminated prepolymer [94], followed by chain linking with diisocyanate such as 1,6hexamethylene diisocyanate [95] or isophorone diisocyanate [96]. This feasible two-step process offered versatile possibilities for tailoring the structure and properties of lactic acid based polymers. Numerous monomers or co-monomers can be introduced to both steps of the synthesis. Other hydroxy acids than lactic acid can be used in the polycondensation step as well as different kinds of dioles and diacids; and different type of chain extenders can be used in the chain extending step. Kylmä and Seppälä [97] applied the two-step process by copolymerizing $\varepsilon^{-}$ caprolactone with lactic acid, which was followed by chain linking, thus introducing thermoplastic poly(ester-urethane) (PEU) elastomer. The incorporation of various comonomers can impede rotation of the molecule and stiffen the polymer chain, which cause an increase in $T_{g}$ [98].

Hiltunen and coworkers condensation polymerized different types of lactic acid pre-polymers using various types of catalyst, dioles, polymerization conditions and combinations of them. These types of structure modifications allow possibilities for the synthesis of materials for both high volume and biomedical applications [99]. In addition to the chemical modification of PEU, mechanical and thermal properties have been improved by physical modification. 
The synthesis of poly(lactic acid-poly(ethylene oxide) diisocyanate chain-linked copolymer, and its application in the nano-encapsulation of bioactive compounds was studied by Pavelkova et al. [100]. The effect of different types of chain-linking agent, along with molecular weight, thermal properties and hydrophilic/hydrophobic behavior of the produced copolymer were also studied.

Different samples of PLA-based thermoplastic polyurethane (PLAPU) polymers were synthesized through the reaction of PLA-diole with hexamethylene diisocyanate, followed by chain extension with polycaprolactone (PCL) diol. The relative compositions of the hard PLA and the soft PCL diols in the PLAPU polymers were controlled systematically form 1:1 to 1:5 to optimize the physical properties of the polymers. Results showed that increasing the content of PCL resulted in higher molecular weight PLAPU polymers that had increased tensile strengths and elongations at break, but their moduli were decreased [101].

\subsection{Synthesis of Poly(ester-urethane)}

Chain extending reactions with diisocyanate take place by addition of hydroxyl-terminated prepolymer across the $\mathrm{C}=\mathrm{N}$ double bond of isocyanate group. $\mathrm{PEU}$ was polymerized by using different molecular weight of hydroxyl-terminated pre-polymers. The molecular weight of the prepolymer determines the length between urethane links and the amount of the $\mathrm{NCO} / \mathrm{OH}$ ratio used in reaction determines the linearity of PEU. If linear, high-molecular-weight PEU is desired, the molar ratio of end-groups/diisocyanate should be close to unity [102]. When the diisocyanate is used in excess, the side reactions cause branches and crosslinking. OH-group containing compounds are by far the most important reactants for isocyanates, but it is well known that the -NCO groups of diisocyanate readily react with every active hydrogen, such as amines, water, urethanes, ureas, and carboxylic acids, in the reaction system [103]. In the case of PLA oligomers, besides engaging in urethane formation (Fig. 2.4.A), the isocyanate group can also react with the carboxyl group leading to an amide bond (Fig. 2.4.B) and the formation of carbon dioxide as by-product. The urethane and amide groups can then further react with additional isocyanate, leading to the formation of allophanates (Fig. 2.4.C) and urea groups (Fig. 2.4.D), and thus leading to the branching and crosslinking of the polymer. 


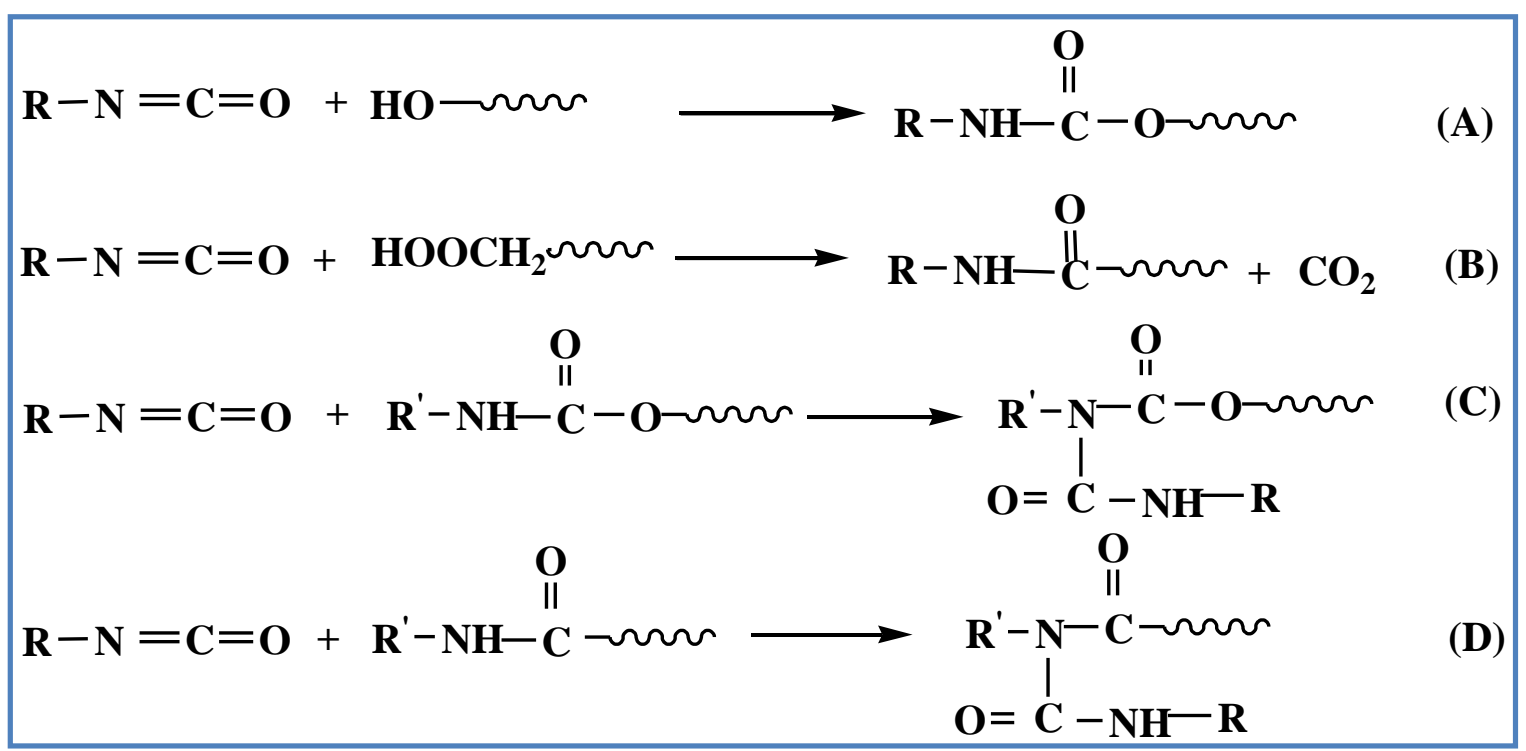

Fig. 2.4 Reaction of isocyanate with (A) alcohol, (B) carboxylic acid, (C) urethane, and (D) amide.

\subsection{Hydrolytic Degradation of Poly(ester-urethane)}

The decrease in molecular weight and weight loss were dependent on the amount of different stereo structures and the length of the ester chain: an increasing amount of D-structures and shortening of the ester chain increased the degradation rate. Both of these lowered $\mathrm{T}_{\mathrm{g}}$ of the PEU, which in turn increased the water absorption. Hetero-chain polymers, particularly those containing oxygen and/or nitrogen atoms in the main chain, are generally susceptible to hydrolysis. For hydrolysis to occur, the polymer must contain hydrolytically unstable bonds such as ester, amide, or urethane, and show some degree of hydrophilicity, as is the case with PEUs. In addition, the hydrolysis rate of the polymer is affected by the polymer properties such as molecular weight, glass transition temperature, and crystallinity and also hydrolysis conditions such as $\mathrm{pH}$, temperature, and the presence of enzymes and microorganisms [104-107]. The degradation rate and behavior of lactic acid based polymers have also been shown to be dependent on the purity of the polymer. Purification of lactic acid polymers removes monomers, oligomers, lactide, catalyst residuals and other impurities, which all promote hydrolysis, and thus reduce water absorption and the degradation process [108]. Unpurified lactic acid based poly(ester-urethanes), absorb much more water and degrade much faster than solvent precipitation purified PEUs [109]. 
Hydrolytic degradation of poly(DL- and L-lactic acids) proceeds by random hydrolytic chain scission of the ester linkages, eventually producing the monomeric lactic acid. This is the most probable hydrolysis mechanism for lactic acid based PEUs [110]. The molecular weight of the bulk degradable polymers, such as PLA and poly( $\varepsilon$-caprolactone) or their copolymers, has to be reduced substantially during the hydrolysis to permit mass loss through solubilization [111]. Mass loss usually begins when molecular weight has decreased to $15000 \mathrm{~g} / \mathrm{mol}$ or less [112].

\subsection{Cellulose Nanowhiskers}

Bacterial cellulose or microbial cellulose (MC) has the same chemical structure of plants cellulose. However, bacterial cellulose has the advantage of being very pure and devoid of lignin, pectin, hemicelluloses, and other biogenic products that are normally associated with plant cell wall structures [113]. It is naturally synthesized in the interior of bacterial cell, and then spun out in the form of pure nanofibers. Fig.2.5 illustrates an overview of the BC nanofibers production by bacteria.

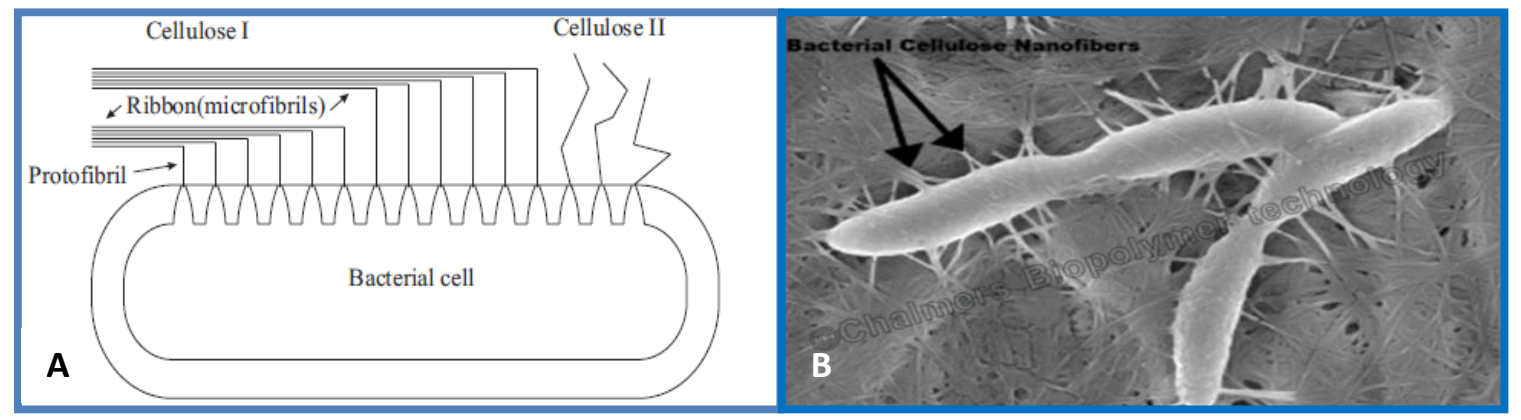

Fig. 2.5 (A) Schematic illustration for BC biosynthesis and nanofibers production; (B) celluloseproducing bacteria, G. Xylinus during production. Reproduced from [114].

Synthetic nanofibers, such as glass and carbon fibers, are brittle, and they are often broken into smaller fragments, this is in addition to significant health risks due to their toxicities [115]. On the other side, cellulose nanofiber is flexible and will not fracture during processing over sharp curvatures [116]. Nevertheless, BC is approved from US Food and Drug Administration (FDA) to be used in intravenous applications and being widely used in producing biomedical devices of various shapes and forms [117].

A typical BC nanofibers is composed of crystalline and noncrystalline domains. The amorphous cellulose regions are randomly oriented and have lower density compared to crystalline regions. 
Therefore, they are more susceptible to acid attack and under controlled conditions and can be hydrolyzed, leaving behind the crystalline regions intact, Fig. 6 (top). These resulted crystalline regions are rod-like shaped particles with dimension 5-20 nm in diameters and 50-500 nm in length and called BC nanowhiskers (BCNW) [118].

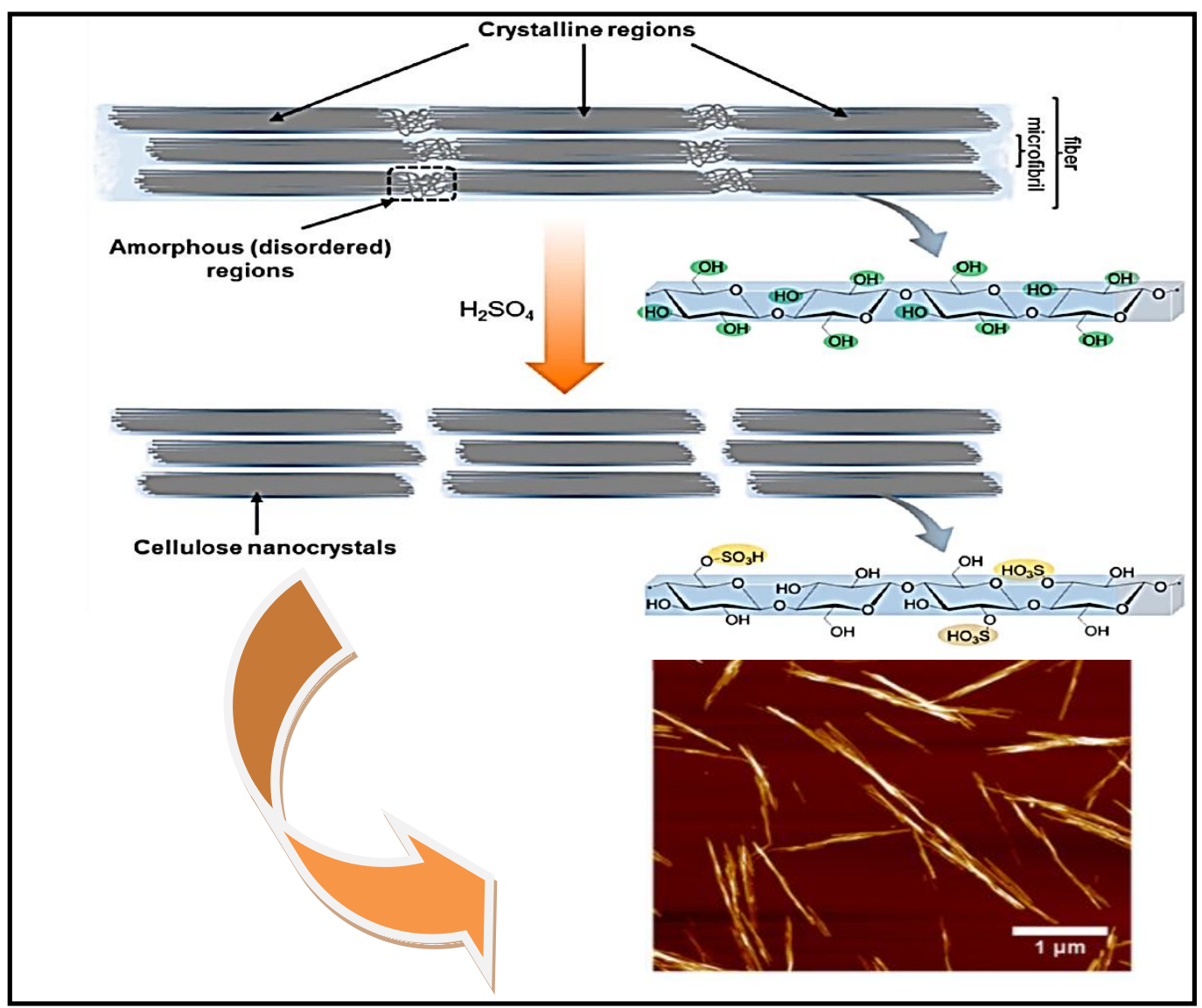

Fig. 2.6 Schematic presentation for acid hydrolysis of amorphous regions and the formation of BCNW along with AFM images of cellulose nanowhiskers produced from BC by $\mathrm{H}_{2} \mathrm{SO}_{4}$ hydrolysis. Reproduced from [119].

\subsubsection{Tensile Properties of BCNW and Their Reinforcement Potentials}

The mechanical properties of $\mathrm{BCNW}$ can be characterized in terms of the properties of both ordered (crystalline) and disordered (amorphous) regions constituting the nanoparticle. The disordered regions contribute to the flexibility and plasticity of the bulk material and the ordered regions contribute to the stiffness and elasticity of the material. The modulus of different types of nanocellulose is expected to result from the mixing rule between the modulus of the crystalline domains and the amorphous fraction. Therefore, the stiffness and modulus of BCNW with more 
crystalline regions should be higher than those of pristine fibers which have both crystalline and amorphous structures [120]. The elastic modulus of crystalline cellulose has been estimated and found in the range of $139.5 \pm 3.5 \mathrm{GPa}$ based on nanoscale indentation [121].

\subsubsection{Nanocomposites of BCNW with Biodegradable Polymers}

Originating from these impressive mechanical properties, nanocellulose has been potentially used as a load bearing element for various host materials provided that homogenous dispersion. Besides, strong interfacial adhesion with matrix is attained, which ultimately allows proper stress transfer from matrix to the reinforcing phase. Several new nanocomposites which incorporate nanosized cellulose have been developed within the last decade and many systems are being commercialized [122].

Nanocellulose showed considerable potential as reinforcing material for biodegradable polymer matrices. However, the main challenge with the incorporation of cellulose nanofibers in polymer matrix is to obtain good dispersion, which is reflected directly on the final mechanical properties of nanocomposite [123]. Moreover, the enhancement of tensile strength and elastic modulus is usually on the expense of elongation at break [120]. Many researchers reported that adding small quantities between (0.5 and $5 \mathrm{wt} \%$ ) of cellulose nanofibers will substantially improve the mechanical properties of the nanocomposite, and higher amounts of cellulose nanofibers over 5 wt.\% could lead to miscibility problems and deteriorate the mechanical properties of the nanocomposite [124].

On the other hand, the reinforcement applications with cellulose nanoparticles present some drawbacks. For instance, high moisture absorption was lead to swilling and diminishes the mechanical properties [125]. In addition, poor wetability and incompatibility with most hydrophobic polymeric matrices, and the limitation of processing temperature, where lignocellulosic materials start to degrade near $220{ }^{\circ} \mathrm{C}$, restricting the type of matrix that can be used [126]. 


\subsubsection{Micromechanical Modeling for Predicting and Investigating the Reinforcing Potential of BCNW in Nanocomposites}

It was found that the effect of CNCs on the nanocomposites' mechanical properties has exceeded the conventional predictions of the traditional classical model of Halpin-Kardos that applied to study filler reinforced nanocomposites [127]. This model is basically used to predict the mechanical behavior of short-fibers homogeneously dispersed in a continuous matrix of semicrystalline polymers. In this approach, the modulus and the geometry of the fibers are accounted for, but no interactions between the fibers are assumed. In the recent years, various studies have been developed with the aim of elucidating the origin of the mechanical reinforcing effect, and also to explain the extraordinary high reinforcing effect observed for cellulose whiskers.

Therefore, in order to explain the unusual high modulus values of cellulose whiskers reinforced nanocomposites, the following phenomena were suggested: (i) strong interactions between whiskers that cemented together by hydrogen bonds, and (ii) a mechanical percolation effect. In this regard, the model was proposed and then modified by Ouali et al. [128] to include the percolation approach which allowed better understanding for the mechanical behavior of these nanocomposites. The percolation threshold is defined as the critical volume fraction that makes separations between two states. The volume threshold depends upon a number of variables, primarily the shape and size of particles, aspect ratio, orientation, and the interparticle interactions. Therefore, to study the reinforcing effect of cellulose nanoparticles, the model invoked should be involving the three different phases in a typical nanocomposite: the matrix, the filler percolating network, and the nonpercolating filler. According to Quali's model, elastic tensile modulus $\mathrm{G}_{\mathrm{c}}$ of the composite can be given by the following equation:

$$
\mathrm{G}_{\mathrm{c}}=\frac{\left(1-2 \varphi+\varphi \emptyset_{\mathrm{r}}\right) \mathrm{G}_{\mathrm{s}} \mathrm{G}_{\mathrm{r}}+\left(1-\emptyset_{\mathrm{r}}\right) \varphi \mathrm{G}_{\mathrm{r}}^{2}}{\left(1-\emptyset_{\mathrm{r}}\right) \mathrm{G}_{\mathrm{r}}+\left(\emptyset_{\mathrm{r}}-\varphi\right) \mathrm{G}_{\mathrm{s}}} \text { Eqn. (2.1) }
$$

where $\mathrm{G}_{\mathrm{s}}$ and $\mathrm{G}_{\mathrm{r}}$ are the shear moduli of the soft (polymeric matrix) and rigid (cellulosic filler) phases, respectively. $\emptyset_{\mathrm{r}}$ corresponds to the volume fraction of the rigid phase (whiskers) and $\varphi$ is an adjustable parameter that corresponds to the volume fraction of the percolating rigid phase.

When the stiffness of the reinforcing phase is much higher than that of the matrix material (i.e., when $\mathrm{G}_{\mathrm{r}} \gg \mathrm{G}_{\mathrm{s}}$ ), Equation (1) can be reduced to $G_{c}=\varphi G_{r}$. 
In the modification proposed by Ouali et al. to include the percolation approach, $\varphi$ can be estimated as:

$$
\begin{array}{ccl}
\varphi=0 & \emptyset_{r}<\emptyset_{c} \\
\varphi=\emptyset_{r}\left(\frac{\emptyset_{r}-\emptyset_{c}}{1-\emptyset_{c}}\right)^{b} & \emptyset_{r} \geq \emptyset_{c}
\end{array}
$$

where $b$ is the critical percolation exponent, which is equal to 0.4 for a three-dimensional system and $\emptyset_{c}$ is the percolation threshold, which varies depending on the studied material and their orientation distribution.

For rod-like nanoparticles, the percolation threshold can be linked to the aspect ratio of the nanoparticles by the following equation:

$$
\emptyset_{c}=\frac{0.7}{L / d} \quad \text { Eqn. }(2.3)
$$

\subsection{Mechanical Properties of PL Based Poly(ester-urethane)}

The mechanical properties of PLA are favorable for load bearing applications, and the only mechanical shortcoming of PLA is its low ultimate tensile strain (e.g., around 10\%). To enhance this property of PLA, thermoplastic polyurethane (TPU) and PCL have been physically added to this polymer $[129,130]$. TPU can tune its tensile modulus within the range of 7-1007 MPa at the strain of above $15 \%$ for neat PLA and a blend with 1:1 weight ratio, respectively. While, the addition of $50 \mathrm{wt} \%$, PCL increases the elongation at break by nearly 10 fold $(107 \% \pm 4.7 \%)$.

Kylma and Seppala reported the synthesis of PLA-based PUs using copolymers of PLA and polycaprolactone (PCL) with HDI as the chain extender. However, the products obtained from these copolymerization methods had low molecular weights and the maximum stress of the highest elongation at break of these PLA-PUs was less than 2.0 MPa [131]. In another study, Zhong et al. [132] developed PLA-based TPUs with various molecular weights by using PLA-bpoly(butyleneadipate) as a polymer diol and hexamethylene diisocyanate (HDI) as the chain extender. They reported a high elongation at break of $779 \%$ and a tensile strength at $7.0 \mathrm{MPa}$ when the molecular weight $\left(\mathrm{M}_{\mathrm{n}}\right)$ was $43.5 \mathrm{~kg} \mathrm{~mol}^{-1}$. Recently, different PLA-PU polymers prepared with different composition ratios of hard PLA to soft PCL segments was reported by FB Ali et al. [101]. At the optimized PLA:PCL ratio of 1:3, the PLA-PU polymer had an 
excellent elongation at break of $1053 \%$ with a relatively high Young's modulus of 51.8MPa, but their moduli were decreased. In addition, the gas barrier properties of the PLA-PUs were significantly enhanced depending on the molecular weight and PCL content of the polymers. Therefore, it remains a great challenge to develop the optimal PLA based PUs with combined features of high molecular weight, flexibility and low gas permeability. Table 2.2. showed polylactic acid-based structures with different modifications to be applied in biomedical and tissue engineering applications.

\subsection{Mechanical Properties of PL based/cellulose Nanocomposites}

Owing to nanocellulose high aspect ratio, high stiffness, and high strength, a combination of nanocellulose as reinforcing materials with polymer matrix has showed enhanced mechanical properties for the resultant nanocomposites [120]. Results obtained from the mechanical properties study carried out by Qu et al. [134] showed that both tensile strength and elongation at break significantly improved and reached a maximum in the composite obtained by blending PLA/PEG when cellulose nanofibril of $3 \%$ content was added to the blend, and decreased with further increase of cellulose nanofibrils. The tensile strength and the elongation increased by $28.2 \%$ and $25 \%$, respectively, compared with pure PLA, and increased by $56.7 \%$ and $60 \%$ compared with the PLA/cellulose nanofibrils. Bondeson and Oksman reported an improvement in the elastic modulus from $2600 \mathrm{MPa}$ to 3,100 MPa, tensile strength from $35 \mathrm{MPa}$ to $52 \mathrm{MPa}$, and also slight increase in elongation at break from $1.8 \%$ to $3.1 \%$ for PLA reinforced with 5 wt.\% of surfactant modified cellulose nanocrystals CNC. Whereas the addition of $5 \mathrm{wt} . \%$ of the pristine CNC produced nanocomposite with lower tensile strength and elastic modulus than neat PLA [135]. A similar study for the effect of adding $5 \mathrm{wt} \%$ pristine CNC on the mechanical properties of PLA-PHB blend was reported by Arrieta et al. [136]. It was reported that the pristine CNC has reduced elastic modulus of PLA-PHB film from $1800 \mathrm{MPa}$ to $900 \mathrm{MPa}$ and tensile strength from $40 \mathrm{MPa}$ to $27 \mathrm{MPa}$, while surfactant modified CNC increased elastic modulus to $1900 \mathrm{MPa}$ and tensile strength to $47 \mathrm{MPa}$. 
Table 2.2. PLA-based structures applied in biomedical and tissue engineering applications. Reproduced from [133].

\begin{tabular}{|c|c|c|c|c|c|}
\hline Polyester & Modifier & $\begin{array}{c}\text { Concentration } \\
(\text { wt } \%)\end{array}$ & $\begin{array}{c}\text { Porosity } \\
(\%)\end{array}$ & $\begin{array}{c}\text { Mechanical properties } \\
\text { (MPa) }\end{array}$ & $\begin{array}{l}\text { Enhanced } \\
\text { properties }\end{array}$ \\
\hline \multirow{8}{*}{ 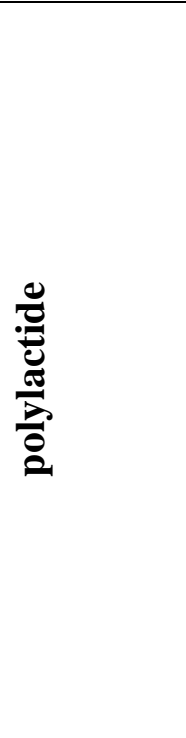 } & PU & 50 & 79 & $80(\mathrm{C}-\mathrm{M})$ & \multirow{3}{*}{$\begin{array}{l}\text { Mechanical } \\
\text { performances }\end{array}$} \\
\hline & PCL & 50 & $81.5 \pm 1.2$ & $0.3(\mathrm{C}-\mathrm{S})$ & \\
\hline & PEG & 20 & 86.75 & $\begin{array}{c}1830(\mathrm{Y}-\mathrm{M}) \\
\text { (nano-indentation) }\end{array}$ & \\
\hline & Triclosan & 20 & Solid structure & $61.98 \pm 0.3(\mathrm{~T}-\mathrm{S})$ & \multirow[b]{2}{*}{ Cell binding } \\
\hline & Chitosan and keratin & $\begin{array}{l}30 \% \text { chitosan } \\
\text { and } 4 \% \text { keratin }\end{array}$ & Solid structure & $35(\mathrm{~T}-\mathrm{S})$ & \\
\hline & Nano BG & 40 & $0.211\left(\mathrm{~cm}^{3} / \mathrm{g}\right)$ & $0.3(\mathrm{C}-\mathrm{S})$ & \multirow{3}{*}{$\begin{array}{l}\text { Bioactivity and } \\
\text { neutralize the } \\
\text { acidic degradation }\end{array}$} \\
\hline & $\mathrm{HA}$ & 50 & 85 & $857 \pm 0.268(\mathrm{E}-\mathrm{M})$ & \\
\hline & Calcium phosphate & 50 & $96.58 \pm 0.85$ & $0.147 \pm 0.02(\mathrm{~S})$ & \\
\hline
\end{tabular}

Y-M: Young's modulus; T-S: Tensile strength; C-S: compressive strength; E-M: Elastic modulus; S: stiffness; C-M: Compressive modulus; BG: Bioglass; HA: Hydroxyapatite 


\subsection{Biomedical Applications of PLA-PEG copolymers}

\subsubsection{Tissue engineering (TE)}

PLA has been investigated for medical applications, such as bone scaffolds due to its biodegradability and good biocompatibility [137], but its poor mechanical properties limits to certain extent its applications to tissue engineering. The mechanical properties of PLA were improved using a range of methods, such as blending, composites forming, and copolymerization. PLA copolymers, such as (PLA-PEG) block copolymers and PLA-p-dioxanonepolyethylene glycol block copolymer (PLA-p-DPEG), were used as carriers for bone morphogenetic proteins (BMPs). BMPs were biologically active molecules capable of inducing new bone formation, and they were expected to be used clinically in combination with biomaterials, such as bone-graft substitutes to promote bone repair [138]. On the other hand, the newly-formed bone was too small in quantity. Therefore, PLA copolymers were used to solve these problems with low molecular weight PLA [139].

\subsubsection{Wound management}

PLA copolymers were used in a range of applications related to wound management, such as surgical sutures, healing dental extraction wounds, and preventing postoperative adhesions. Li et al. evaluated the efficacy and feasibility of PLA/PEG copolymer ureteral stents for the treatment of ureteral war injuries [140]. The stents made of PLA/PEG were reliable in the treatment of ureteral war injuries where PLA/PEG stents were degraded so that they were removed from the body. Therefore, PLA/PEG stents represented a promising future for the treatment of ureteral war injuries.

\subsubsection{Drug Delivery Systems (DDS)}

PLA/PEG copolymers in the form of hydrogel and nanoparticles were used in the encapsulation process of many drugs, such as psychotic [141], restenosis [142], hormones [143], oridonin [144], and dermatotherapy [145], and protein (BSA) [146], see Fig. 2.7. Table 2.3 displayed closer look on the use of PLA-PEG copolymers as drug delivery systems. 


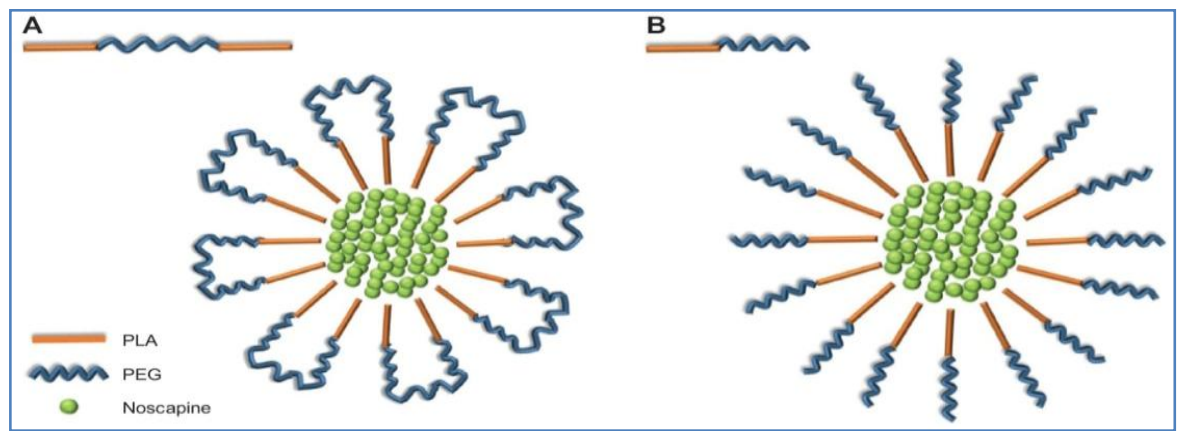

Fig. 2.7 Di- and triblock copolymers and their association to form nanoparticles that can contain noscapine. (A) Polymeric nanoparticles of triblock PLA-PEG-PLA. (B) Polymeric nanoparticles of diblock PEG-PLA. PEG, polyethylene glycol; PLA, polylactide. Noscapine, hydrophobic cancer drug, used for the treatment of different types of solid tumor, such as prostate, lung, brain, and breast cancer [153].

Table 2.3 Investigations on PLA-PEG copolymers as drug delivery systems.

\begin{tabular}{|c|c|c|c|}
\hline Material & Application & Results & Reference \\
\hline PLA-PEG particles & Carrier for tetanus toxoid & $\begin{array}{l}\text { Enhanced transport across } \\
\text { the rat nasal mucosa }\end{array}$ & {$[147]$} \\
\hline PEG-PLA NP & Conjugated with lactoferrin & $\begin{array}{l}\text { Increased uptake of the Lf- } \\
\text { NP by bEnd. } 3 \text { cells }\end{array}$ & {$[148]$} \\
\hline PEO-PLA copolymers & Carrier for 5-FU and paclitaxel & Complete drug release & [149] \\
\hline PLA-PEG-PLA copolymer & Carrier for 5-FU and paclitaxel & $\begin{array}{l}\text { Good control over the } \\
\text { release }\end{array}$ & {$[150]$} \\
\hline AP-PEG-PLA/MPEG-PAE & $\begin{array}{l}\text { Drug carrier for cancer } \\
\text { therapy } \beta\end{array}$ & $\begin{array}{l}\text { Presented high tumor } \\
\text { specific targeting ability }\end{array}$ & {$[151]$} \\
\hline cNGR-PEG-PLA NP & Carrier for DNA & $\begin{array}{l}\text { Rapid and efficient } \\
\text { nanoparticle internalization }\end{array}$ & {$[152]$} \\
\hline PLA-PEG, PLA-p-DPEG & $\begin{array}{l}\text { Carriers for bone morphogenetic } \\
\text { proteins (BMPs) }\end{array}$ & $\begin{array}{l}\text { bone-graft substitutes to } \\
\text { promote bone repair }\end{array}$ & {$[138]$} \\
\hline
\end{tabular}

AP: peptide; MPEG: methyl ether poly(ethylene glycol); PAE: poly( $\beta$-amino ester); PEI: polyethylenimine; cNGR:

Cyclic Asn-Gly-Arg; PLA-p-DPEG: PLA-p-dioxanone-polyethylene glycol block copolymer. 


\subsubsection{Orthopedic devices}

PLA is the only member of the polyester family that has been used for load bearing applications, such as orthopedics, owing to its high mechanical strength. Its biodegradable copolymers were also used in orthopedic applications to achieve several goals. One of the most important goals is to avoid a second surgical procedure to remove unnecessary hardware e.g. titanium devices. PLA copolymers were used to produce biodegradable screws and fixation pins, plates, and suture anchors. These types of absorbable screws and pins have been gaining the widespread clinical use, particularly in cases where high mechanical stiffness or strength was not required. Important orthopedic areas might include the knee [154], shoulder, foot and ankle [155], hand, wrist [156], elbow [157], and zygomatic fractures [158], see Fig. 2.8.

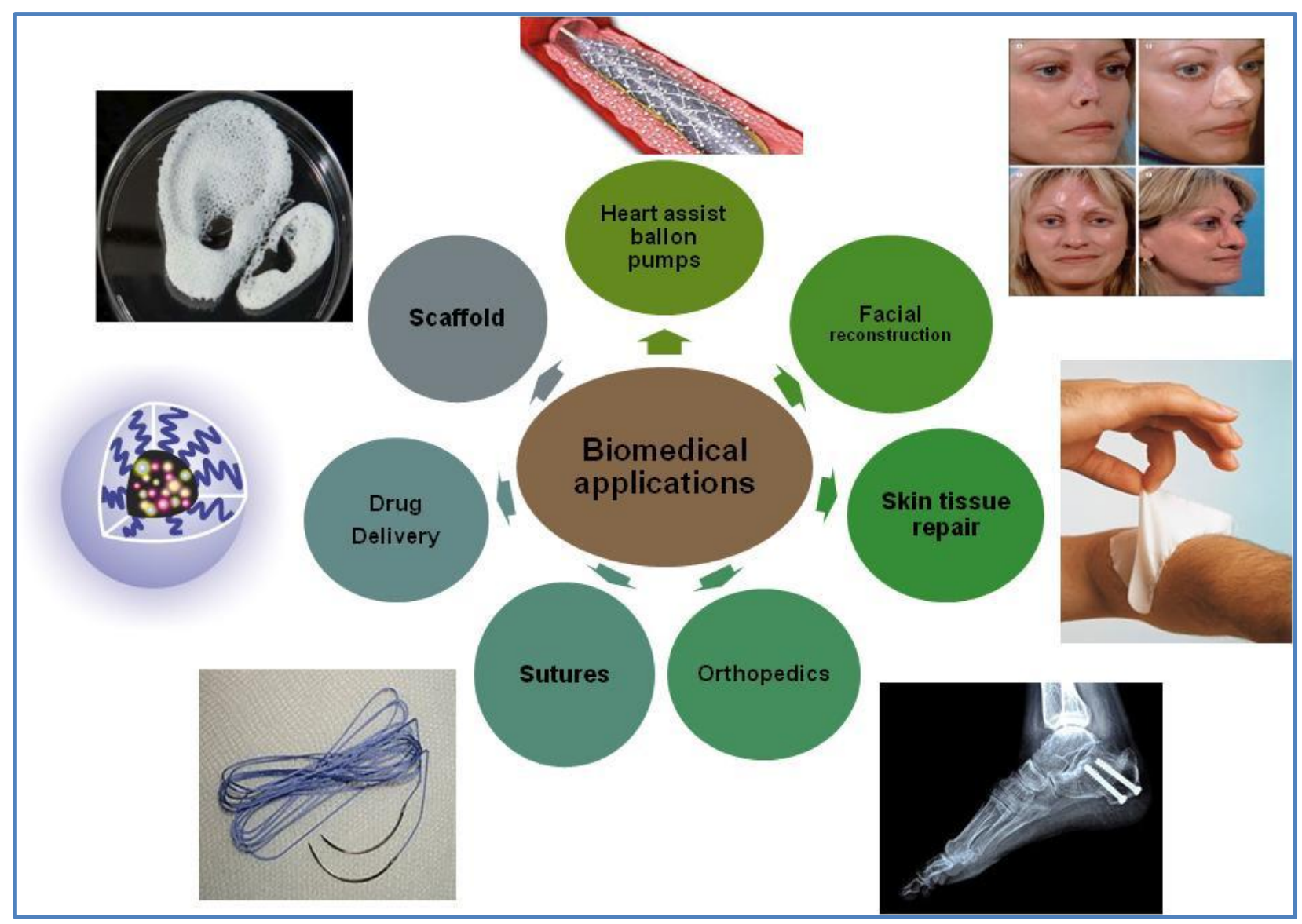

Fig. 2.8 Different biomedical applications of PL based copolymers. 


\section{CHAPTER 3 - EXPERIMENTAL}

\subsection{Materials}

All chemicals were purchased from Sigma-Aldrich and were used as received unless stated otherwise. Lactide $\left[\mathrm{M}_{\mathrm{n}}=144.13 \mathrm{~g} / \mathrm{mol}\right.$ ], poly(ethylene glycol) as a linker [PEG; $\mathrm{M}_{\mathrm{n}}=4000 \mathrm{~g} / \mathrm{mol}$ ] and $\operatorname{Sn}(\mathrm{Oct})_{2}$ catalyst were used to synthesize triblock copolymer. 1,4 Butanediisocyanat [BDI; $\mathrm{M}_{\mathrm{n}}=140.14 \mathrm{~g} / \mathrm{mol}$ ] and Polycaprolactone diol [PCL-diol; $\mathrm{M}_{\mathrm{n}}=2000 \mathrm{~g} / \mathrm{mol}$ ] as the soft segment were used in chain extending reactions and the formation of final polyurethane matrix. Diethyl ether, dimethyfrmamide (DMF), dichloromethane (DCM, 99.5\%), N,N-dimethylacetamide (DMAc), acetone and methanol of ACS reagent were used in the present work as common solvent for purification and film casting of polyurethane. Deuterated chloroform $\left(\mathrm{CDCl}_{3}\right)$ solvent was used for NMR analysis (99.8\%). Phosphate buffered saline $\mathrm{pH} 7.4$, sodium azide $\mathrm{NaN}_{3}$ and Lipase from porcine pancreas type II was obtained from Sigma-Aldrich Canada, (lipase activity: 100-500 units/mg protein (using olive oil (30 min incubation)), 30-90 units/mg protein (using triacetin). Sodium Chloride $(\mathrm{NaCl})$ salt (Sigma Ultra 99.5\%). Bacterial Cellulose nanofibers were synthesized in lab as described below, and was provided in the form of suspension solution in water with the concentration of $46 \mathrm{~g} / \mathrm{L}$. Sulfuric acid (98\%) was used in hydrolysis to obtain bacterial cellulose nanowhiskers (BCNW).

\subsection{Culture Growth Medium}

Bacterial strain Gluconoacetobacter Xylinum (ATCC 700178) was supplied by American Type Culture Collection (ATCC), Manassas, VA 20108, USA. Agar, Corn steep liquor (CSL), Ammonium Sulfate $\left(\mathrm{NH}_{4}\right)_{2} \mathrm{SO}_{4}, \mathrm{~L}(+)$ Albinos, D-biotin, Calcium Carbonate $\left(\mathrm{CaCO}_{3}\right)$, Calcium Chloride Dihydrate $\left(\mathrm{CaCl}_{2} \cdot 2 \mathrm{H}_{2} \mathrm{O}\right)$, Copper Sulfate Pentahydrate $\left(\mathrm{CuSO}_{4} .5 \mathrm{H}_{2} \mathrm{O}\right)$, Ferrous Sulfate Heptahydrate $\left(\mathrm{FeSO}_{4} \cdot 7 \mathrm{H}_{2} \mathrm{O}\right)$, Folic Acid, Fructose, Hydroxymethyl Furfural (5-HMF), Inositol, Magnesium Sulfate Heptahydrate $\left(\mathrm{MgSO}_{4} \cdot 7 \mathrm{H}_{2} \mathrm{O}\right)$, Manganese Sulfate Pentahydrate $\left(\mathrm{MnSO}_{4} .5 \mathrm{H}_{2} \mathrm{O}\right)$, Monopotassium Phosphate $\left(\mathrm{KH}_{2} \mathrm{PO}_{4}\right)$, Nicotinic Acid, D-Pantothenic Acid, Pyridoxine Hydrochloride, Riboflavin, Sodium Molybdenum Oxide Dihydrate $\left(\mathrm{NaMoO}_{4} \cdot 2 \mathrm{H}_{2} \mathrm{O}\right)$, Zinc Sulfate Heptahydrate $\left(\mathrm{ZnSO}_{4} \cdot 7 \mathrm{H}_{2} \mathrm{O}\right)$, Thiamine Hydrochloride, and D-(+)Xylose. 


\subsection{Preparations}

\subsubsection{Bacterial Strain and Culture Growth Conditions}

Gluconoacetobacter Xylinum (ATCC 700178) was used to produce BC nanofibers in agitated culture (shake flask). G. Xylinum bacteria was activated, according to ATCC guidelines (Appendix A), using $50 \mathrm{~g} / \mathrm{L}$ glucose, $5 \mathrm{~g} / \mathrm{L}$ yeast, $12.5 \mathrm{~g} / \mathrm{L} \mathrm{CaCO}$, and $15 \mathrm{~g} / \mathrm{L}$ of agar were added with solid mediums. Liquid culture was prepared by transferring dry bacterial powder into sterile YGC 459 medium, and statically incubated (Symphony 8.5A, VWR) at $29^{\circ} \mathrm{C}$ and initial pH 5.0 (Easy Seven, Metter Toledo) for 3 days. Bacterium cultivation on Agar plates was done by transferring liquid culture aseptically into Petri plates, containing YGC 459 agar medium, and incubated at $29^{\circ} \mathrm{C}$ and initial $\mathrm{pH} 5.0$ for 7 days. Inoculum solution was prepared by aseptically flooding the 7 days old culture plates with $20 \mathrm{~mL}$ sterile distilled water and gently suspending the culture with a cell spreader. Then the resulted solution was transferred to sterile inoculum tubes and mixed thoroughly using a VWR Analogue Vortex Mixer.

\subsubsection{Production of BC Nanofibers}

Bacterial Cellulose productions were conducted in $500 \mathrm{~mL}$ flasks, under static and shaking conditions, each containing $200 \mathrm{~mL}$ of fermentations medium [159]. The media composition was as follows: $40 \mathrm{~g} / \mathrm{L}$ Fructose (carbon source), $5 \mathrm{~mL}$ of corn steep liquor (CSL; nitrogen source), $1 \mathrm{~g} / \mathrm{L}$ of $\mathrm{KH}_{2} \mathrm{PO}_{4}, 0.25 \mathrm{~g} / \mathrm{L}$ of $\mathrm{MgSO}_{4} .7 \mathrm{H} 2 \mathrm{O}, 3.3 \mathrm{~g} / \mathrm{L}$ of $\left(\mathrm{NH}_{4}\right)_{2} \mathrm{SO}_{4}, 3.6 \mathrm{mg} / \mathrm{L}$ of $\mathrm{FeSO}_{4} .7 \mathrm{H}_{2} \mathrm{O}$, $14.7 \mathrm{mg} / \mathrm{L}$ of $\mathrm{CaCl}_{2} .2 \mathrm{H}_{2} \mathrm{O}, 2.42 \mathrm{mg} / \mathrm{L}$ of Sodium molybdate $\left(\mathrm{NaMoO}_{4} .2 \mathrm{H}_{2} \mathrm{O}\right), 1.73 \mathrm{mg} / \mathrm{L}$ of $\mathrm{ZnSO}_{4} .7 \mathrm{H}_{2} \mathrm{O}, 1.39 \mathrm{mg} / \mathrm{L}$ of $\mathrm{MnSO}_{4} .5 \mathrm{H}_{2} \mathrm{O}, 0.05 \mathrm{mg} / \mathrm{L}$ of $\mathrm{CuSO}_{4} .5 \mathrm{H}_{2} \mathrm{O}, 2 \mathrm{mg} / \mathrm{L}$ of Inositol, $0.4 \mathrm{mg} / \mathrm{L}$ of Nicotinic Acid, $0.4 \mathrm{mg} / \mathrm{L}$ of Pyridoxine Hydrochloride, $0.2 \mathrm{mg} / \mathrm{L}$ of D-Pantothenic Acid $0.2 \mathrm{mg} / \mathrm{L}$ of Riboflavin, $0.2 \mathrm{~g} / \mathrm{L}$ of Folic Acid, $0.2 \mu \mathrm{g} / \mathrm{L}$ of D-biotin and $0.4 \mathrm{~g} / \mathrm{L}$ of Thiamine Hydrochloride (Matsuoka et al., 1996). All glassware was sterilized in autoclave (Sanyo MLS 3780) at $121^{\circ} \mathrm{C}$ for 10 min prior to use. Carbohydrate solution and its additives was sterilized at $121^{\circ} \mathrm{C}$ for 10 min with initial $\mathrm{pH}$ 5.0. This was done separately from CSL to prevent high temperature reaction of sugars and amino acids (Maillard reaction), which may produce black nitrogen containing compounds that impede microorganisms growth. CSL was aseptically added to the growth medium additives mixture and sterile distilled water was added to compensate for evaporated water during autoclave if necessary. When the solutions reached room temperature, each flask was aseptically inoculated using $2 \mathrm{~mL}$ of the inoculum and the tip 
of the flask covered with a sponge that allow oxygen transfer, and then incubated at $29^{\circ} \mathrm{C}$ for 7 days with shaking speed of $250 \mathrm{rpm}$ (MaxQ 2000). At the end of the 7 days, the $\mathrm{pH}$ of each flask was checked, and solutions were treated with excess $2 \mathrm{M} \mathrm{NaOH}$ at $100^{\circ} \mathrm{C}$ for $15 \mathrm{~min}$ in the autoclave for cell lyses. BC nanofibres were extracted and repeatedly washed with distilled water. Production of $\mathrm{BC}$ was quantified gravimetrically based on the dry weight of the $\mathrm{BC}$ obtained. A production of $46 \mathrm{~g} / \mathrm{L}$ on wet basis was achieved from stirred culture (see Figure 3.1).

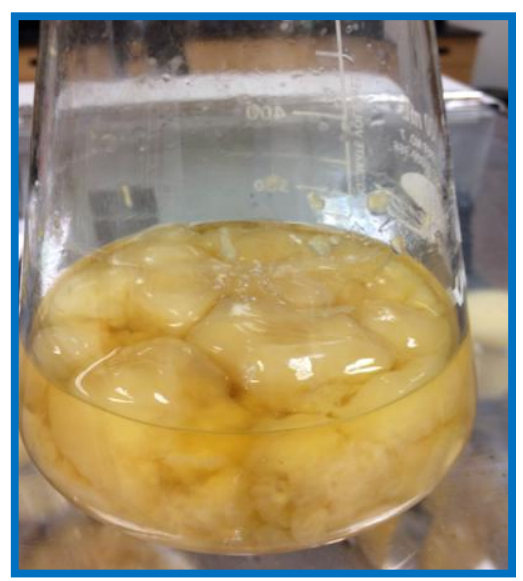

Fig. 3.1 Lab photo showing BC pellicles during their production from shake culture.

\subsubsection{Preparation of $\mathrm{BCNW}$}

First, BC pellicles were ground in a blender and the gel-like material was then squeezed in order to remove most of the absorbed water. The preparation procedure of $\mathrm{BCNW}$ was similar to that reported by Hirai et al. [160]. In brief, approximately dried BC was immersed in $60 \mathrm{wt} \%$ sulfuric acid under stirring for hydrolysis for 2-3 h at $50{ }^{\circ} \mathrm{C}$ until a homogeneous solution was obtained. The acid/BC ratio was kept at approximately $70 \mathrm{ml} / \mathrm{g}$. After that, the cellulose nanowhiskers were obtained by centrifugation as a white precipitate, and then neutralized with sodium hydroxide until neutral pH was obtained. Subsequently, BCNW was re-suspended and washed by deionized water using several centrifugation cycles and finally obtained as a partially hydrated precipitate.

\subsubsection{Suspension of BCNW in Organic Solvent}

BCNW was solvent exchanged into N,N-dimethylacetamide (DMAc), where water in the partially hydrated precipitate was replaced by DMAc by applying several centrifugation cycles in which the supernatant was removed and replaced with fresh DMAc several times. After that, 
dichloromethane (DCM) was added to DMAc-whisker solution and refluxed for $2 \mathrm{~h}$ at $80^{\circ} \mathrm{C}$ with contentious stirring until BCNW became well dispersed in DMAc/DCM mixture. A 2.2 $\mathrm{wt} \%$ of BCNW was obtained after partially evaporating the solvents.

\subsubsection{Synthesis of PL-PEG-PL Triblock Copolymer (TB)}

Bulk polymerization of lactide initiated by the hydroxyl moiety of PEG was carried out according to Leenslag and Pennings' method [161] with minor modification. Prescribed amounts of an initiator PEG and lactide were uniformly mixed as the preplanned feed weight ratio shown in Table 4.1, placed in a three-necked flask equipped with overhead mechanical stirring shaft, reflux condenser, and a nitrogen gas inlet, see Fig. 3.2. The mixture was directly evacuated, and then dehydrated for $1 \mathrm{~h}$ under reduced pressure at $120^{\circ} \mathrm{C}$. After LA and PEG have been melted, the system was purged with $\mathrm{N}_{2}$ gas and the catalyst in chloroform solution was added according to the weight percent (wt \%) of dehydrated reactants. The polymerization reaction was continued for $24 \mathrm{~h}$, where the temperature of the oil bath in which the reactor was immersed was kept at $140^{\circ} \mathrm{C}$. As the polymerization proceeded, the reactants become less transparent and viscous. To react any residual monomer which might be present, the reaction product was annealed at $135^{\circ} \mathrm{C}$ for about $180 \mathrm{~min}$. The reaction vessel was partially cooled down, and once the stirring had stopped, small amount of chloroform solution was added to extract the product from reaction vessel before solidification. Six different TB copolymers were synthesized by varying the initial feed ratios of LA to PEG. The compositions and molecular weights of the TB copolymers are shown in Table 4.1. As a comparison reference, PL-homopolymers was also synthesized under similar conditions as the previously mentioned without adding PEG.

\subsubsection{Purification and Recovery of TB Copolymers}

The high molecular weight TB copolymer products were purified as follows: A given product was by being initially dissolved in chloroform, and then methanol was slowly added to the solution with stirring at $30^{\circ} \mathrm{C}$ until the solution became turbid. The solution was aged for about 2 $\mathrm{h}$ at this temperature for complete precipitation. The viscous polymer was separated by decantation. Whereas the low molecular weight TB was precipitated as white powder from chloroform solution into ether, and then separated by vacuum filtration. The products were dried in desiccators for at least $24 \mathrm{~h}$ at room temperature prior further utilized. 


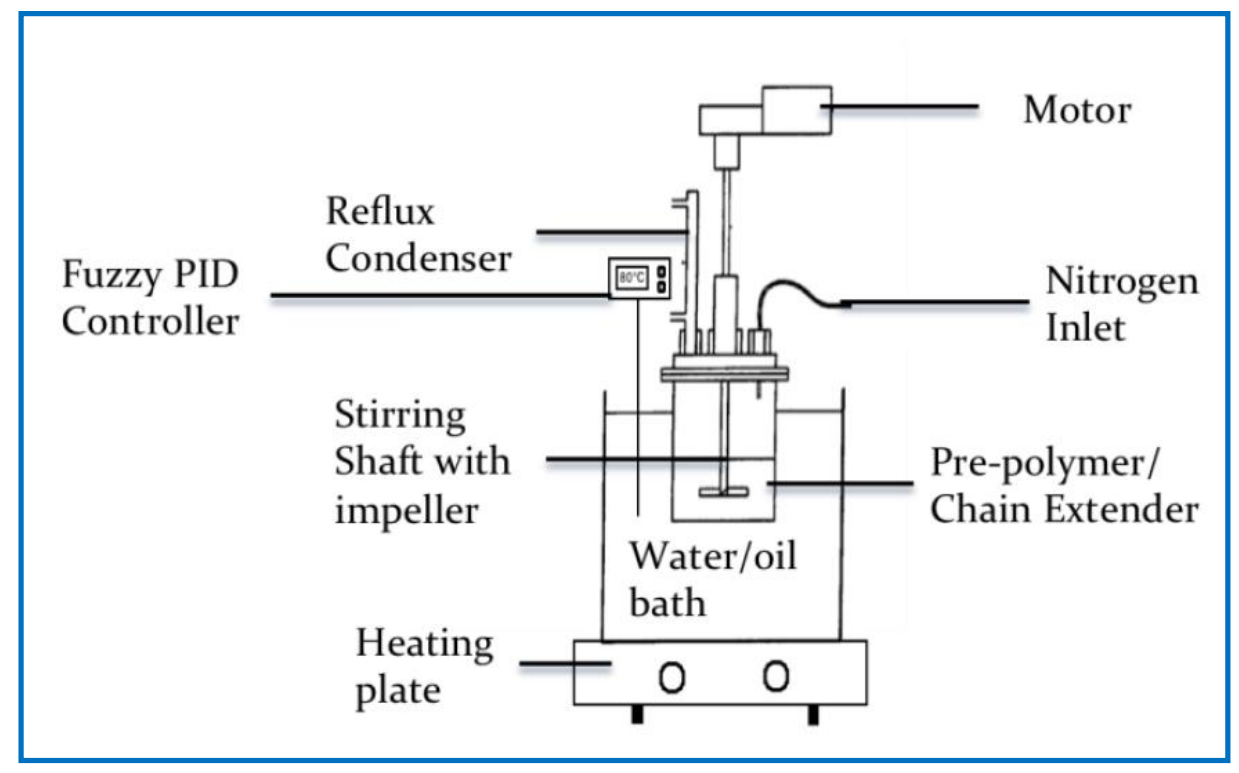

Fig. 3.2 Lab setup used for carrying out polymerization reactions.

\subsubsection{Synthesis of TB-BDI Pre-polymer}

The TB-BDI pre-polymer was synthesized by mixing the prescribed amount of TB copolymer with stannous octoate catalyst in a three-necked flask equipped with overhead mechanical stirring under nitrogen atmosphere. BDI linker in the least amount of chloroform was added in 2:1 molar ratio with $\mathrm{TB}$, and then the mixture was heated in oil bath for $2 \mathrm{~h}$ at $70^{\circ} \mathrm{C}$. The resulting product was precipitated in excess methanol. The product was dried in desiccator for 24 $\mathrm{h}$ at room temperature.

\subsubsection{Synthesis of Triblock Polyurethane Polymers (TBPUs)}

A chain-extension reaction was applied to produce high molecular weight TBPU polymers was carried out as before. PCL diol was used as a soft segment. The PCL concentrations were based on balancing the isocyanate:PCL diol content of the PCL at a 1:1 mole ratio. The reaction vessel was kept at $70^{\circ} \mathrm{C}$ for $4 \mathrm{~h}$ under a nitrogen atmosphere. High $\mathrm{M}_{\mathrm{n}}$ polymers were precipitated in methanol, whereas the low molecular weights were precipitated in diethyl ether. The precipitated product was filtered, rinsed with methanol and dried in a vacuum oven at $40{ }^{\circ} \mathrm{C}$ overnight for complete dryness. Six different TBPU polymers were obtained with varying composition. The compositions and molecular weights of the TBPU polymers are shown in Table 4.3. 


\subsubsection{Preparation of Polymer Films}

Polymer films of dimensions ( $1 \mathrm{~mm}$ thickness $\times 1 \mathrm{~cm}$ width $\times 10 \mathrm{~cm}$ length) were prepared by casting $15 \mathrm{wt} \%$ DMAc solutions of polymers, prepared by stirring the polymer in a water bath at $80{ }^{\circ} \mathrm{C}$, into handmade stainless-steel mold, Fig. 3.3. After the solvent evaporated at room temperature, the films were removed from the mold and dried under vacuum condition at $40{ }^{\circ} \mathrm{C}$ for $24 \mathrm{~h}$ to ensure that the solvent had completely evaporated.

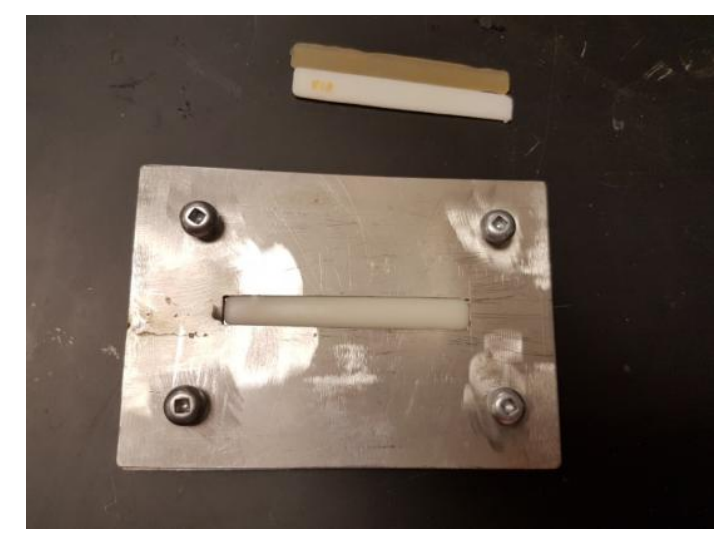

Fig. 3.3 Handmade stainless steel mold used for preparing tensile samples of dimensions $[1 \mathrm{~mm}$ $(\mathrm{t}) \times 1 \mathrm{~cm}(\mathrm{w}) \times 10 \mathrm{~cm}$; yellowish sample is TBPU-3 while the white samples are TBPU-3 reinforced BCNW composites.

\subsubsection{Preparation of TBPU/BCNW Nanocomposites}

The TBPU/BCNW nanocomposites were prepared by the solvent casting method, previously reported by Fortunati et al. [162] but with different solvent system. First, TBPU polymer solution in DMAc/DCM mixture at $70{ }^{\circ} \mathrm{C}$ which was added gradually with agitation into the suspension of cellulose nanowhiskers of (1,3,5,7 and $8 \mathrm{wt} \%$ based on polymer content) dispersed in DMAc/DCM. Then, the mixed solution was poured into a mold and flash frozen in liquid nitrogen and the mold was then transferred to a refrigerator set at $-50^{\circ} \mathrm{C}$ and kept for $24 \mathrm{~h}$. After that, obtained composites were placed under vacuum condition at $40{ }^{\circ} \mathrm{C}$ for $48 \mathrm{~h}$ to ensure that the solvent had completely evaporated. 


\subsection{Characterization Techniques and Analysis Procedure}

\subsubsection{Fourier Transform Infra-red Spectroscopy (FTIR/ATR)}

Structural changes during the stepwise formation of TBPU polymers were investigated by FTIR spectroscopy using Perkin Elmer Spectrum-1 system (RUAC) in attenuated total reflectance mode (ATR). The ATR spectra of all samples were recorded in the transmittance mode in the range of 4000-500 $\mathrm{cm}^{-1}$. The ATR-crystal used was $\mathrm{ZnSe}$, and each spectrum was recorded with resolution of $4 \mathrm{~cm}^{-1}$ and consisted of 20 scans.

\subsection{2 ${ }^{1} \mathrm{H}-\mathrm{NMR}$ spectra}

The chemical compositions of TB copolymers and their polyurethanes were characterized by ${ }^{1} \mathrm{H}-$ NMR spectra. The polymer samples were recorded using Bruker $400 \mathrm{MHz}$ Spectrometer by Bruker Biospin (Rheinstetten, Germany) at Ryerson Facilities. The polymers were dissolved in $\mathrm{CDCl}_{3}$, where the concentration used was $10 \mathrm{mg} / \mathrm{mL}$ with tetramethylsilane as an internal reference at $25^{\circ} \mathrm{C}$.

\subsubsection{Calculation of molecular weight of copolymer using ${ }^{1} \mathrm{H}-\mathrm{NMR}$ spectroscopy}

\subsubsection{Determination of Degree of Polymerization and Molecular Weight}

The degree of polymerization (DP) of PL in all copolymer samples was determined from ${ }^{1} \mathrm{H}$ NMR spectra. This was done by comparing relative proton peak intensity of a distinguishing moiety (typically an end-group(s) with a known number of protons) to that of the repeating chain unit of interest [163]. Herein, the calculation of DP of PL was done as follow:

$$
\mathbf{a}_{\mathrm{i}}=\mathrm{kn}_{\mathrm{i}} \mathrm{m}_{\mathrm{i}} \quad \mathbf{E q} \mathbf{3 . 1}
$$

taking k the subject of the formula, $\quad k=\frac{a_{i}}{n_{i} m_{i}} \quad$ Eq 3.2

where $a_{i}$ is the area or intensity of the ${ }^{1} \mathrm{H}-\mathrm{NMR}$ peak of species $\mathrm{i} ; \mathrm{n}_{\mathrm{i}}$ is the number of repeating units of species $i$; $m_{i}$ is the number of protons of species $i$; and $k$ is the constant.

Considering the ${ }^{1} \mathrm{H}-\mathrm{NMR}$ signals of two moieties $\mathrm{x}$ and $\mathrm{y}$, from Eq 3.2:

$$
k_{x}=\frac{a_{x}}{n_{x} m_{x}} \quad \text { Eq } 3.3
$$




$$
k_{y}=\frac{a_{y}}{n_{y} m_{y}} \quad \text { Eq } 3.4
$$

Where $\mathrm{k}_{\mathrm{x}}=\mathrm{k}_{\mathrm{y}}$ in a given polymer,

$$
\frac{a_{y}}{n_{y} m_{y}}=\frac{a_{x}}{n_{x} m_{x}} \quad \text { Eq } 3.5
$$

where $a_{x}$ is the area or intensity of the ${ }^{1} H-N M R$ peak of moiety $x ; n_{x}$ is the number of repeating units of moiety $x ; m_{x}$ is the number of protons of moiety $x ; a_{y}$ is the area or intensity of the ${ }^{1} \mathrm{H}$ NMR peak of moiety $y ; n_{y}$ is the number of repeating units of moiety $y$; and $\mathrm{m}_{\mathrm{y}}$ is the number of protons of moiety $\mathrm{y}$. Rearranging eq 3.5 for $\mathrm{n}_{\mathrm{x}}$,

$$
n_{x}=\frac{a_{x} m_{y} n_{y}}{a_{y} m_{x}} \quad \operatorname{Eq} 3.6
$$

where $\mathrm{n}_{\mathrm{x}}$ can be used to assess the polymer's DP or number of repeating units. Consequently, Mn can be calculated by substituting for $\mathrm{n}$ in $\mathrm{Eq} 3.6$,

$$
\mathbf{M}_{n}=\mathbf{n M}_{0}+M_{e} \quad \mathbf{E q} 3.7
$$

where $\mathrm{n}$ is the number of repeating units or DP; $\mathrm{M}_{0}$ is the molecular weight of one repeating unit, and $\mathrm{M}_{\mathrm{e}}$ is the combined molecular weight of the end-groups. Some of the data extracted from the

${ }^{1} \mathrm{H}-\mathrm{NMR}$ spectra of the model polymers for molecular weight determination are collected in Table 4.2.

\subsubsection{Copolymer Composition Characterization}

The monomer ratio of monomer $\mathrm{x}$ in block copolymer was also estimated from ${ }^{1} \mathrm{H}-\mathrm{NMR}$ [164] by comparing peak areas form block $\mathrm{x}$ to that of from the $\mathrm{y}$ block, using Eq 3.8,

$$
\% x=\frac{a_{x} / m_{x}}{a_{x} m_{x}+a_{y} / m_{y}} X 100 \% \quad \text { Eq } 3.8
$$

where $a_{x}$ is the area of the ${ }^{1} H-N M R$ peak of unit $x ; m_{x}$ is the number of protons of unit $x$; $a_{y}$ is the area of the ${ }^{1} \mathrm{H}-\mathrm{NMR}$ peak of unit $\mathrm{y}$; and $\mathrm{m}_{\mathrm{y}}$ is the number of protons of unit $\mathrm{y}$. 


\subsubsection{Gel Permeation Chromatography (GPC)}

The number-average molecular weights $\left(\mathrm{M}_{\mathrm{n}}\right)$ of PL-PEG-PL TB copolymer were determined using Viscotek GPC/SEC system (Ryerson University Analytical Centre, RUAC). Molecular weight determination is accomplished through use of the Triple detector array (TDA 302) and the OmniSec software. The triple detector consists of Right Angle Light Scattering (RALS), a high sensitivity Viscometer (for DP and IP), and a Refractive index detector (RI). The combination of these can give very accurate $\mathrm{dn} / \mathrm{dc}$ determinations and subsequently molecular weight. Tetrahydrofurane solvent (HPLC grade) was used as the eluent with flow rate of $1.0 \mathrm{ml}$ $\min ^{-1}$ at $32^{\circ} \mathrm{C}$ through Shodex GPC KF-802 series column. Polymer samples were dissolved in THF at a concentration of $10 \mathrm{mg} / \mathrm{mL}$, and then filtered through $0.45 \mu \mathrm{m}$ filter. The number average molecular weights of the polymers were determined by universal calibration obtained from polystyrene reference samples having narrow molecular weight distributions ranging from 1,260 to $184,900 \mathrm{~g} / \mathrm{mol}$.

\subsubsection{Differential Scanning Calorimetry (DSC)}

A differential scanning calorimeter (DSC) was used to measure thermal properties of the polymers. The Perkin Elmer Diamond Differential Scanning Calorimeter controlled with PYRIS 7 software was used at (RUAC). The thermograms covered the $-20^{\circ} \mathrm{C}-200^{\circ} \mathrm{C}$ temperature range in a nitrogen atmosphere at flow rate $20 \mathrm{~mL} / \mathrm{min}$ at a $10^{\circ} \mathrm{C} \mathrm{m^{-1 }}$ heating rate. Approximately 5 mg polymer samples were placed and sealed in aluminum pan $(20 \mu \mathrm{L})$. The first scan measured the melting endotherm, and the second measured $\mathrm{T}_{\mathrm{g}}$ values.

\subsubsection{Water Content Measurements}

The water content of the polymers was determined by soaking the samples in deionized water at $25^{\circ} \mathrm{C}$. The specimens were taken out periodically for weighing until equilibrium was attained. Samples were gently blotted prior weighing to remove the excess surface water. The water content is expressed as percentage of dry polymer samples using equation 3.9. Reported water contents are the average of at least two determinations.

$$
\% \text { Water content }=\left(\mathrm{W}_{\text {swollen }}-\mathrm{W}_{\text {dried }}\right) / \mathrm{W}_{\text {dried }} \mathbf{x} 100 \% \quad \text { Eq } 3.9
$$

where $\mathrm{W}_{\text {swollen }}$ and $\mathrm{W}_{\text {dried }}$ are the weights of the swollen and dried polymer, respectively. 


\subsubsection{Contact Angle Measurements}

Advancing water contact angle measurements in air were performed on different TBPUs films on an Optical-Bench Contact Angle Goniometer (UTM facilities), each reported value being the average of at least three measurements. A droplet of distilled water was deposited on the samples and the contact angle was measured at different times.

\subsubsection{Biodegradation}

In this study, hydrolytic and enzymatic degradation were employed for all the synthesized polyurethane samples. Hydrolytic degradation was carried out in PBS solution (0.1 M PBS with $0.9 \% \mathrm{NaCl}, 0.02 \% \mathrm{NaN}_{3}$ and $\mathrm{pH} 7.4$ ), and enzymatic degradation was carried out in enzymatic solution $\left(0.1 \mathrm{mg} \mathrm{mL}^{-1}\right)$ Lipase from porcine pancreas in $0.1 \mathrm{M}$ PBS with $0.9 \% \mathrm{NaCl}, 0.02 \%$ $\mathrm{NaN}_{3}$ and $\mathrm{pH}$ 7.4). Each sample was placed into an individual vial containing $10 \mathrm{~mL}$ PBS, and then incubated with shaking at $37^{\circ} \mathrm{C}$ to simulate in vivo dynamic tissue environment. The samples were taken out after $5 \mathrm{~h}, 15 \mathrm{~h}, 30 \mathrm{~h}, 60 \mathrm{~h}$ and $120 \mathrm{~h}$, rinsed by deionized water, vacuum dried at $60{ }^{\circ} \mathrm{C}$ for $24 \mathrm{~h}$, and reweighed to determine weight loss using the following equation:

\section{Weight loss $(\%)=\left(\mathrm{W}_{0}-\mathrm{W}_{\mathrm{t}}\right) / \mathrm{W}_{0} \times 100 \% \quad$ Eq 3.10}

where $\mathrm{W}_{0}$ and $\mathrm{W}_{\mathrm{t}}$ are the dry weight of the sample before and after degradation, respectively. The reported weight loss was the average of three samples. The degradation mediums were also collected for $\mathrm{pH}$ value measurements. The samples after degradation were gold coated for surface morphology with scanning electron microscope (SEM).

\subsubsection{Field Emission Scanning Electron Microscopy (FE-SEM)}

The surface morphology of PU samples before and after degradation were examined using (FESEM) (FEI Quanta $200 \mathrm{~F}$, Netherlands) microscope with an accelerating voltage of 15-20 kV. Before examination, a fine layer of gold was sprayed on samples by an ion sputter coater with a low deposition rate.

\subsubsection{Mechanical Testing}

The mechanical properties of the TB, TBPU and TBPU-BCNW nanocomposites were evaluated by measuring tensile strength, tensile modulus and elongation at break using Labthink's Param 
XLW (PC) Auto Tensile Tester equipped with a $500 \mathrm{~N}$ load cell and operating at a crosshead speed of $100 \mathrm{~mm} / \mathrm{min}$ at room temperature, as shown in Fig. 3.4.

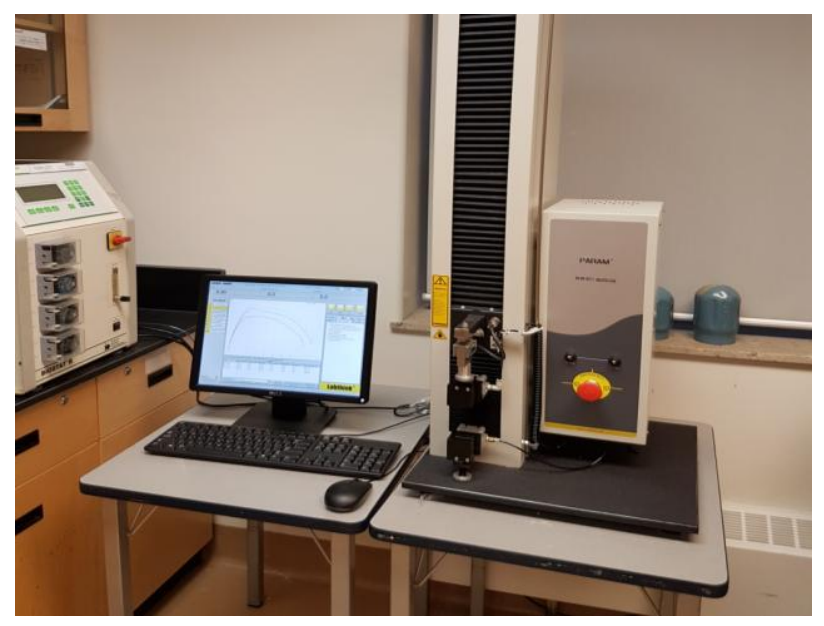

Fig. 3.4 Labthink's Param XLW (PC) Auto Tensile Tester. 


\section{CHAPTER 4 - RESULTS AND DISCUSSION}

\subsection{Synthesis of Triblock (PL-PEG-PL) and PUs}

A series of triblock polyurethane consisting of PL, PEG and PCL were prepared via three-step polymerization reactions (Scheme 4.1). First, the triblock copolymers PL-PEG-PL were synthesized through the ring opening polymerization of lactide in presence of bifunctional macro-monomer dihydroxy PEG as imitator and stannous octoate as the catalyst. The molecular weights of the triblock PL-PEG-PL were controlled by changing the feed ratio of lactide and PEG, for convenience, six triblock polymer samples were prepared and named as TB1, TB2, TB3, TB4, TB5 and TB6. The TB copolymers with a high PEG content and low molecular weight showed noticeable solubility in water. The $\% \mathrm{w} / \mathrm{w}$ feed ratios of lactide/PEG, reaction yield and reaction conditions along with observations are summarized in Table 4.1.

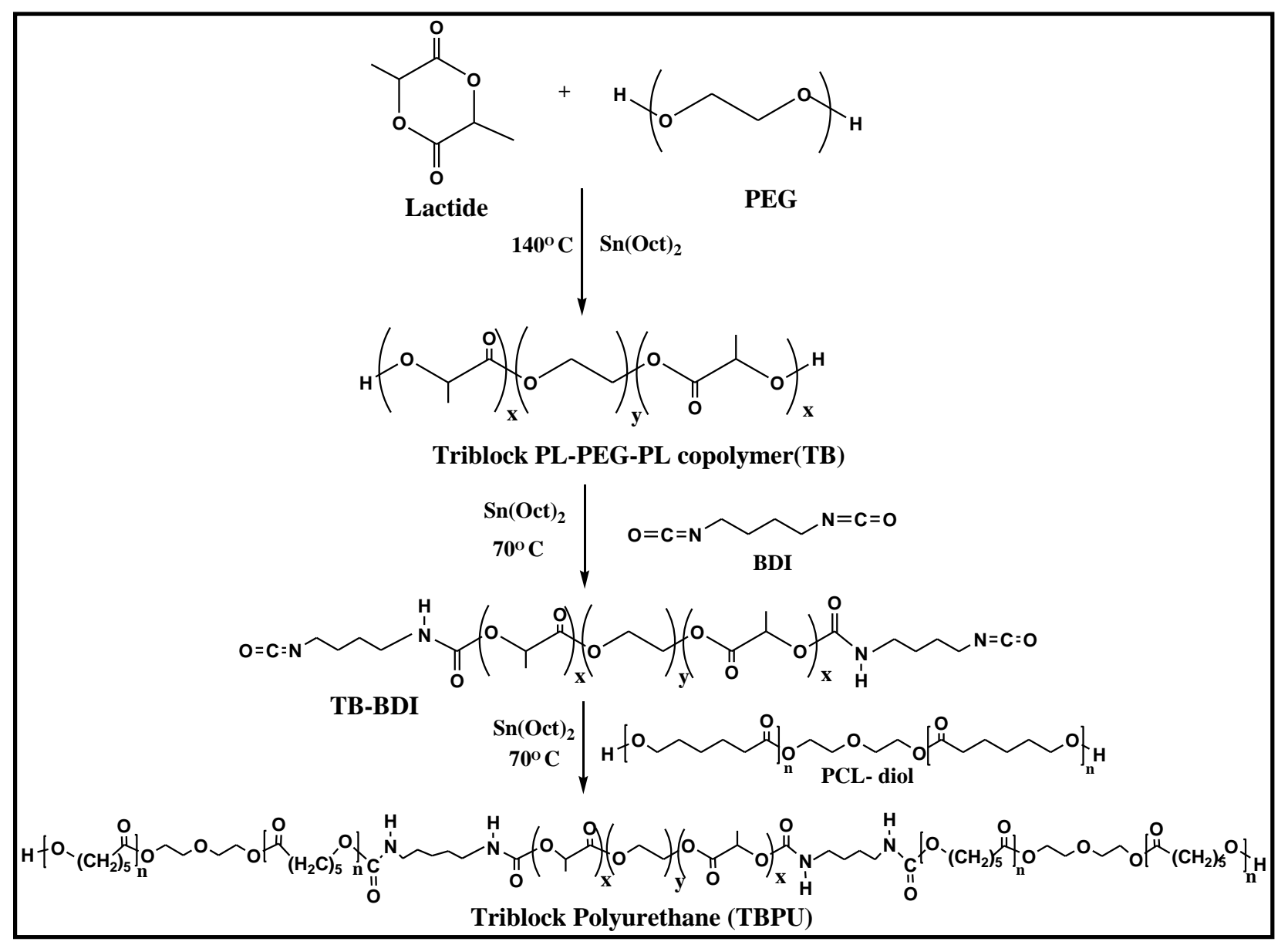

Scheme 4.1 Synthesis routes and structures of PL-PEG-PL triblock copolymer, TB-BDI and triblock polyurethane (TBPUs). 
Table 4.1 Inatial composition used in preparing PL-PEG-PL triblock copolymer

\begin{tabular}{|l|c|c|c|c|c|c|}
\hline Lot & $\begin{array}{c}\text { Feed (\%w/w) of } \\
\text { LA: PEG(400) }\end{array}$ & $\begin{array}{c}\text { Sn(Oct) } \\
(\% \text { w/w })\end{array}$ & $\begin{array}{c}\text { Yield } \\
(\%)\end{array}$ & $\begin{array}{c}\text { Reaction } \\
\text { time (h) }\end{array}$ & $\begin{array}{c}\text { Extraction and } \\
\text { purification solvents }\end{array}$ & $\begin{array}{c}\text { Colour after } \\
\text { purification }\end{array}$ \\
\hline TB1 & $98: 2$ & 0.05 & $72 \%$ & 24 & $\mathrm{CH}_{3} \mathrm{Cl} / / \mathrm{MeOH}$ & $\begin{array}{c}\text { Colorless very } \\
\text { viscous liquid }\end{array}$ \\
\hline TB2 & $97: 3$ & 0.05 & $75 \%$ & 24 & $\mathrm{CH}_{3} \mathrm{Cl} / / \mathrm{MeOH}$ & $\begin{array}{c}\text { Yellowish viscous } \\
\text { liquid }\end{array}$ \\
\hline TB3 & $95: 5$ & 0.05 & $87 \%$ & 24 & $\mathrm{CH}_{3} \mathrm{Cl} / / \mathrm{MeOH}$ & $\begin{array}{c}\text { Brown and } \\
\text { semitransparent }\end{array}$ \\
\hline TB4 $^{*}$ & $90: 10$ & 0.05 & $90 \%$ & 24 & $\mathrm{CH}_{3} \mathrm{Cl} / / \mathrm{ether}$ & Brownish powder \\
\hline TB5 $^{*}$ & $80: 20$ & 0.05 & $92 \%$ & 24 & $\mathrm{CH}_{3} \mathrm{Cl} / / \mathrm{ether}$ & Yellowish powder \\
\hline TB6 $^{*}$ & $70: 25$ & 0.05 & $96 \%$ & 24 & $\mathrm{CH}_{3} \mathrm{Cl} / / \mathrm{ether}$ & White powder \\
\hline
\end{tabular}

"Are partial water soluble block copolymer.

In the second step, TB-BDI was synthesized through the condensation reaction between the previously synthesized TB prepolymer and BDI in (1:2) molar ratio in presence of $\mathrm{Sn}(\mathrm{Oct})_{2}$. Following the second step, the chain-extension reaction was carried out to form the final polyurethane polymers TBPUs after adding PCL-diol as flexible segment to TB-BDI in (2:1) molar ratio, respectively. To control the final molecular weight, and also to examine the effect of PL/PEG segment ratio on the final physical properties of the TBPUs polymers, the initial molar ratios of TB: PCL diol: BDI were kept fixed to 1:2:2. For convenience, these polyurethane samples are labeled from TBPU-1 to TBPU-6.

\subsection{Characterization of PL-PEG-PL and PUs}

\subsubsection{FTIR-ATR Spectra}

The composition of the triblock PL-PEG-PL copolymers was determined by FTIR in ATR mode. A typical IR spectrum of the formation of triblock copolymers is shown in Fig. 4.1. For LA, ester carbonyl band appears at around $1750 \mathrm{~cm}^{-1}$ and for PEG C-H stretching band of $\mathrm{CH}_{2}$ appears at $2880 \mathrm{~cm}^{-1}$ [165]. In comparison with those two homopolymers LA and PEG, the following assignment was made for the main absorption bands of the triblock copolymer: the band at 2995 $\mathrm{cm}^{-1}$ belongs to $\mathrm{C}-\mathrm{H}$ stretching of $-\mathrm{CH}_{3}$ of LA units; the bands at $2865 \mathrm{~cm}^{-1}$ is due to $\mathrm{C}-\mathrm{H}$ stretching of $-\mathrm{CH}_{2}$ of PEG; the band at $1750 \mathrm{~cm}^{-1}$ to $\mathrm{C}=\mathrm{O}$ stretching of the LA units; and the bands at $1095 \mathrm{~cm}^{-1}$ is due to C-O stretching of LA and the ether bond of PEG as well. Therefore, the 
spectrum of the triblock copolymer contained all the characteristic absorption bands belonging to LA, and PEG, suggesting that the copolymer was composed of the two components.

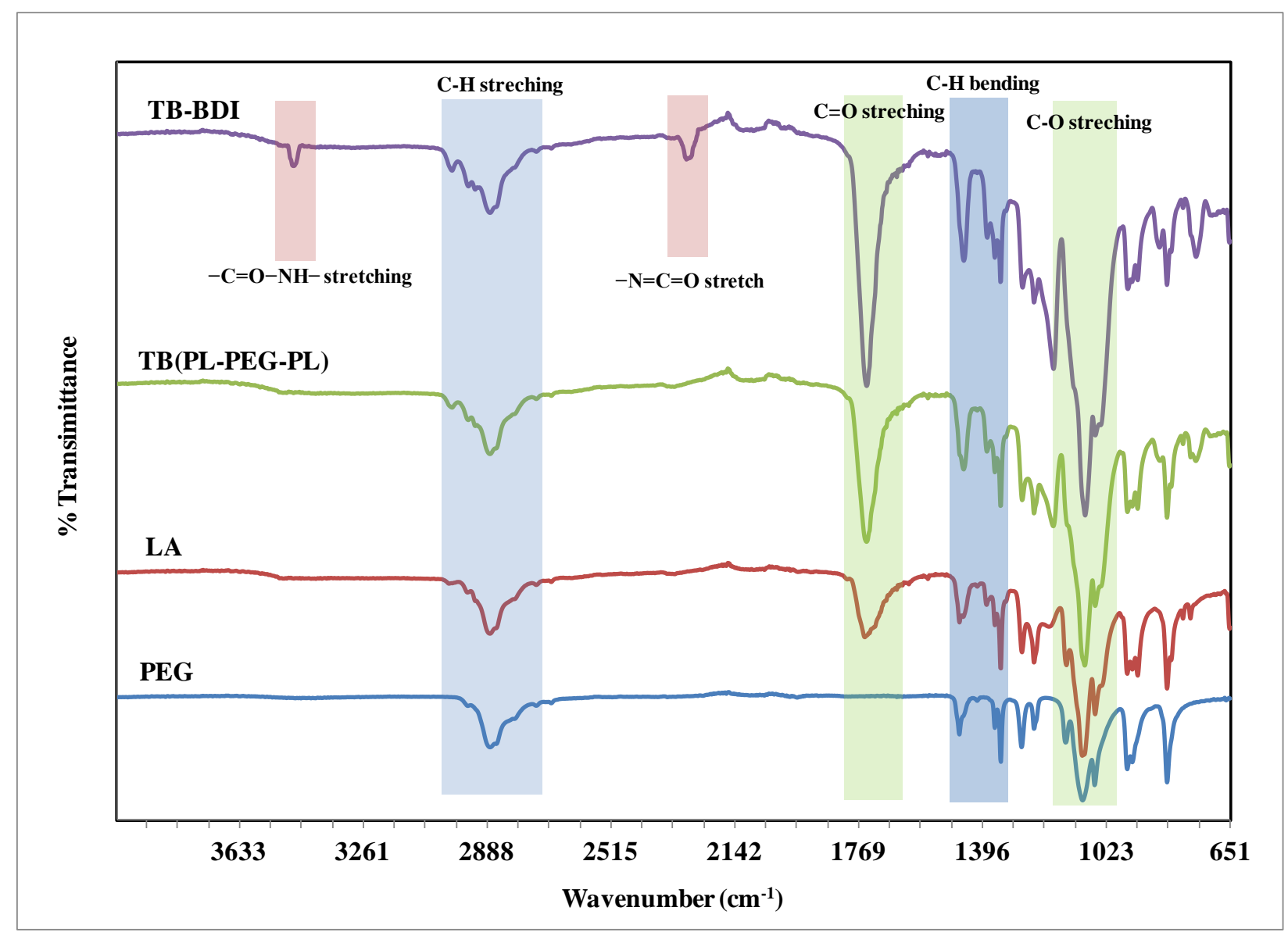

Fig. 4.1 FTIR-ATR spectra of LA, PEG, triblock copolymer PL-PEG-PL, and triblock copolymer conjugated with BDI.

The structures of the polyurethanes were characterized by FTIR, where ATR/ FTIR spectra of PCL-diol, TB-BDI, and TBPU-1 as the representative of TBPU samples are shown in Fig. 4.2. In addition to the characteristic peaks that present in TB copolymer, FTIR spectra of TBPU-1 to TBPU-6 showed new characteristic absorption peaks at 2945, 1182, and $1485 \mathrm{~cm}^{-1}$ were ascribed to $\mathrm{C}-\mathrm{H}$ stretching of $-\mathrm{CH}_{2}$ and $\mathrm{C}-\mathrm{O}$ stretching of PCL units [166], and $\mathrm{C}-\mathrm{N}$ stretching, respectively. After the reaction of $\mathrm{TB}$ copolymer with $\mathrm{BDI}$ the characteristic broad peak due to the hydroxyl group $\mathrm{OH}$ stretching band of TB copolymer disappeared, while new secondary amide peaks and isocyanate peaks were observed at $3473 \mathrm{~cm}^{-1}(-\mathrm{C}=\mathrm{O}-\mathrm{NH}-$ stretching $)$ and 2287 $\mathrm{cm}^{-1}(-\mathrm{N}=\mathrm{C}=\mathrm{O})$, respectively [167]. After the addition of the chain extender PCL-diole, the 
isocyanate peak disappeared, while the peak due to $(-\mathrm{C}=\mathrm{O}-\mathrm{NH}-$ stretching $)$ at $3473 \mathrm{~cm}^{-1}$ is retained, which clearly implying the successful preparation of TBPU polymers.

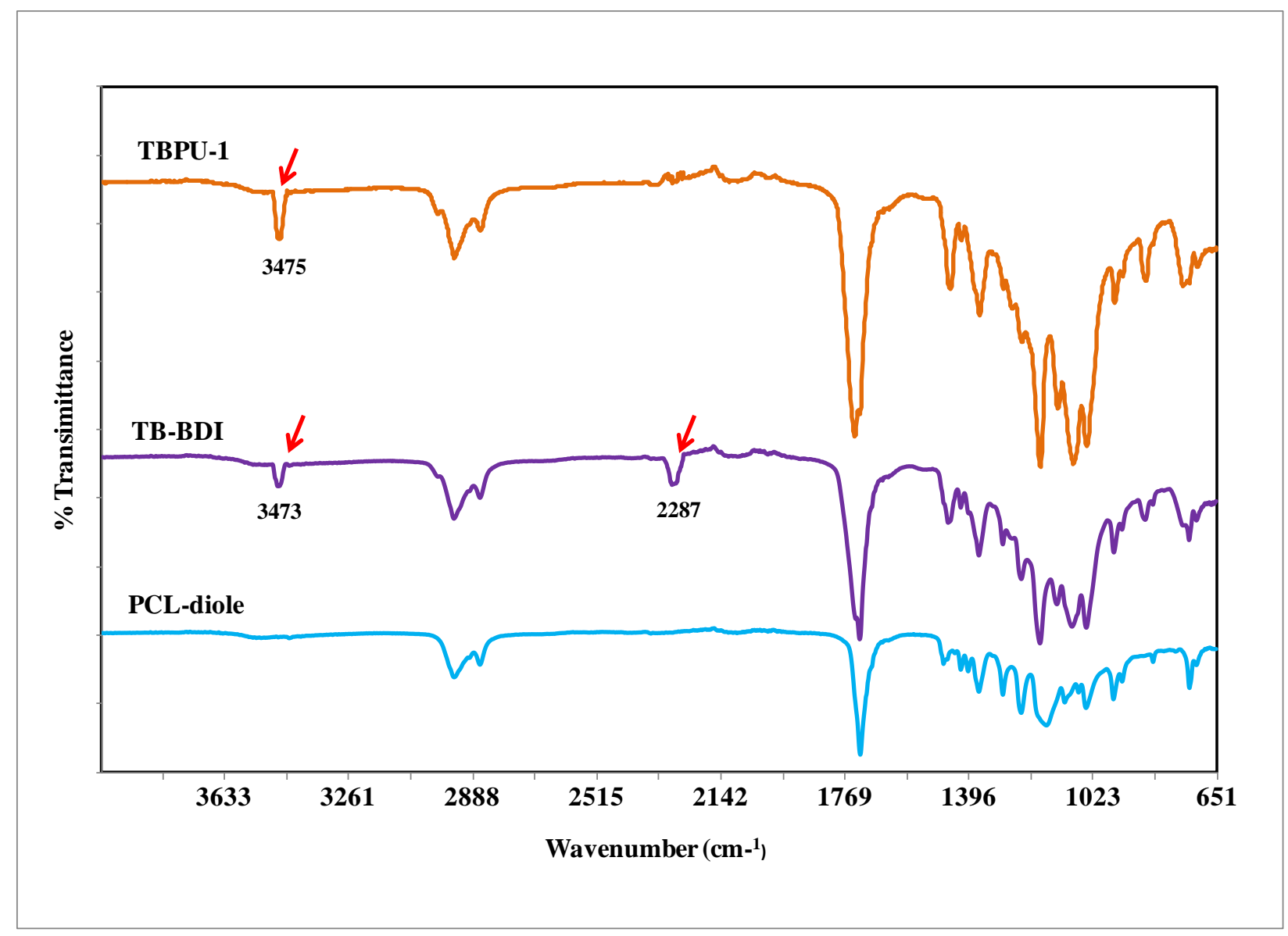

Fig. 4.2 ATR-FTIR spectra of PCL-diole, triblock copolymer conjugated with BDI (TB-BDI) and triblock copolymer polyurethane (TBPU-1).

\subsection{2 ${ }^{1} \mathrm{H}-\mathrm{NMR}$}

The ${ }^{1}$ H-NMR spectra for all samples showed in (Appendix B) Figs. B1-B9 ascertains the chemical composition of the TB copolymers and TBPUs. The peaks at $5.1 \mathrm{ppm}(\mathrm{CH})$ and 1.5 ppm $\left(\mathrm{CH}_{3}\right)$ belong to PL blocks and the peak at $3.64 \mathrm{ppm}$ is characteristic of main chain methylene units in the PEG blocks. An additional small, but nevertheless highly significant signal of the methylene protons of PL-connecting ethylene glycol units $\left(-\mathrm{CH}-\mathrm{COO}-\mathrm{CH}_{2}-\right)$ that appeared at $4.25 \mathrm{ppm}$, see Fig. 4.3. These results correspond well to those reported in the literature for PEG/PL block copolymers of different block types $[168,169]$. In light of all these findings it is concluded that covalently bound block copolymers were synthesized comprising 
PEG and PL sequences of different molecular weights. In all spectra, the "extra peaks" determined at chemical shifts of $(\delta=1.85 \mathrm{ppm}, \mathrm{m})$ and $(\delta=2.175 \mathrm{ppm}, \mathrm{s})$ are solvent residual peaks due to interaction of $\mathrm{CH}_{2}$ of tetrahydrofuran and $\mathrm{CH}_{3}$ of acetone with $\mathrm{CDCl}_{3}$ [170]. The chemical shifts of the various hydrogen atoms in the copolymer that determined with ${ }^{1} \mathrm{H}-\mathrm{NMR}$ spectrum are present in Table 4.2.

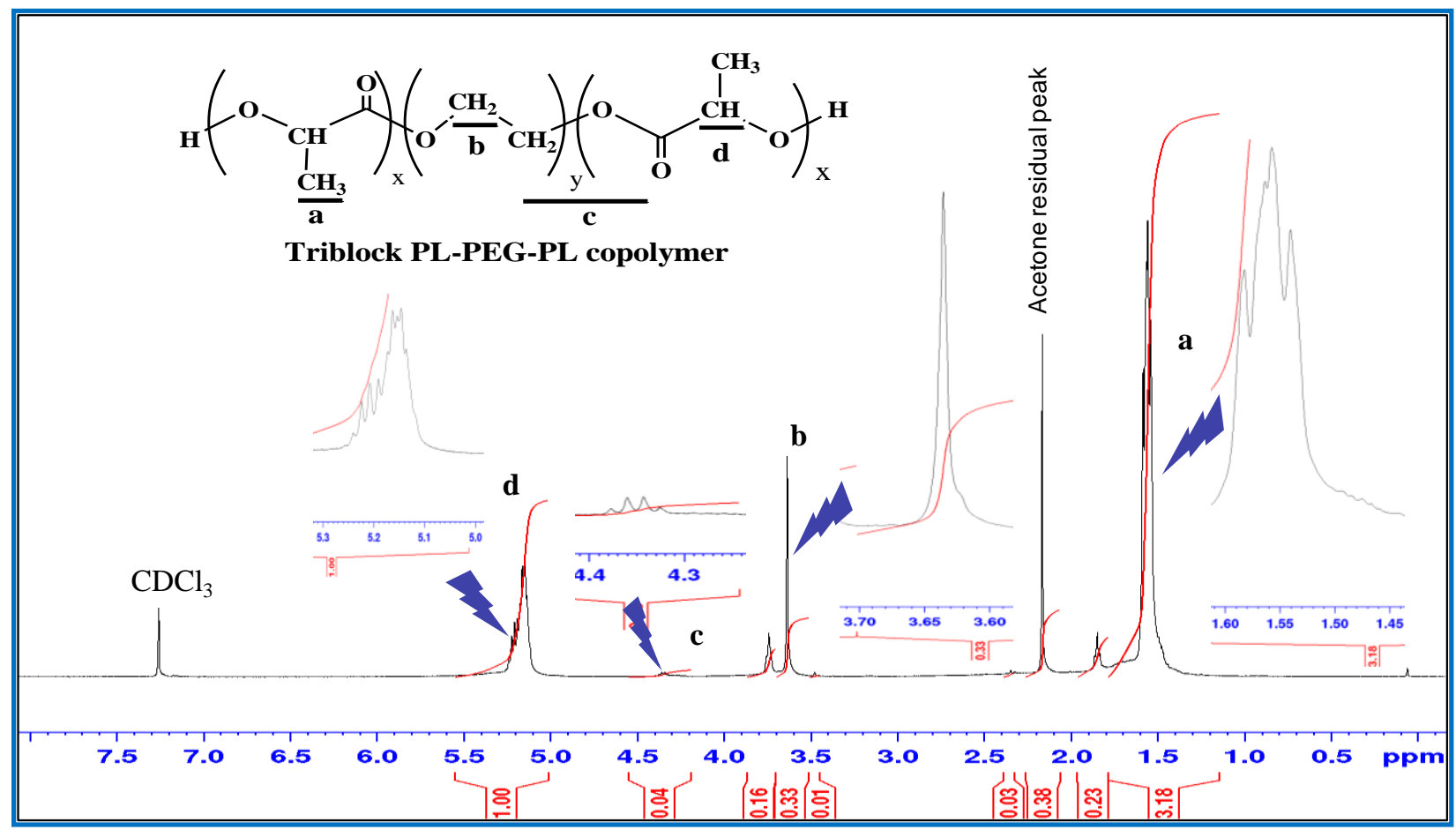

Fig. $4.3{ }^{1} \mathrm{H}-\mathrm{NMR}$ spectrum of the triblock PL-PEG-PL copolymer in $\mathrm{CDCl}_{3}$.

Table 4.2 ${ }^{1} \mathrm{H}-\mathrm{NMR}\left(\mathrm{CDCl}_{3}\right)$ chemical shift of (PL-PEG-PL) triblock copolymer

\begin{tabular}{|c|c|l|}
\hline Code name of the hydrogen & Chemical shift $\boldsymbol{\delta}(\mathbf{p p m})$ & Kind of hydrogen \\
\hline a & 1.57 & $-\mathrm{CH}_{3}$ of PL \\
\hline b & 3.64 & $-\left(\mathrm{CH}_{2}\right)-$ of PEG \\
\hline c & 4.25 & $\begin{array}{l}-\mathrm{CO}-\mathrm{O}-\mathrm{CH}_{2} \text { junction } \\
\text { between PL-PEG }\end{array}$ \\
\hline d & $5.1-5.25$ & $-\mathrm{CH}-\mathrm{O}-$ of PL \\
\hline
\end{tabular}

A series of PL-PEG-PL triblock copolymers covering a wide range of molecular weights and compositions were synthesized; the average segmental length of both components was also varied. The molecular weights and composition of the copolymers was calculated from ${ }^{1} \mathrm{H}-\mathrm{NMR}$ 
spectra; more specifically, this was done comparing the methylene protons integration peaks of PEG segments (b) and the lactoyl methane protons integration peaks of PL segments (d), which centered at $3.64 \mathrm{ppm}$ and $5.2 \mathrm{ppm}$, respectively (see Fig. 4.3). As shown in the different ${ }^{1} \mathrm{H}$ NMR spectra, the relative area of proton peaks (b) and (d) changed according to the initial amount of feed ratio of LA/PEG monomers. The ratio of the peak areas obtained from the integration values of the $\mathrm{CH}_{2}$ peaks for $\mathrm{EG}$ and $\mathrm{CH}$ for $\mathrm{PL}$ were used to determine the \% content of EG in the copolymers, as well as block ratio according to equation 4.1 and 4.2.

$\%$ content of EG in triblock copolymer $=\{(\mathrm{Y} / 4) /[(\mathrm{Y} / 4)+(\mathrm{X} / 2)] \times 100\}$ Eq. 4.1

Block ratio $=$ the number of EG blocks / the number of LA blocks $=\left[\left(\mathbf{Y} /\left(2 \times \mathbf{D P} \mathbf{P L}_{\mathbf{P L}}\right) / \mathbf{X} /\left(\mathbf{4} \times \mathbf{D P} \mathbf{P E G}_{\mathbf{P E}}\right)\right]\right.$

Eq. 4.2

where $\mathrm{Y}$ is the integration value for the EG ethylene units peak and $\mathrm{X}$ is that of LA's CH peak. Moreover, the degree of polymerization of PL and the segments length of the PL in the block copolymer were also estimated from the ${ }^{1} \mathrm{H}$-NMRspectra based on the peak intensity ratio of the methylene protons of $\mathrm{EG}\left(\mathrm{OCH}_{2} \mathrm{CH}_{2}: \delta=3.64 \mathrm{ppm}\right)$ and the methine proton of the LA unit $\left(\mathrm{COCH}\left(\mathrm{CH}_{3}\right): \delta=5.2 \mathrm{ppm}\right)$. For instance, considering the $\mathrm{M}_{\mathrm{n}}$ of PEG to be 4000 , the degree of polymerization of $\mathrm{PL}$ can be calculated from the relation; $\mathrm{DP}_{\mathrm{PL}}=\mathrm{DP}_{\mathrm{PEG}} \mathrm{x}\left(2 \mathrm{X}_{\mathrm{LA}} / \mathrm{Y}_{\mathrm{EG}}\right)$. Ultimately, the $M_{n}$ of the PL segments determined was found in the range of 6,256-66,682 $\mathrm{g} /$ mole. The molecular weight of the triblock copolymer can be then estimated from the relation $\mathrm{M}_{\mathrm{n}(\mathrm{TB})}=144\left[\mathrm{DP} \mathrm{PL}_{\mathrm{PL}}\right]+\left[\mathrm{M}_{\mathrm{n}(\mathrm{PEG})}-18\right]$. The obtained $\mathrm{M}_{\mathrm{n}}$ values of the triblock PL-PEG-PL were found in the range (16,494-137,343 g/mole) and agreed well with the calculated value based on GPC measurements, see Table 4.3.

The structure of the final TBPU polymer after the addition of PCL to the triblock copolymer were further confirmed using ${ }^{1} \mathrm{H}-\mathrm{NMR}$ spectra, where new chemical shift signals are emerged due to the presence of PCL segments, beside the predetermined characteristic signals of the triblock PL-PEGPL, see Table 4.4 and Fig. 4.4. The chemical shifts of the various hydrogen atoms located on $\alpha, \beta$, $\gamma, \delta$ and $\omega\left(\mathrm{CH}_{2}\right)$ groups of PCL segments are evidence of the presence of PCL segments in TBPU polymer. The urethane bonds are partly overlapped by the solvent peak at $7.23 \mathrm{ppm}$ and not seen well. However, the formation of the urethane peak in this region was confirmed with the use of deuterated acetone as solvent, and also confirmed previously by FTIR (4.2.1). 
Table 4.3 $\mathrm{PL}_{\mathrm{x}} / \mathrm{PEG}_{\mathrm{y}} / \mathrm{PL}_{\mathrm{x}}$ triblock copolymers obtained from polymerization of lactide and PEG of different feed ratios

\begin{tabular}{|c|c|c|c|c|c|c|c|c|c|c|}
\hline Lot & Copolymer & $\begin{array}{l}\text { Feed }(\% \text { w/w) of } \\
\text { LA: PEG }(4000)\end{array}$ & \multicolumn{2}{|c|}{$\begin{array}{c}\text { Molar ratio of } \\
\text { LA/EG }\end{array}$} & $\mathbf{D P}_{\mathbf{P L}}{ }^{\mathrm{a}}$ & $\begin{array}{l}\mathbf{M}_{\mathbf{n}} \mathbf{P L} \\
(\mathrm{g} / \mathrm{mol})\end{array}$ & \multicolumn{2}{|c|}{$\begin{array}{c}\mathbf{M}_{\mathbf{n}}^{\mathbf{b}}(\mathrm{g} / \mathrm{mol}) \\
\left(\mathbf{P L}_{\mathbf{x}} / \mathbf{P E G}_{\mathbf{y}} / \mathbf{P L}_{\mathbf{x}}\right)\end{array}$} & $\begin{array}{l}\text { \% content } \\
\text { of }^{\text {EG }}{ }^{\mathrm{d}}\end{array}$ & $\begin{array}{c}\% \\
\text { conversion }^{\mathrm{e}} \\
\text { of LA to PL }\end{array}$ \\
\hline TB1 & $\mathrm{PL}_{866}-\mathrm{PEG}_{91}-\mathrm{PL}_{866}$ & $98: 2$ & 14.95 & 9.52 & 866 & 66,682 & 137,346 & 128,700 & 9.9 & 64 \\
\hline TB2 & $\mathrm{PL}_{551}-\mathrm{PEG}_{91}-\mathrm{PL}_{551}$ & $97: 3$ & 9.80 & 6.06 & 551 & 42,466 & 88,915 & 84,115 & 14.2 & 62 \\
\hline TB4 & $\mathrm{PL}_{99}-\mathrm{PEG}_{91}-\mathrm{PL}_{99}$ & $90: 10$ & 1.74 & 1.10 & 99 & 7,657 & 19,297 & 19,100 & 47.8 & 63 \\
\hline TB5 & $\mathrm{PL}_{86}-\mathrm{PEG}_{91}-\mathrm{PL}_{86}$ & $80: 20$ & 1.20 & 0.95 & 86 & 6,673 & 17,328 & 16,170 & 51.5 & 74 \\
\hline TB6 & $\mathrm{PL}_{81}-\mathrm{PEG}_{91}-\mathrm{PL}_{81}$ & $70: 25$ & 0.92 & 0.89 & 81 & 6,256 & 16,494 & 15,715 & 52.8 & 97 \\
\hline
\end{tabular}

${ }^{\text {a }}$ Calculated from ${ }^{1} \mathrm{H}-\mathrm{NMR}$ spectra with end-group intensities using the following equation:

$\mathrm{DP}_{\mathrm{PL}}=\mathrm{DP}_{\mathrm{PEG}} *\left(2 \mathrm{X}_{\mathrm{LA}} / \mathrm{Y}_{\mathrm{PEG}}\right)$, where $\mathrm{DP}_{\mathrm{PEG}}=4000-18 / 44$.

${ }^{\mathrm{b}}$ Calculated from ${ }^{1} \mathrm{H}-\mathrm{NMR}$ spectra with end-group intensities with the following equation:

$\mathrm{M}_{\mathrm{n}(\mathrm{TB})}=144\left[\mathrm{DP}_{\mathrm{PL}}\right]+\left[\mathrm{M}_{\mathrm{n}(\mathrm{PEG})}-18\right]$, where $\mathrm{M}_{\mathrm{n}(\mathrm{PEG})}=4000$.

${ }^{\mathrm{c}}$ Calculated by GPC with polystyrene calibration.

d $\%$ of EG content in triblock copolymer calculated from ${ }^{1} \mathrm{H}-\mathrm{NMR}=\left\{(\mathrm{Y} / 4) /[(\mathrm{Y} / 4)+(\mathrm{X} / 2)]^{*} 100\right\}$.

e $\%$ conversion of LA to $\mathrm{PL}=$ (molar ratio of LA in product/ molar ratio of LA in feed $) \times 100$ 
Table 4.4. ${ }^{1} \mathrm{H}-\mathrm{NMR}\left(\mathrm{CDCl}_{3}\right)$ chemical shift of (PL-PEG-PL)-PCL copolymer

\begin{tabular}{|c|c|l|}
\hline Code name of proton & Chemical shift $\delta(\mathrm{ppm})$ & Kind of proton \\
\hline $\mathrm{f}$ & $1.41-1.52$ & $\gamma-\left(\mathrm{CH}_{2}\right)-$ of PCL $[171]$ \\
\hline $\mathrm{a}$ & 1.57 & $-\mathrm{CH}_{3}$ of PL \\
\hline $\mathrm{e}+\mathrm{g}$ & $1.58-1.65$ & $\beta$ and $\delta-\left(\mathrm{CH}_{2}\right)-$ of PCL \\
\hline $\mathrm{d}$ & 2.3 & $\alpha-\left(\mathrm{CH}_{2}\right)-$ of PCL \\
\hline $\mathrm{b}$ & 3.65 & $-\left(\mathrm{CH}_{2}\right)-$ of PEG \\
\hline $\mathrm{c}+\mathrm{h}$ & $4.35-4.4$ & $\omega-\left(\mathrm{CH}_{2}\right)-$ of PCL \\
\hline $\mathrm{d}$ & $5.1-5.25$ & $-\mathrm{CH}-\mathrm{O}-$ of PL \\
\hline
\end{tabular}

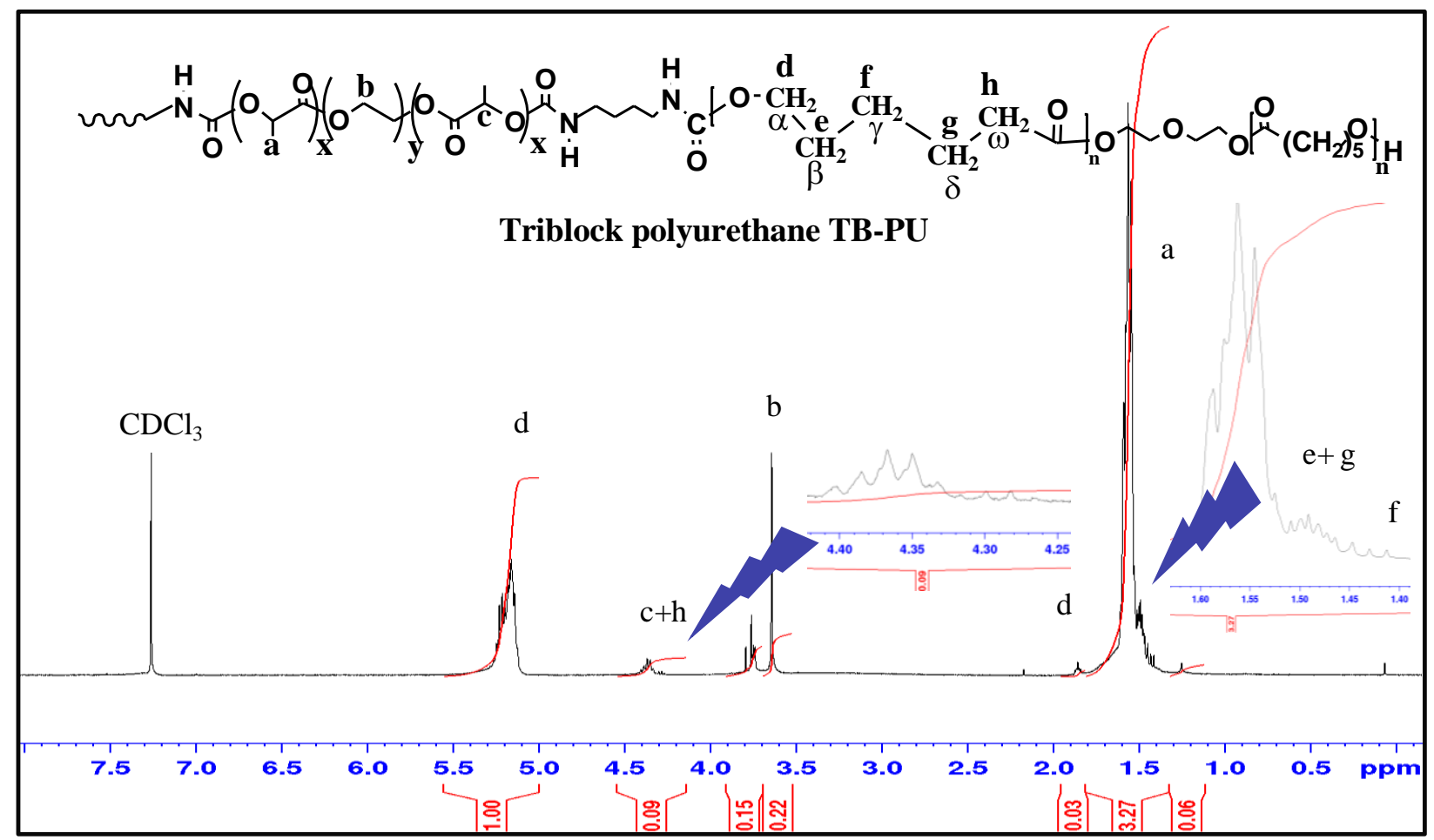

Fig. $4.4{ }^{1} \mathrm{H}-\mathrm{NMR}$ spectrum of TBPU copolymer in $\mathrm{CDCl}_{3}$.

After coupling reaction between triblock copolymer and BDI molecules, ${ }^{1} \mathrm{H}-\mathrm{NMRspectra}$ for all samples showed neither remarkable change happened in PL/PEG segment ratio nor increase in the molecular weight of polymer. These findings evidenced that BDI molecules interact only with the terminal $\mathrm{OH}$ groups without any crosslinking reactions happened between $\mathrm{TB}$ copolymer chains, Figs. B1-B9.

Based on the controlled molar ratio of the terminal OH groups of PCL-diole and the amount of added BDI, the final number average molecular weight of TBPUs can be then estimated using the 
relation; $\mathrm{M}_{\mathrm{n}(\mathrm{TBPU})}=\mathrm{M}_{\mathrm{n}(\mathrm{TB})}+\left[2 \mathrm{x} \mathrm{MW}_{\mathrm{BDI}]}+\left[\left(2 \mathrm{x} \mathrm{M}_{\mathrm{n} \text { PCL-diole })}\right]\right.\right.$, and found in the range of $(18,779-$ $139,769 \mathrm{~g} / \mathrm{mol})$.

Table 4.5 summarizes the content of the TBPUs polymers prepared with different compositions of $\mathrm{PL} / \mathrm{PEG} / \mathrm{PCL}$ along with their estimated number average molecular weights and thermal properties

\begin{tabular}{|l|c|c|c|c|}
\hline Sample & $\begin{array}{c}\text { TB/PCL-diole/BDI } \\
\text { molar ratio }\end{array}$ & $\begin{array}{c}\mathbf{M}_{\mathbf{n}} \text { of } \\
\mathbf{T B P U}^{\mathbf{e}}\end{array}$ & $\mathbf{T}_{\mathbf{m}}\left({ }^{\circ} \mathbf{C}\right)^{\mathbf{f}}$ & $\mathbf{T}_{\mathbf{m}}\left({ }^{\circ} \mathbf{C}\right)^{\mathbf{g}}$ \\
\hline TBPU-1 & $1: 2: 2$ & 139,763 & ND & 186 \\
\hline TBPU-2 & $1: 2: 2$ & 91,195 & ND & 179 \\
\hline TBPU-3 & $1: 2: 2$ & 69,725 & ND & 173 \\
\hline TBPU-4 & $1: 2: 2$ & 21,577 & ND & 169 \\
\hline TBPU-5 & $1: 2: 2$ & 19,608 & 66 & 150 \\
\hline TBPU-6 & $1: 2: 2$ & 18,774 & 70 & 144 \\
\hline
\end{tabular}

${ }^{\mathrm{e}}$ Calculated from the following equation:

$\mathrm{M}_{\mathrm{n}(\mathrm{TBPUx})}=\mathrm{M}_{\mathrm{n}(\mathrm{TBx})}+\left[2 * \mathrm{MW}_{\mathrm{BDI}}+\left[\left(2 * \mathrm{M}_{\mathrm{n}(\mathrm{PCL}-\mathrm{diol})}\right]\right.\right.$,

where $\mathrm{MW}_{\mathrm{BDI}}=140.14$ and $\mathrm{M}_{\mathrm{n} \text { PCL-diol }}=2000$.

${ }^{\mathrm{f}}$ Melting temperature of crystallized PEG segments in TBPUs.

${ }^{\mathrm{g}}$ Melting temperature of crystallized PL segments in TBPUs.

ND: Not determined

The molecular weights of the triblock copolymer were found to be inversely proportional to the amount of PEG added in the range of feed ratio applied, see Fig. 4.5. This might be claimed from the decrease in DP of PL as PEG content increased. Therefore, it's quite clear that adjusting the block length of the PL in the triblock PL-PEG-PL by changing the amount of PEG macro-monomer in feed is possible and may lead to control over the physicochemical properties in the final TBPUs. 


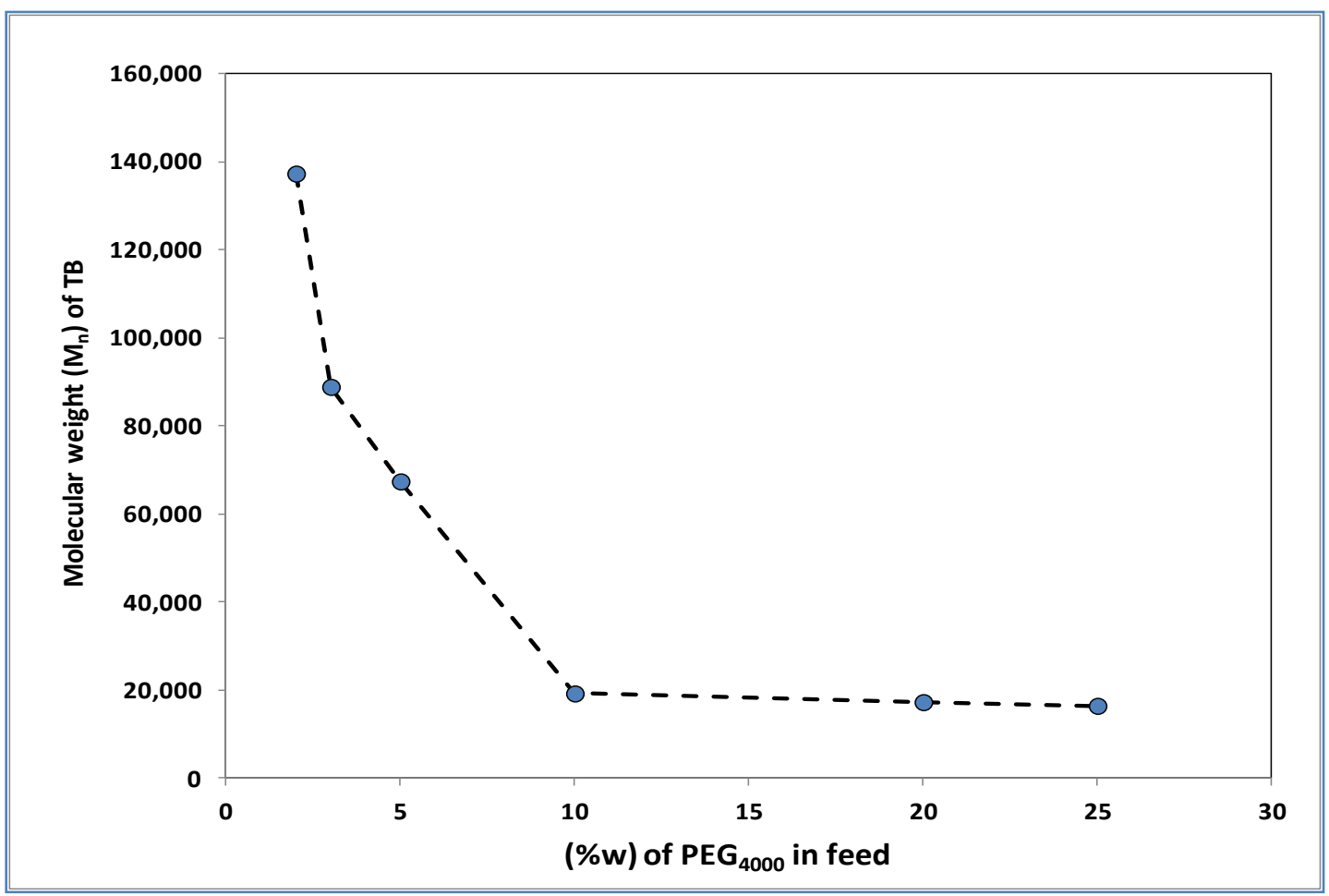

Fig. 4.5 Molecular weight dependence of TB copolymer on $w \%$ of $\mathrm{PEG}_{4000}$ in the feed.

\subsection{Water Absorption and Contact Angle Testing of TB Copolymer and TBPUs}

Since the synthesized materials are designed to be implanted and degraded in the biological environment, the surface and bulk hydrophilicity of the various PL-PEG-PL TB copolymers, as well as their polyurethanes were determined by contact angle and water uptake measurements. When specimens made of homo-PL and TB copolymer were immersed in water, the homo-PL specimen floated on the water due to its hydrophobic nature, whereas the TB specimens absorbed water rapidly and sank. This observations elucidated that TB copolymer should be a more powerful candidate for scaffold materials in comparison with homo-PL. It could be seen that the water uptake of homo-PL was near from 3\%, while those of the TB copolymers were above $16 \%$. The water uptake of the TBPUs copolymers could be enhanced with increasing the PEG contents in the copolymer. The later finding supports the well known fact that the degradation of hydrophobic PL is extremely slowly with over $80 \%$ of the original mass remaining at the implant site, 6 months after implantation [172].

The water contact angle testing was one of the ways to characterize the surface hydrophilicity of biodegradable polymer material, and usually, the better is the hydrophilicity the less is the contact angle [173]. It was observed that the contact angle decreased with the increase of PEG 
molar ratio in both TB copolymers and TBPUs. Compared with PL homopolymer, sample (R), the hydrophilicity of TB copolymers which have high hydrophilic PEG segment content and shorter PL segments were obviously bettered. Therefore, as expected, the hydrophilic modification of PL by the introduction of PEG during ring opening polymerization of LA is a successful way to provide more control over hydrophilicity of homo-PL. This in consequence has a reflection as an improvement either in the cell attachment to the high molecular weight TBPU scaffolds or better degradation for those low molecular weights that utilized in drug delivery systems.

Even after coupling between TB copolymers and PCL-diole to form the corresponding TBPUs, the hydrophilicity of TBPUs were also improved, see Table 4.6. This indicated that the addition of short PCL segments to TB copolymers did not alter the increasing trend of hydrophilicity. It is worth to mention that samples containing higher percentages of PEG, i.e., TBPU-4, TBPU-5 and TBPU-6 were impossible to study due to their high hydrophilicity, which caused almost instant spreading of the water drop and, sometimes, local distortion of the polymeric surface due to their partial solubility in water. Therefore, the data presented are confined to LA-rich systems for which reliable measurements could be performed. The measured samples clearly showed that PEPUs copolymer exhibited markedly enhanced hydrophilicity, when compared to PL homopolymer. For instance, TBPU-3 attained substantially larger equilibrium water contents around $31 \%$ if it compared with 3\% for homo-PL. The increasing PEG content in TBPU-3 than TBPU-2 and TBPU-1 readily explains the behavior encountered, see Fig. 4.6.

The variations in hydrophilicity as a function of composition was further assessed by means of advancing water contact angle measurements in air. The time variation of the contact angles was observed for each polymer, until $\theta=30^{\circ}$ was attained which implies good surface wetting. Figure 4.7 presents the change in contact angle $(\theta)$ as a function of time of PL homopolymer and various TBPUs copolymers. Results summarized in Table 4.6 showed that both the initial contact angle and $\mathrm{t}_{30}$ increased for the lower PEG content or the longer PL segments in the copolymer, which indicates increase in the hydrophobicity. Figure 4.16 also shows that not only the initial contact angle is much higher for homo PL than that of the TBPU copolymers, but also the rate of change, as expressed by the slope of the curves which is significantly lower. 
Table 4.6 Contact angles of TB and TBPUs synthesized at different LA:PEG ratios

\begin{tabular}{|c|l|c|l|c|c|c|}
\hline \multirow{2}{*}{$\begin{array}{c}(\%) \\
\text { content of } \\
\text { PEG }\end{array}$} & \multicolumn{2}{|c|}{ TB } & \multicolumn{4}{|c|}{ TBPU } \\
\cline { 2 - 6 } & Lot & $\begin{array}{c}\text { Contact } \\
\text { angle }\left(\boldsymbol{\theta}^{\circ}\right)\end{array}$ & Lot $\left(\mathbf{M}_{\mathbf{n}}\right)$ & $\begin{array}{c}\text { Contact } \\
\text { angle }\left(\boldsymbol{\theta}^{\circ}\right)\end{array}$ & $\begin{array}{c}\boldsymbol{*}_{\mathbf{t}_{\mathbf{3 0}}} \\
(\mathbf{m i n})\end{array}$ & $\begin{array}{c}\text { \% water } \\
\text { uptake }\end{array}$ \\
\hline NA & $\mathrm{PL}^{\mathrm{R}}$ & 77.7 & $\mathrm{PL}^{\mathrm{R}}(67,500)$ & 77.7 & - & 3 \\
\hline 9.9 & TB1 & 64.5 & TBPU-1(139,800) & 65.3 & 48 & 16 \\
\hline 14.2 & TB2 & 61.0 & TBPU-2 (91,200) & 57.8 & 35 & 20 \\
\hline 18.0 & TB3 & 57.2 & TBPU-3 (69,700) & 52.2 & 27 & 31 \\
\hline
\end{tabular}

d $\%$ of EG content in triblock copolymer calculated from ${ }^{1} \mathrm{H}-\mathrm{NMR}$.

${ }^{\mathrm{R}}$ is a comparison reference PL-homopolymer was synthesized under the similar reaction conditions, including $\mathrm{N}_{2}$ atmosphere, a temperature of $140^{\circ} \mathrm{C}$, a reaction time of $24 \mathrm{~h}$, and $0.05 \mathrm{Sn}(\mathrm{Oct})_{2}(\% \mathrm{w} / \mathrm{w})$ as the catalyst [174] and tested under the same conditions.

$* \mathrm{t}_{30}$ is defined as the time it takes for the contact angle to decrease from the initial value to reach $30^{\circ}$.

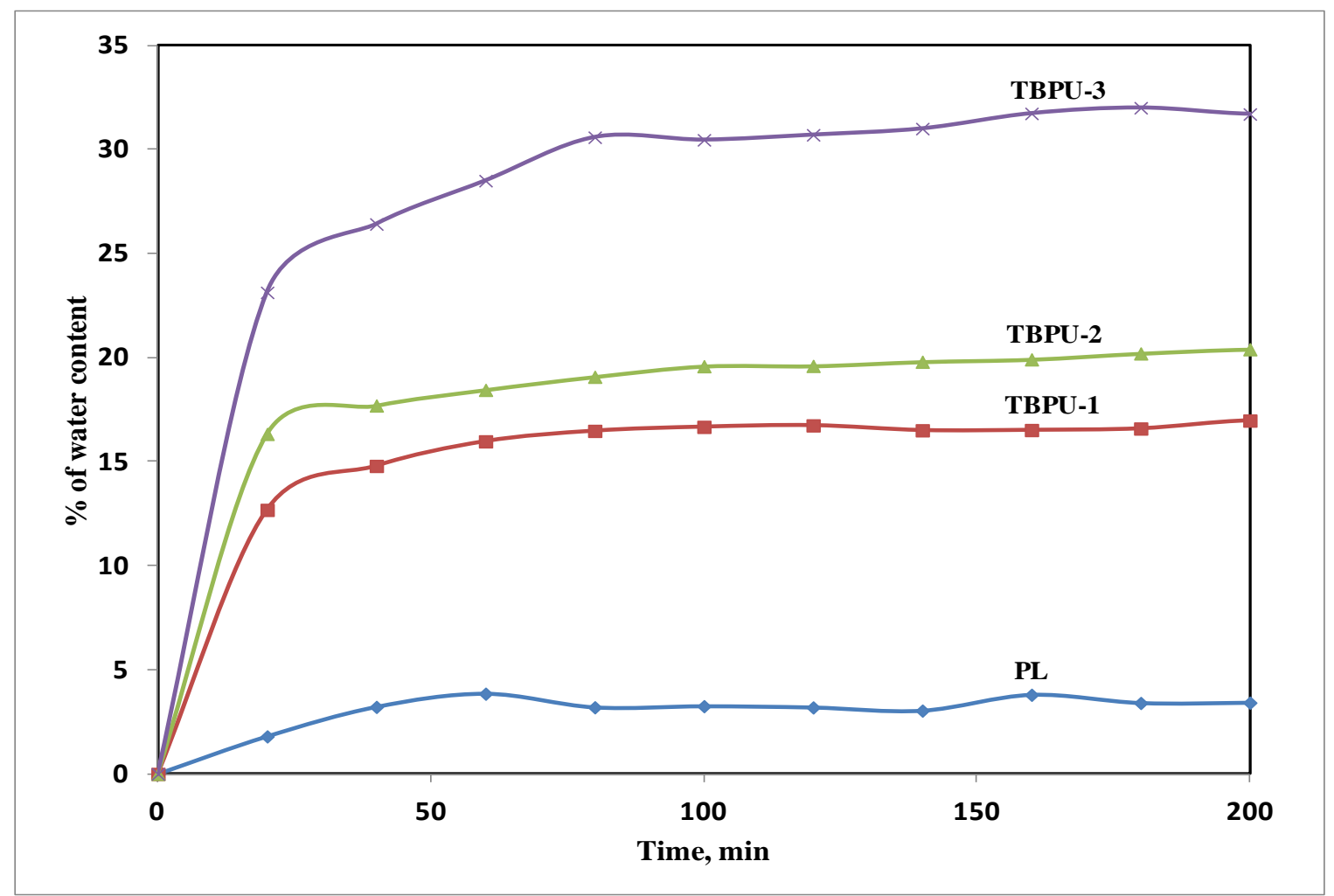

Fig. 4.6 Water absorption as \% of dry polymer samples vs. time for PL homopolymer, TBPU-1, TBPU-2 and TBPU-3 at room temperature. 


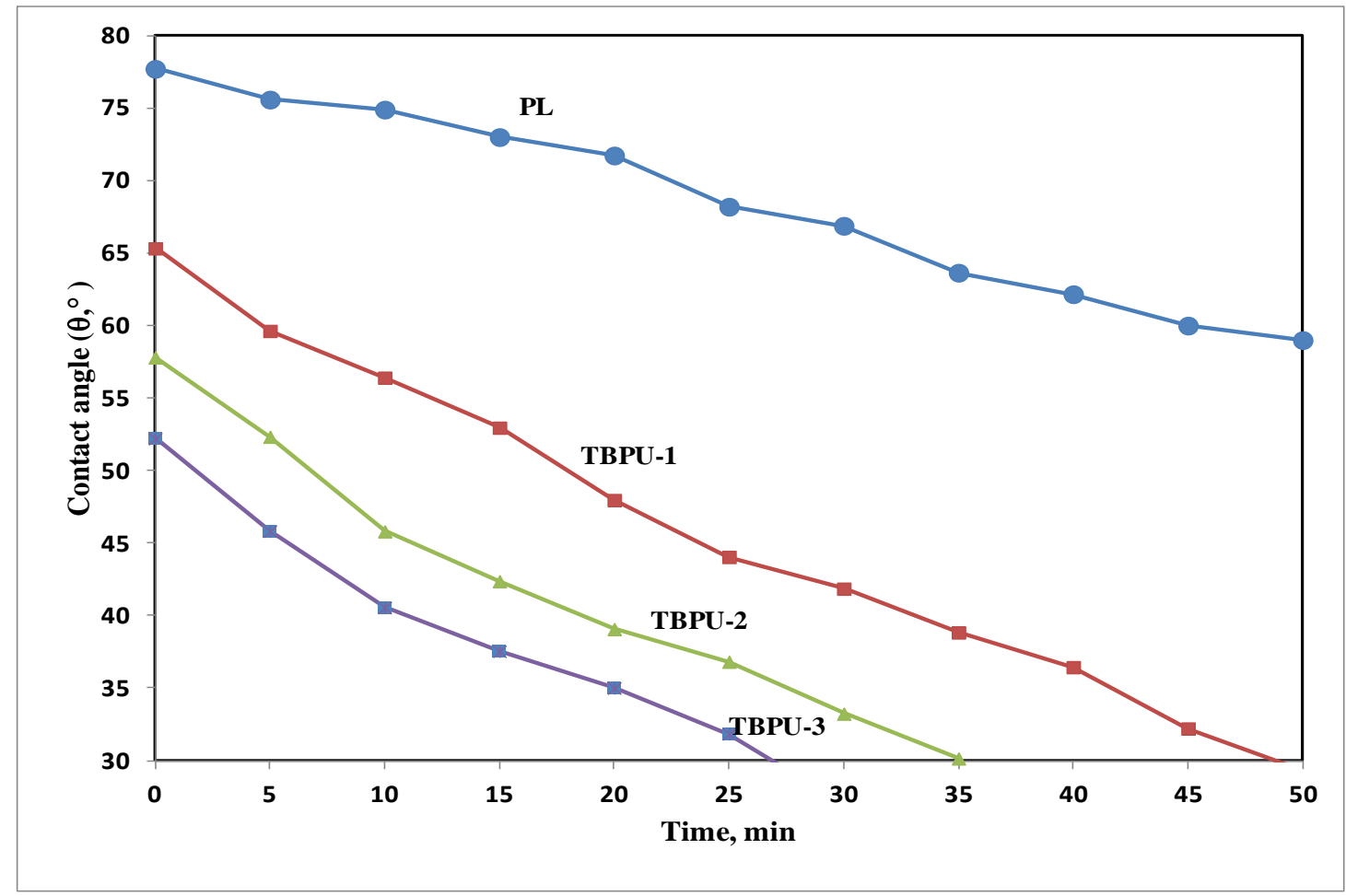

Fig. 4.7 Comparison between the variation of water contact angles with time of three TBPU samples and PL-homopolymer at room temperature.

\subsection{Degradation and Morphological Changes}

Generally, for biodegradable polyurethane polymers, hydrophilicity of polymer segments, molecular weight of polymers, degree of microphase separation and enzyme function are well known contributing factors in biodegradation [175]. Lipase from porcine pancreas was employed in the enzymatic degradation because its ability to degrade PLA has been reported [176]. TBPU samples that are rich in PEG segment showed a rapid enzymatic degradation profiles in $120 \mathrm{~h}$, where the weight loss initially increased rapidly in first $15 \mathrm{~h}$, and then slowed down after degradation time of $60 \mathrm{~h}$ was reached, see Fig. 4.8. A weight loss of 75\%, $82 \%$ and $91 \%$ were observed for TBPU-4, TBPU-5, TBPU-6, respectively. This high rate of hydrolysis is probably attributed to the low initial molecular weight of polyurethane polymer chains which might be resulted in low polymer chain-chain interaction and consequently facilitating water attack. Additionally, the high content of the hydrophilic PEG segments ( 47-52\%), is simultaneously made these hydrophilic polyurethane chains easy to swell and dissolve in aqueous solutions. Thus, not only hydrolysis and enzymatic degradation occur, but also dissolution of these TBPUs was considered in the mass loss. The high solubility of the fragments formed will be helpful to 
reduce the inflammatory response of vicinity tissues in comparison with insoluble ones and consequently prioritize the utilization of these materials in drug delivery systems.

Zhang et al. reported that both high phase separation and higher $\mathbf{M}_{n}$ lead to low degradation rate of polyurethane [176]. This is because the enhanced interaction force among the polymer chains, which resisted water and enzyme attack. This possibly can explain the slower enzymatic degradation rate of the first three polyurethanes TBPU-1, TBPU-2 and TBPU-3 than other samples in the series, where values of $21 \%, 23 \%$ and $27 \%$, respectively were achieved after 5 days. This might be due to the high content and large molecular Wight of hydrophobic PL segments that present in those polymer chains, see Fig. 4.8. Comparing the enzymatic degradation rate of TBPU-3 with that of the blank PL-homopolymer of comparable $M_{n}\left(M_{n}=\right.$ $67,500 \mathrm{~g} / \mathrm{mol}$ ), which has enzymatic degradation rate $\sim 10 \%$, it was found that the enzymatic degradation rate of TBPUs was approximately double times greater than PL-homopolymer. So, complete degradation of this TBPU sample needs half the degradation time of homo-PL polymer. All the previous results indicate that the degradation rates might be more affected by microphase separation, molecular weight and the degree of hydrophobicity of TBPU chains.

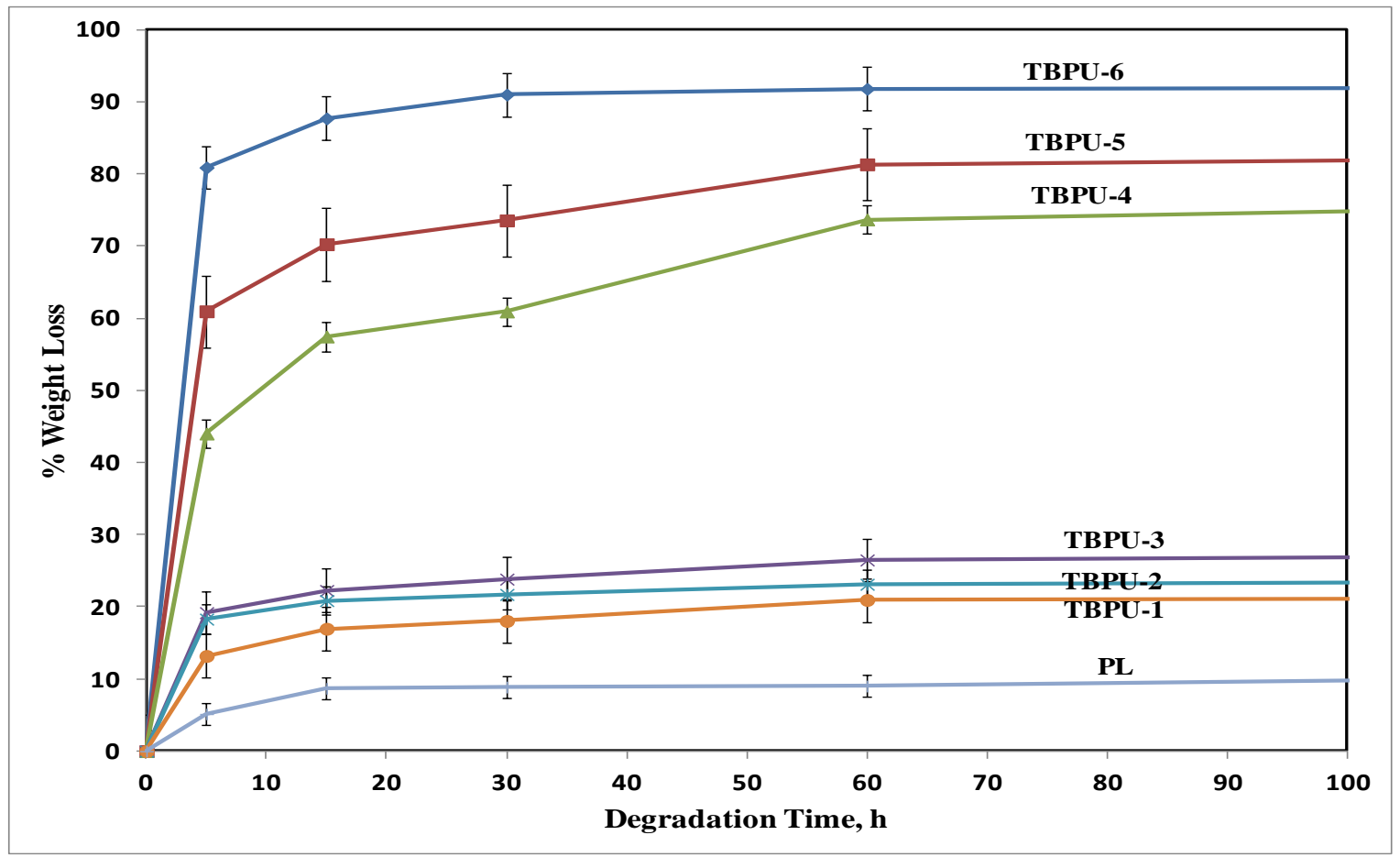

Fig. 4.8 Enzymatic degradation profiles of polyurethanes with various molecular weights and PL. Error bars represent standard errors for three trials $( \pm 1-5 \%)$ and the means for each group show a difference statistically significant with $\mathrm{p}<0.005$, see Appendix $\mathrm{C}$. for details. 
To investigate the effect of enzyme on degradation, comparative test of hydrolytic degradation was carried out in PBS at $\mathrm{pH} 7.4$ and $37^{\circ} \mathrm{C}$ ), Fig. 4.9. As can be seen from the figure, for all TBPU samples, the hydrolytic degradation rates is much less than the enzymatic degradation rates. This in turn is verifying that Lipase from porcine pancreas preferably accelerate the hydrolysis of polyurethanes through attacking the ester linkages of the hard PL segment inTB PUs chains but not the soft PEG.

Among the samples, TBPU-3 of the relatively high $\mathrm{M}_{\mathrm{n}}$ and good degradation rate was employed in further degradation experiments. Fig. 4.10 shows the full degradation of TBPU-3 in PBS (pH 7.4) solution needs approximately only 1.5 months compared with 6.5 months required for PL homopolymer sample, where TBPU-3 displayed faster degradation rates ( 12\%), which was higher than PL in both hydrolytic and enzymatic degradation.

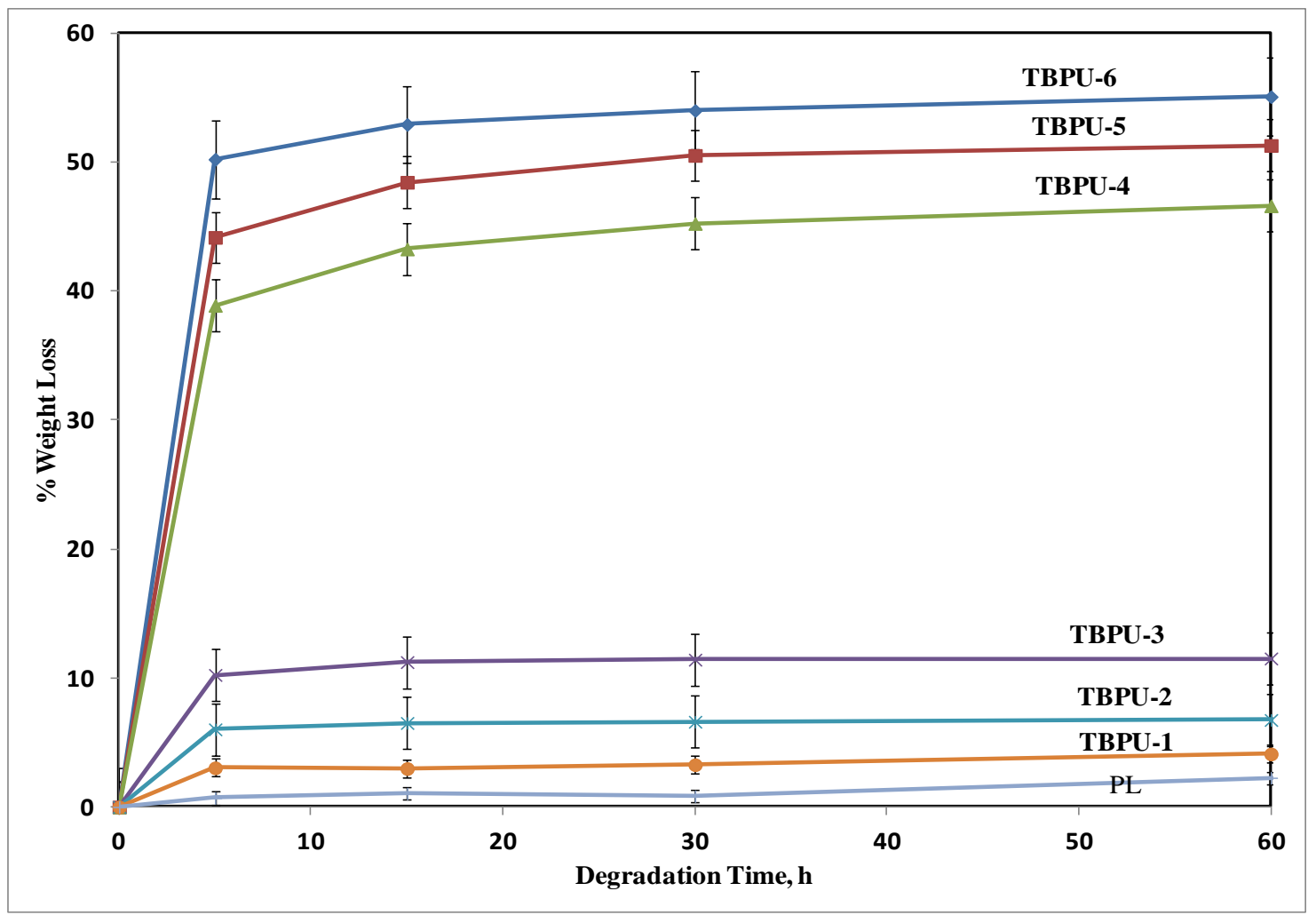

Fig. 4.9 Degradation profiles of TBPUs and PL in PBS solution (pH 7.4). Error bars represent standard errors for three trials $( \pm 1-5 \%)$ and the means for each group show a difference statistically significant with $\mathrm{p}<0.005$. 


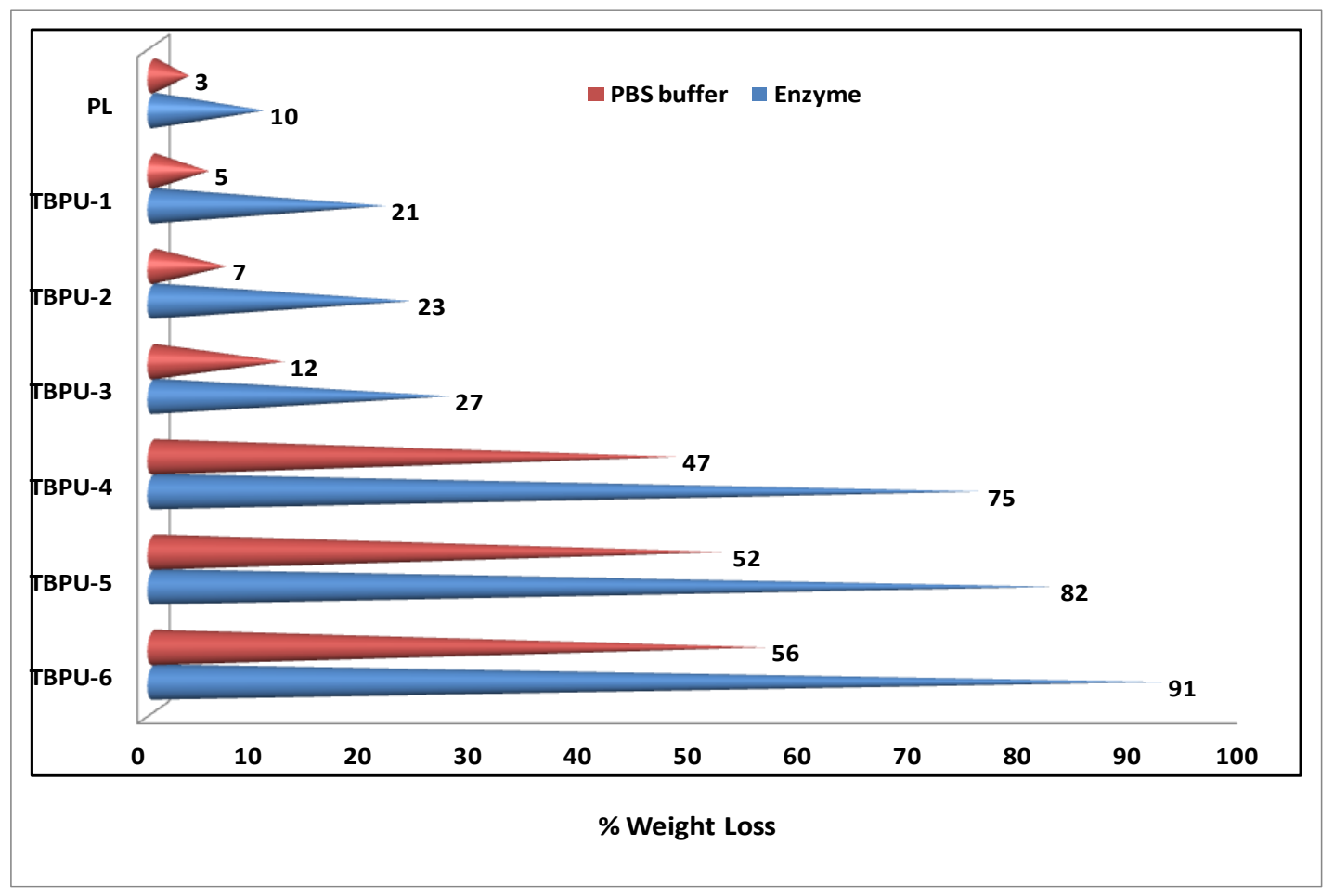

Fig. 4.10 Comparison between the weight loss by degradation of TBPUs and PL in enzymatic and PBS solution (pH 7.4) for 5 days.

The surface morphology changes during degradation process of TBPU-3 films were monitored using SEM. The surface topography of the film before enzymatic or hydrolytic degradation was smooth (Fig. 4.11(A)). After degradation for $120 \mathrm{~h}$ in Lipase enzyme, the surface was eroded markedly, holes and cracks were existed (Fig. 4.11(B)). However, non-enzymatic degradation in PBS (pH7.4) had a similar phenomenon, but it was slower than enzymatic degradation (Fig. 4.11(C)). SEM results suggested that these polyurethanes could be slowly degraded, in agreement with weight loss results.

The effect of $\mathrm{pH}$ value on hydrolytic degradation of TBPU-3 was also evaluated. Fig. 4.12 shows the degradation profiles of TBPU-3 in PBS at different $\mathrm{pH}$ values; 7.4, 6.0 and 5.0. It was found that the degradation rate was faster in (PBS 7.4) solution than the other acid media. Similar observation was reported by Wibullucksanakul et al. [177]. One probable reason is that $\mathrm{pH} 7.5$ is mildly basic medium which promoted the hydrolysis of esters linkage by providing $\mathrm{OH}^{-}$anions which act as strong nucleophils [178]. The other reason is that the degradation of TBPUs produces acidic products containing $\mathrm{COOH}$ groups, which are more soluble in basic medium [179]. 


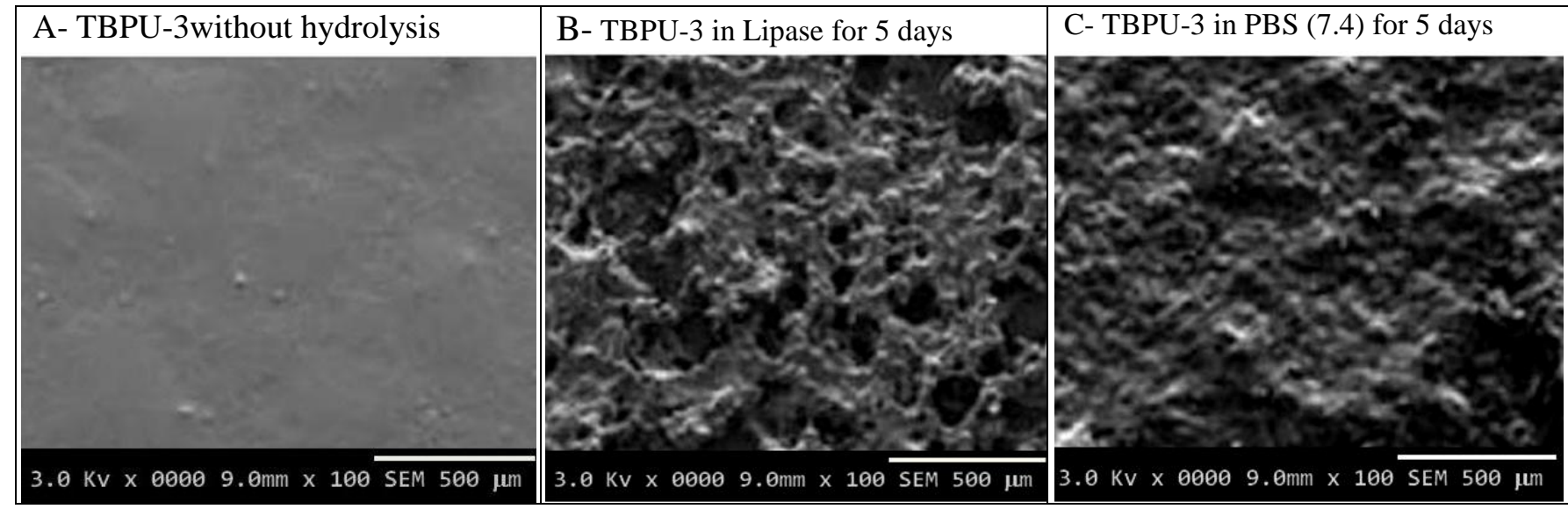

Fig. 4.11 SEM images of TBPU-3 films showing the morphological changes after hydrolytic and enzymatic degradation for 5 days $(120 \mathrm{~h})$.

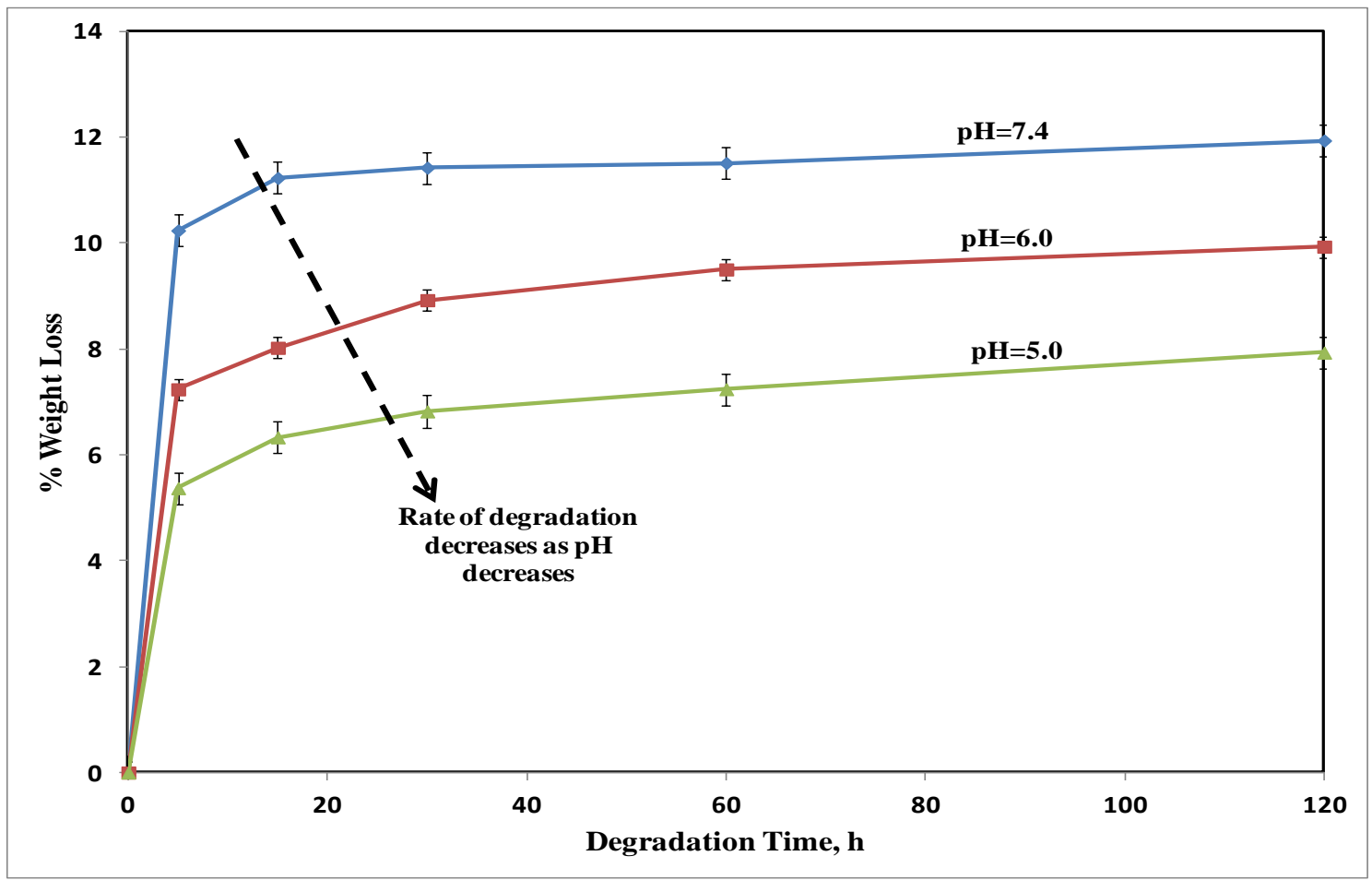

Fig. 4.12 Degradation profiles of TBPU-3 in PBS at various $\mathrm{pH}$ values (7.4, 6.0 and 5.0). Error bars represent standard errors for three trials $( \pm 0.5-3 \%)$ and the means for each group show a difference statistically significant with $\mathrm{p}<0.005$.

Further investigation study was the effect of degradation products on the final $\mathrm{pH}$ value of the degradation media. Fig. 4.13 showed slight decrease in the $\mathrm{pH}$ of all degradation media with time for both TBPU-3, which was taken as scaffold representative, and PL samples in PBS 5, 6, and 7.4. The slight decrease in $\mathrm{pH}$ with time is related to the release of acidic products after 
degradation of PL segment. These results suggested that there is no significant change in $\mathrm{pH}$ associated with the weight loss of TBPUs, which in turn reduces the inflammatory responses in vivo and proof the suitability of these material for utilization as internal implants [180].

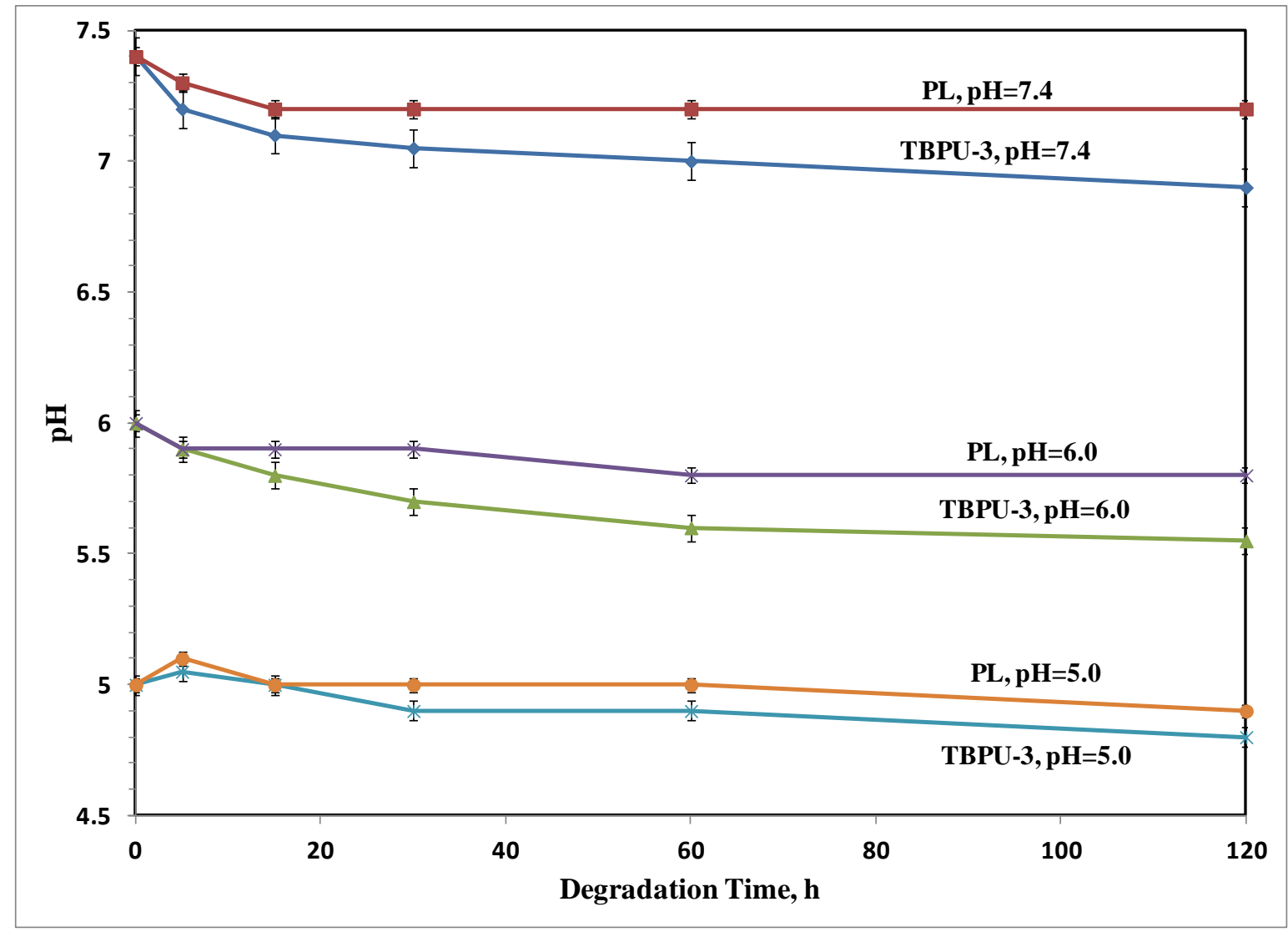

Fig. 4.13 The change in $\mathrm{pH}$ values of the degradation media with time during degradation of TB PU-3 and PL in PBS at various pH values (7.4, 6.0 and 5.0). Error bars represent standard errors for three trials $( \pm 0.1-0.3 \mathrm{pH}$ unit) and the means for each group show a difference statistically significant with $\mathrm{p}<0.005$.

\subsection{Thermal Properties of TBPUs Copolymers}

The DSC thermograms of the polymers are shown in Fig. 4.14. The $\mathrm{T}_{\mathrm{m}}$ of neat PEG and PL are $64^{\circ} \mathrm{C}$ and $186^{\circ} \mathrm{C}$, respectively. For the TBPUs copolymers with lower PEG content $10-18 \%$, i.e. TBPU1-TBPU3, the thermograms showed only one single $\mathrm{T}_{\mathrm{m}}$ for PL segments slightly lower than that of neat PL where the $\mathrm{T}_{\mathrm{m}}$ of PL segments decreased further as the amount of PEG increased. The absence of melting endotherm for PEG segment in those three TBPUs might be due to that PEG soft segments were not long enough as PL hard segments and consequently were not able to form highly ordered soft domains. For TBPUs with 48-53\% PEG, the thermograms 
show another broad peak at a temperature slightly higher than the $T_{m}$ of PEG. This is because the PL blocks partially disturbed the crystallization of PEG blocks, resulting in an increased melting point. Since the $T_{m}$ of both neat PEG and PL segment were altered one another, it can be used as a proof that the copolymerization was successful. No $T_{g}$ related to hard or soft segments was observed in DSC curves of TBPUs. A probable reason is that copolymerization reaction might be caused decrease in the structure symmetry which significantly inhibited the chain packing [181]. In the second run, the $T_{m}$ peaks of PEG segments disappeared while the $T_{m}$ peaks for PL segments remained. The result showed that PL blocks, but not PEG blocks, were readily recrystallized with greater tendencies. This limits the mobility of the PEG segments and consequently the crystallization of the PEG is severely hindered by the already solidified PL chains.

$\mathrm{T}_{\mathrm{m}}$ of the soft PCL segments was not clearly observed in TBPUs isotherms. This is might be due to the low $M_{n}$ of PCL segment did not allow the formation of soft regions or because it may overlap the endotherm accompanying the melting of PEG segments.

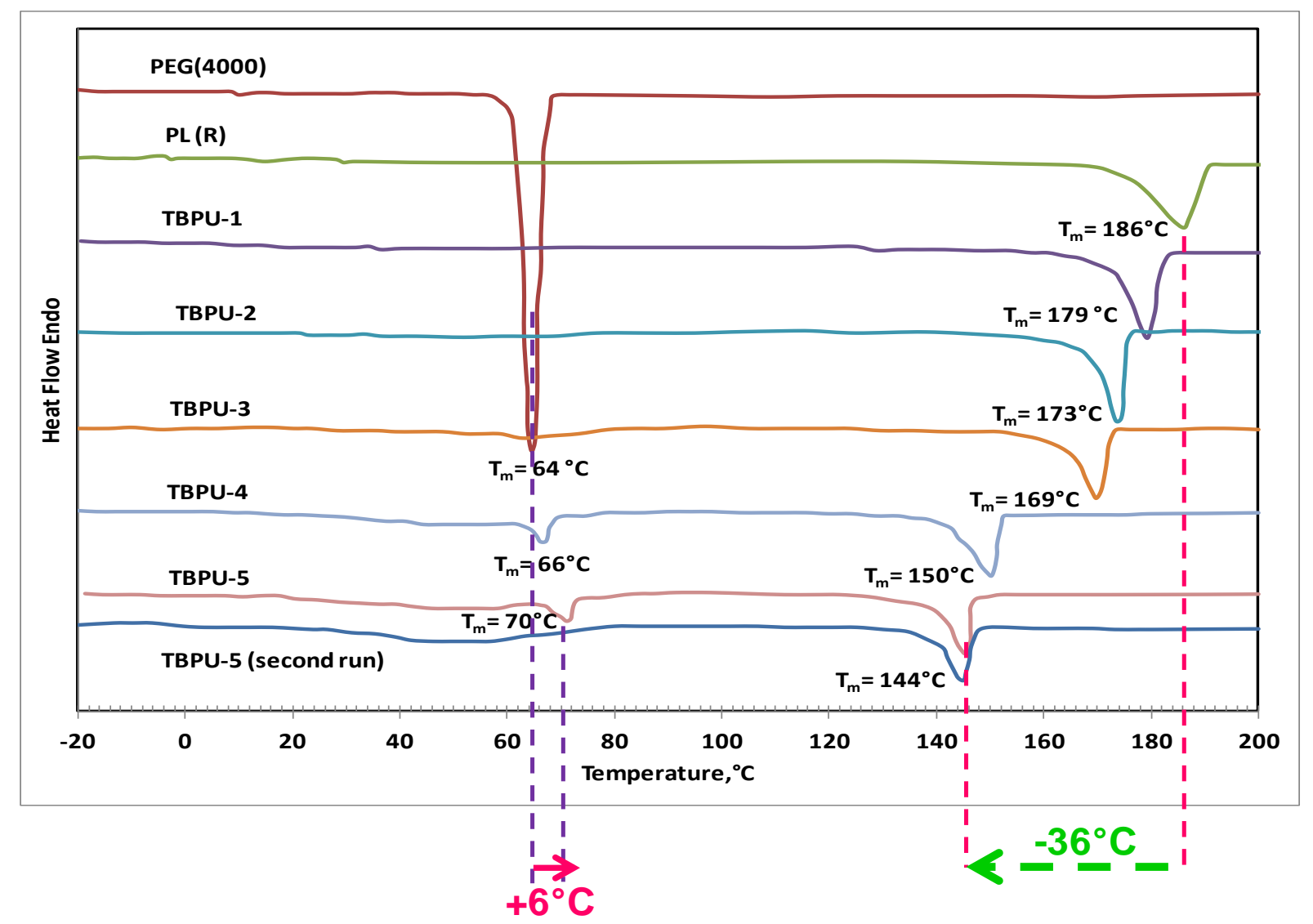

Fig. 4.14 DSC thermograms of PEG (4000), PL-homopolymer and TBPUs. 


\subsection{Mechanical Properties of TB and TBPUs}

For mechanical testing, the properties most frequently evaluated are the elongation at break $\left(\varepsilon_{\mathrm{b}}\right)$, tensile strength at break $\left(\sigma_{\mathrm{b}}\right)$, and tensile modulus (E). For biodegradable PL, a typical goal is to increase the elongation at break and tensile toughness without adversely affecting the tensile strength and tensile modulus. Although it was possible to cast all the TB copolymers into films, low molecular weight TB copolymers which have high PEG content and shorter PL segments could not be tested. Moreover, their corresponding TBPUs still had not enough mechanical strength to be made into scaffolds. Therefore, it was hard to obtain TBPU copolymer of both high mechanical strength and high hydrophilicity.

Generally as appeared from mechanical testing measurements, the mechanical properties of TB copolymers and their corresponding TBPUs were increased as the chain length of PL increased and PEG content decreased, see Table 4.7. However, among the three highest molecular weight TBPU samples, TBPU-3 was chosen as a pilot for fabrication of nanocomposite with BCNW, rather than the other samples. This is because of its high hydrophilicity and good degradation due to the high PEG content, as well as its good mechanical properties.

The tensile properties of PL, TB3, TBPU-3 were examined at room temperature and shown in Figures 4.15, and 4.16. The stress-strain curves displayed that PL-homopolymer was typically rigid and brittle. It had high tensile modulus as well as tensile strength, but with very limited elongation at break. For TB3 copolymer, the presence of PEG segments in copolymer chains caused decrease in both tensile strength than that of PL-homopolymer, whereas tensile modulus and elongation at break were interestingly increased. An increase of elongation at break means that the brittleness of PL decreased since the elongation at break and brittleness are inversely proportional. TBPU-3 had a similar behavior to TB3 except a significant increase in elongation at break was observed and might be related to the presence of soft PCL segments that added after urethane reaction. 
Table 4.7 Tensile properties of the different polymer films and their nanocomposites with BCNW, The results reported in table are the means for each group show a difference statistically significant with $\mathrm{p}<0.005$.

\begin{tabular}{|c|c|c|c|c|}
\hline Polymer & Lot name & $\begin{array}{c}\text { Tensile } \\
\text { Strength (MPa) }\end{array}$ & $\begin{array}{l}\text { \% Elongation } \\
\text { at Break }\end{array}$ & $\begin{array}{l}\text { Young Modulus } \\
\text { (MPa) }\end{array}$ \\
\hline Homopolymer & PL & $35.58 \pm 0.78$ & $3.50 \pm 0.12$ & $3100 \pm 36$ \\
\hline \multirow{3}{*}{ Triblock (TB) } & TB1 & $33.66 \pm 1.67$ & $4.19 \pm 0.20$ & $4555 \pm 56$ \\
\hline & TB2 & $31.75 \pm 1.86$ & $5.18 \pm 0.11$ & $5223 \pm 36$ \\
\hline & TB3 & $30.00 \pm 1.27$ & $7.12 \pm 0.41$ & $6055 \pm 46$ \\
\hline \multirow{3}{*}{$\begin{array}{c}\text { Triblock-Polyurethane } \\
\text { (TBPU) }\end{array}$} & TBPU-1 & $30.05 \pm 0.77$ & $5.34 \pm 0.12$ & $4100 \pm 66$ \\
\hline & TBPU-2 & $29.22 \pm 1.13$ & $7.22 \pm 0.25$ & $4531 \pm 61$ \\
\hline & TBPU-3 & $27.00 \pm 1.00$ & $9.54 \pm 0.38$ & $5518 \pm 69$ \\
\hline \multirow{5}{*}{$\begin{array}{l}\text { TBPU-3/BCNW } \\
\text { nanocomposite }\end{array}$} & $1 \% \mathrm{w}$ BCNW & 27.55 & 11 & 5323 \\
\hline & $3 \% \mathrm{w}$ BCNW & 29.00 & 13 & 5014 \\
\hline & $5 \% \mathrm{w}$ BCNW & 30.03 & 14 & 4525 \\
\hline & $7 \% \mathrm{w}$ BCNW & 31.50 & 15 & 3372 \\
\hline & $8 \% \mathrm{w}$ BCNW & 25.12 & 12 & 2315 \\
\hline
\end{tabular}

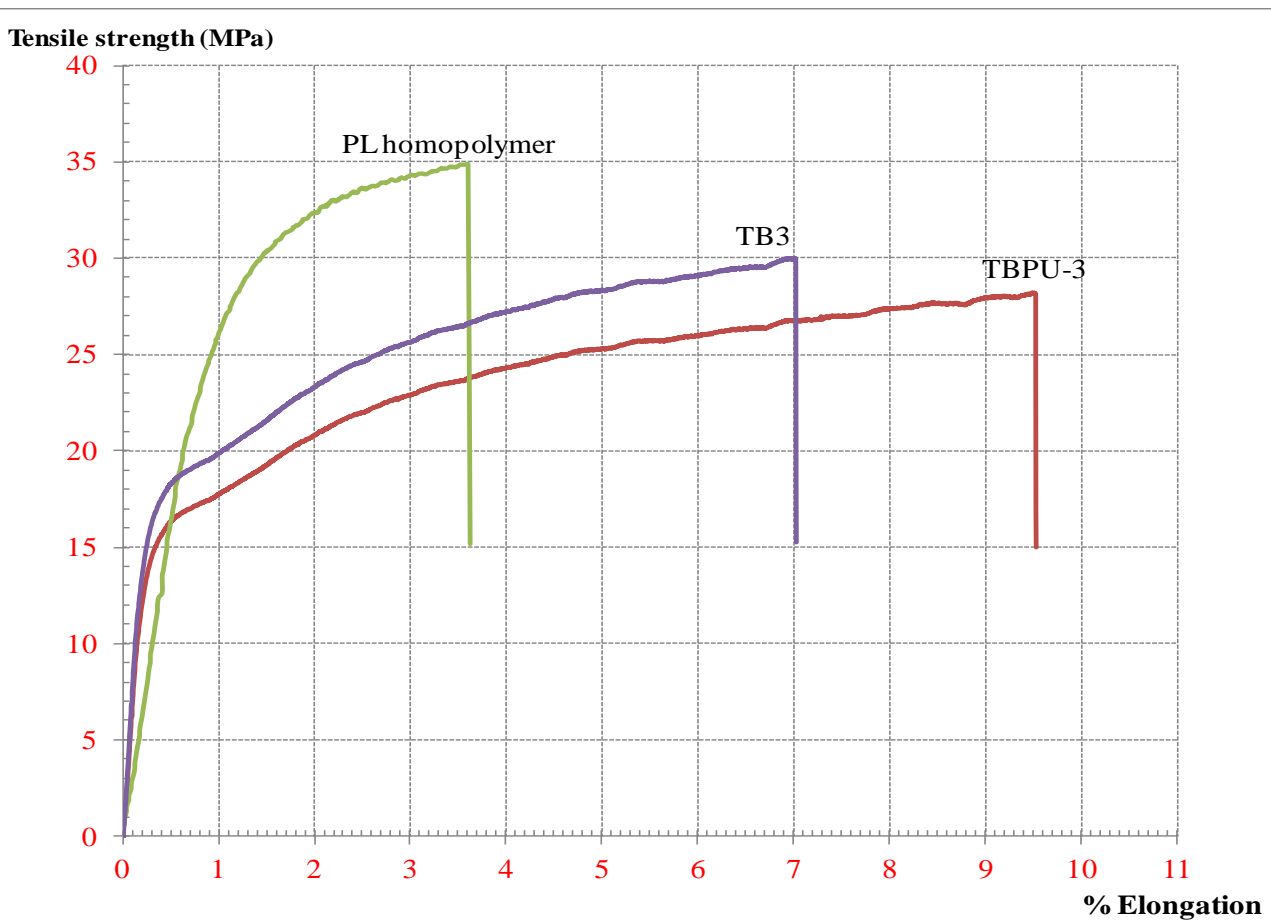

Fig. 4.15 Stress-strain curves of PL, TB3, and TBPU-3. 


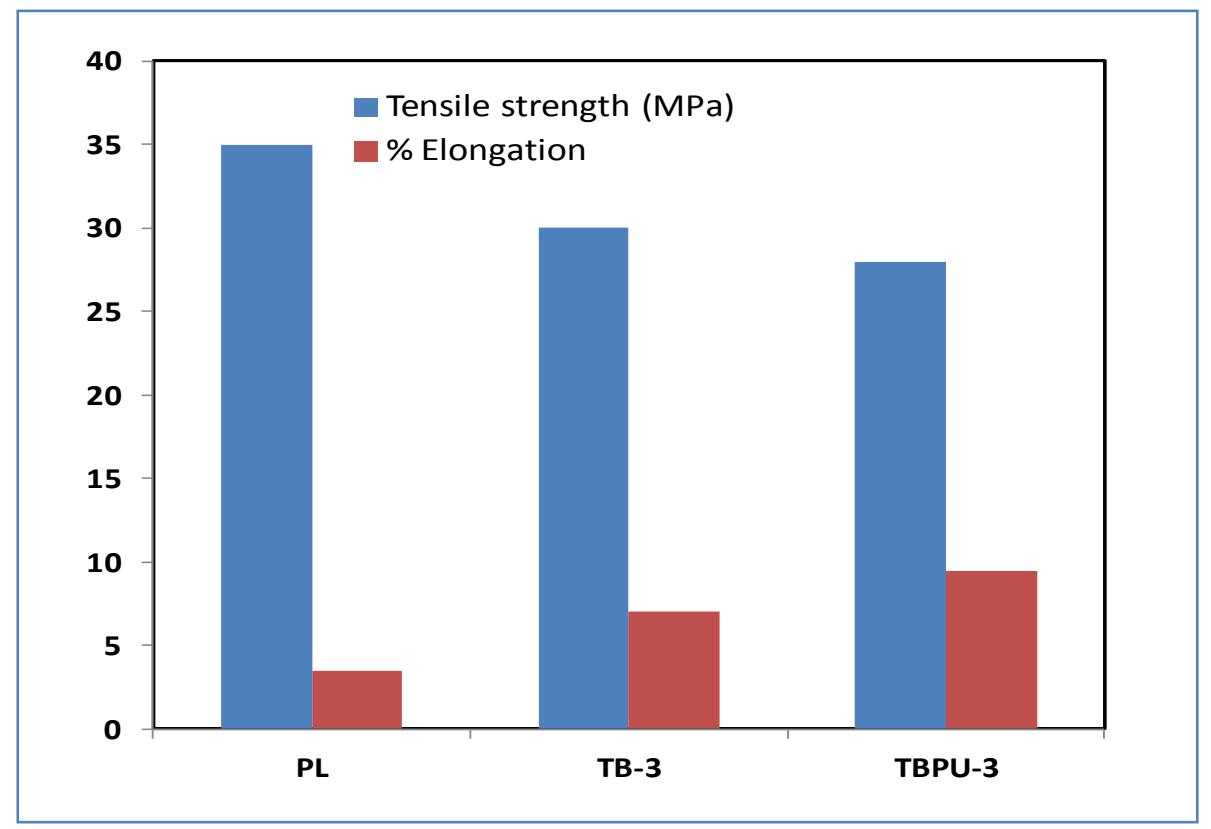

Fig. 4.16 Comparison between tensile strength and \% elongation of the PL, TB3 and TBPU-3.

Though, TBPU-3 presented a remarkable tensile strength of about $27.0 \mathrm{MPa}$ and a considerable elongation of $273 \%$ over that of PL homopolymer, see Table 4.7. The later properties made it interesting candidate for fabrication of biomedical materials that can be used in tissue regeneration. For instance, according to Table 4.8 which displayed the mechanical properties of some biodegradable polyesters that are commercially available for tissues engineering, TBPU-3 can be utilized in tissue engineering of cartilage, trabecular and cancellous bones, Fig. 4.17.

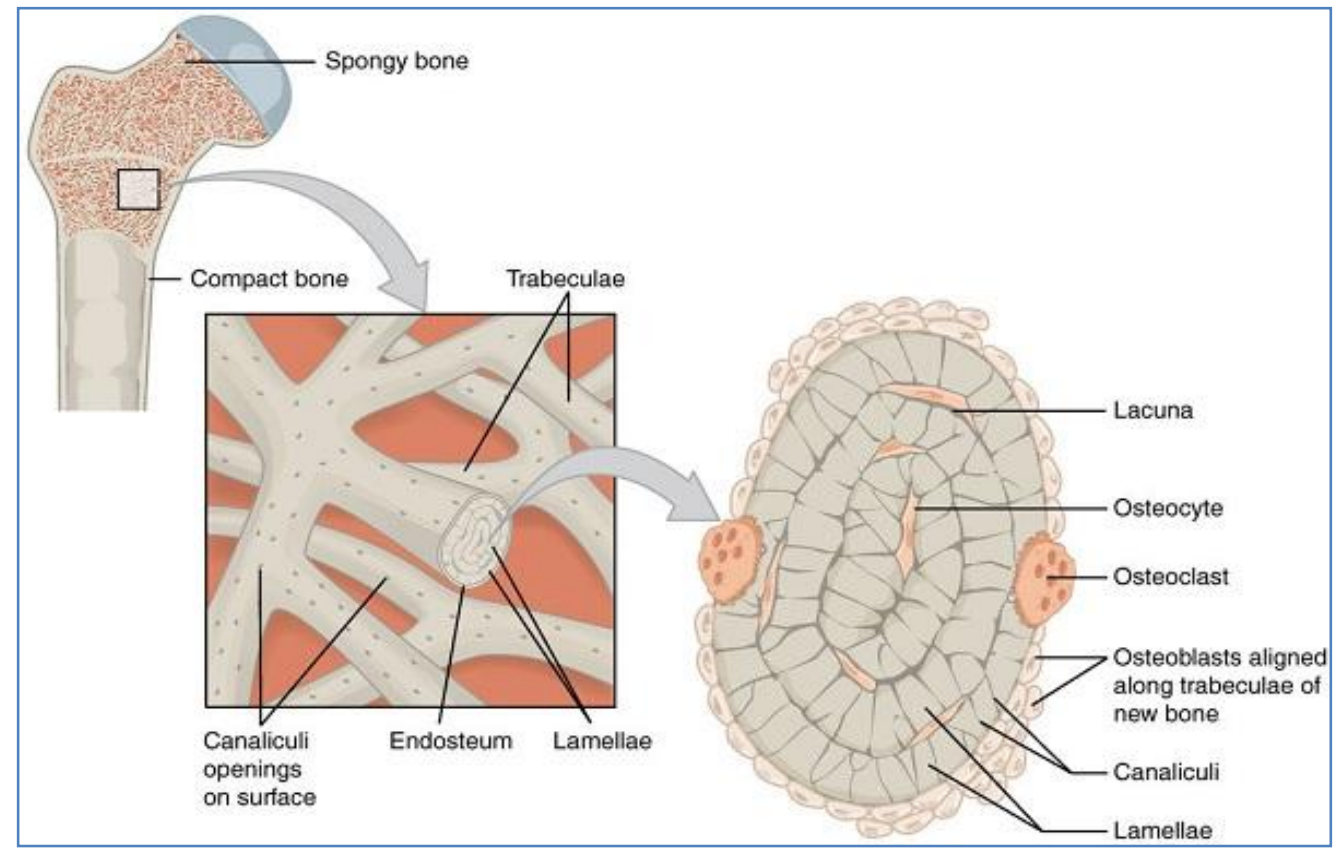

Fig. 4.17 Trabecular and cancellous bones in human body [93]. 
After adding BCNW to PL-homopolymer matrix, both tensile strength and elongation of obtained nanocomposite were decreased to $20 \mathrm{MPa}$ and $2.0 \%$, respectively compared to pure PLhomopolymer. However, adding BCNW to TB3 and TBPU-3 surprisingly showed significant improvements for both tensile strength and \% elongation than that in the free polymers. For instance, adding $7 \mathrm{w} \%$ of BCNW to TBPU-3 leads to an increase of $16.5 \%$ and $58 \%$ in tensile strength and \% elongation, respectively if it is compared with pure polymer and an increase of $330 \%$ in \% elongation if it is compared with PL-homopolymer, see Figures 4.18 and 4.19. This finding is in a good agreement attributed to poor interfacial bonding between the hydrophilic BCNW and the hydrophobic PL matrix, where the existence of the BCNW acts as an obstruction and separates the molecular chains of PL, which makes the force among the molecular chains of PL weaker. This in turn makes very weak load transfer between BCNW and PL matrix. Whereas, the presence of PEG segments in TB copolymers and TBPUs chains had a positive effect on the improvement of the mechanical properties of the composites, where PEG segments are acting as a kind of compatibilizer, successfully improved the interaction between the hydrophobic PL and the hydrophilic BCNW.

Table 4.8 Mechanical properties of the biodegradable polyesters and a few tissues and commercially available biomaterials. Reproduced from [93]

\begin{tabular}{|c|c|c|c|c|}
\hline Material & Type & $\begin{array}{l}\text { Tensile modulus } \\
\text { (E, MPa) }\end{array}$ & $\begin{array}{c}\text { Ultimate tensile } \\
\text { strength }\left(\sigma_{\mathrm{m}}, \mathrm{MPa}\right)\end{array}$ & $\begin{array}{l}\text { Elongation at } \\
\text { break }\left(\varepsilon_{\mathrm{m}}, \%\right)\end{array}$ \\
\hline \multirow{3}{*}{ 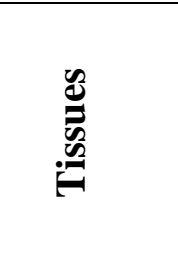 } & $\begin{array}{r}\text { Bone (trabecular) } \\
\text { (cancellous) }\end{array}$ & 483 & 2 & 2.5 \\
\hline & Cartilage & $10-100$ & $10-40$ & $15-20$ \\
\hline & Cardiovascular & $2-61$ & 1 & 200 \\
\hline \multirow{3}{*}{ 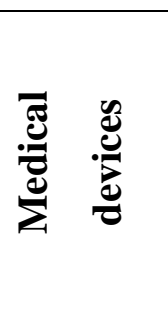 } & $\begin{array}{c}\text { Mg-based } \\
\text { orthopedic screw }\end{array}$ & Not reported & $\sim 200$ & $\sim 9$ \\
\hline & Suture & $\sim 850$ & $\sim 37$ & $\sim 70$ \\
\hline & $\begin{array}{l}\text { Medical mesh } \\
\quad(\text { Vicryl@) }\end{array}$ & $\begin{array}{c}4.6 \pm 0.6 \\
\text { (stiffness N/mm) }\end{array}$ & $\begin{array}{c}78.2 \pm 10.5 \\
\text { (maximum force } \mathrm{N} / \mathrm{cm} \text { ) }\end{array}$ & $150 \pm 6$ \\
\hline \multirow{4}{*}{$\begin{array}{l}\frac{\pi}{0} \\
\frac{0}{0} \\
\frac{0}{0} \\
0\end{array}$} & PLA & 3500 & 55 & $30-240$ \\
\hline & PCL & $\sim 700$ & $4-28$ & $700-1000$ \\
\hline & PGA & $7000-8400$ & 890 & 30 \\
\hline & PLGA(50:50) & $\sim 2000$ & 63.6 & $3-10$ \\
\hline
\end{tabular}


Nevertheless, due to the hydrophilicity of PEG is also, as expected, prevented the aggregation of BCNW so that it can be dispersed homogeneously in the TBPU-3 matrix in larger amount reaching $7 \%$ to form a network structure for reinforcing the TBPU, Figure 3. Results obtained from the mechanical properties show that both tensile strength and elongation at break reached their maximum when the content of $\mathrm{BCNW}$ is reached to $7 \% \mathrm{w}$, and decreased with further increase of nanowhiskers content. This may be attributed to the increased aggregation among cellulose whiskers, which consequently leads to phase separation and drop in mechanical properties, see Fig 4.20 and Table 4.7.

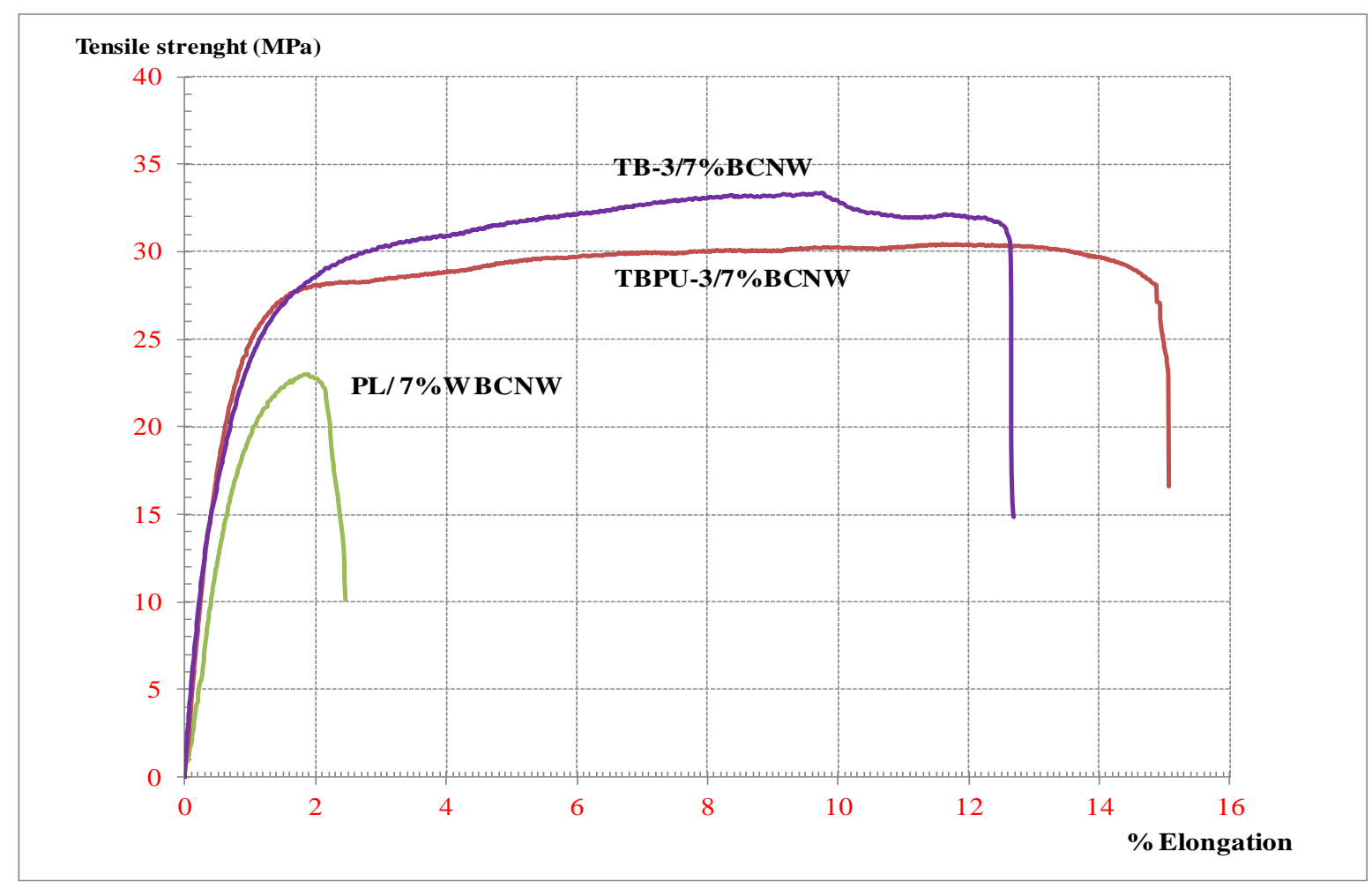

Fig. 4.18 Stress-strain curves of the nanocomposites PL/7\%w BCNW, TB3/7\%w BCNW, and TBPU-3/7\% $\%$ BCNW. 


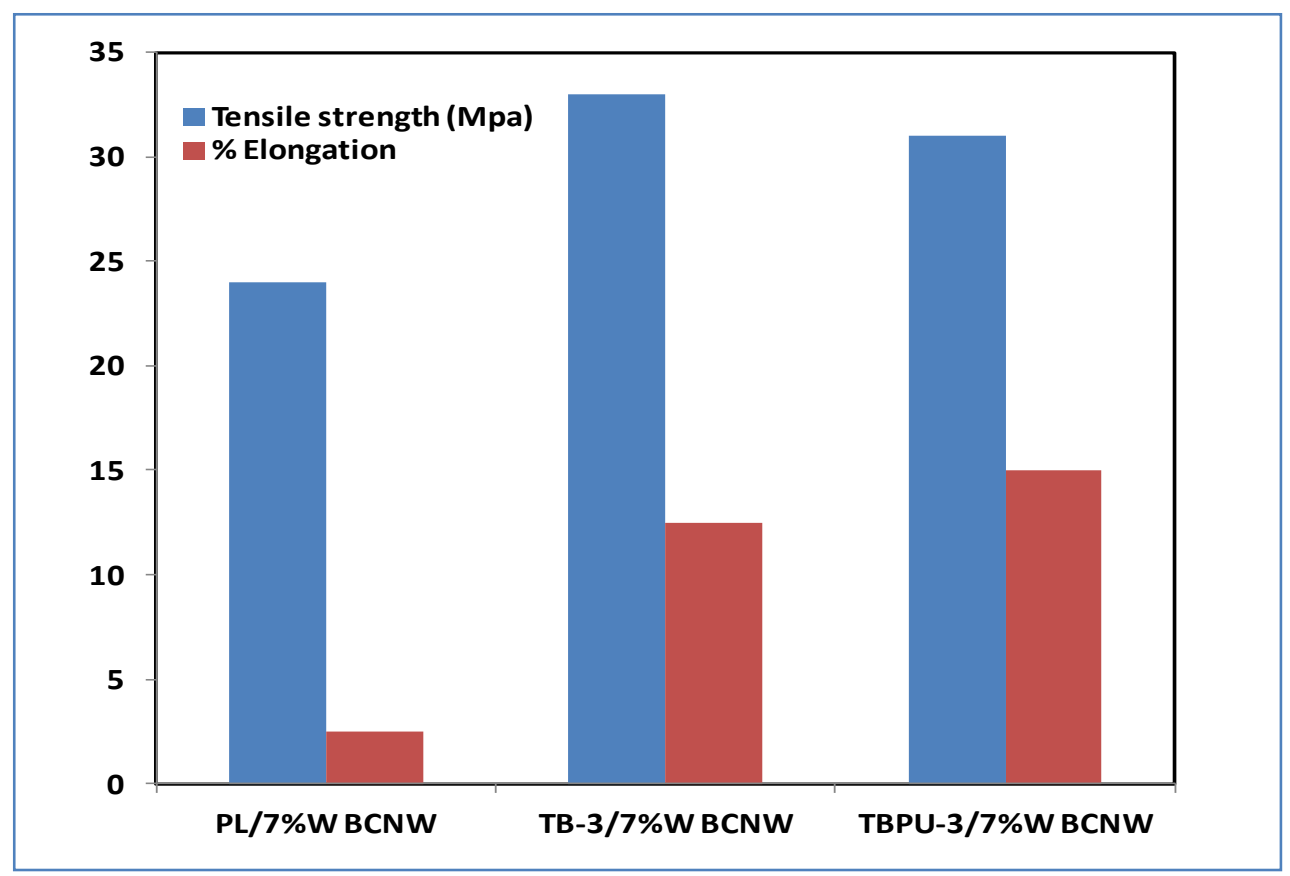

Fig. 4.19 Comparison between tensile strength and \% elongation of the nanocomposites of PL, TB3 and TBPU-3 with 7\%w of BCNW.

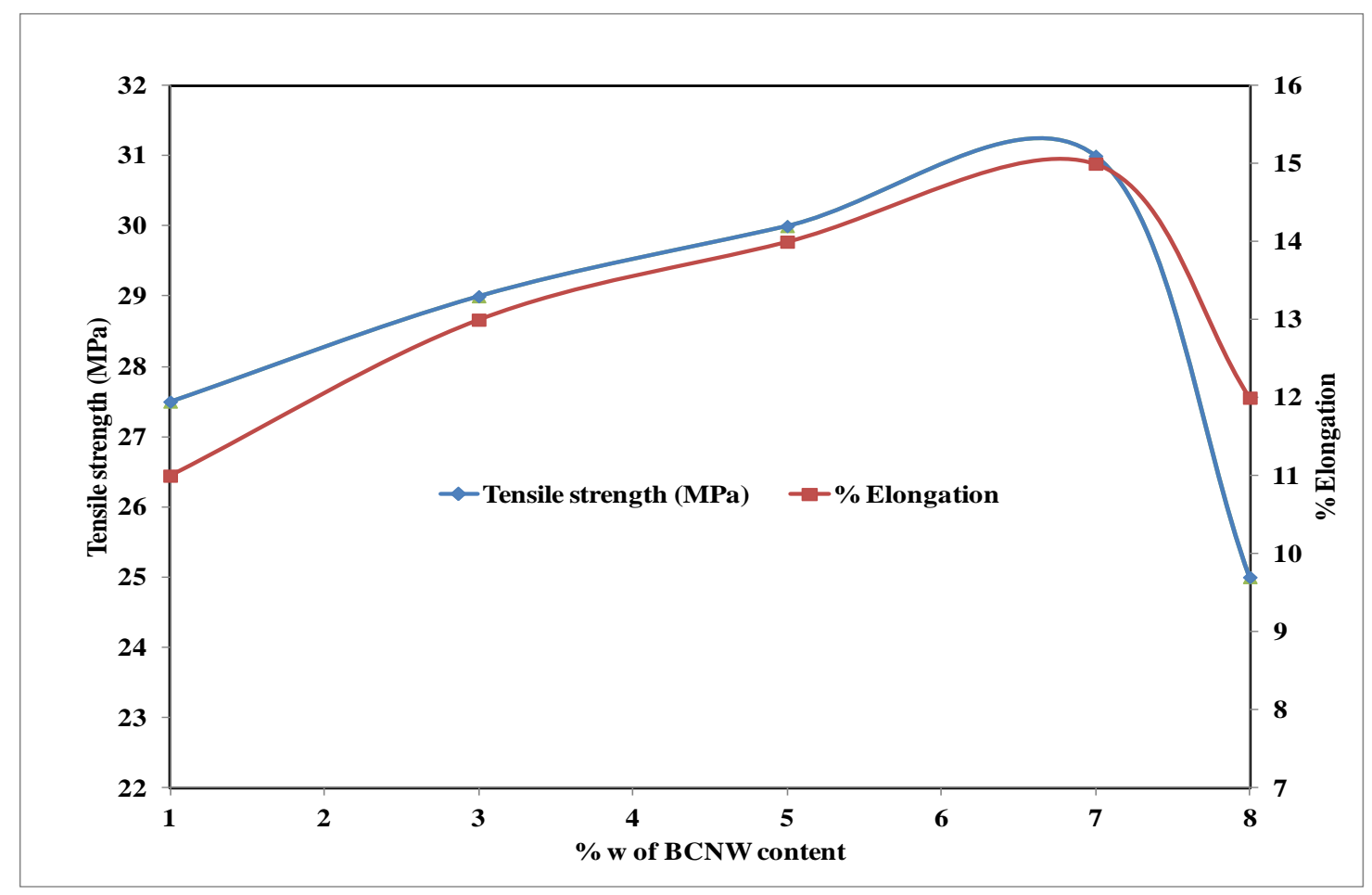

Fig. 4.20 Effect of the different BCNW content on mechanical properties of the TBPU-3 nanocomposite. 


\subsection{Statistical Analysis and Error Calculations}

Most experimental procedure was done in triplicates. Each date point in table or graph is expressed as mean for $n=3$. The mean is presented in table as an interval, in which the true value is likely to be found, and expressed mathematically as $\bar{x} \pm$ (SE). While in graph, the (SE) is represented by error bar on every data point. The statistical analysis of the data was conducted using one-way ANOVA. Differences between the groups with $p<0.05$ were considered to be statistically significant, where the average error in every set of data presented was less than $5 \%$. Appendix $\mathrm{C}$ listed raw data that obtained from replicated experiments.

It is worth to mention that for all repeated experiments standard errors did not exceed $\pm 5 \%$ and $p$ values $<0.05$. This in turn reflects the significance of the obtained results.

Equations 3.11 and 3.12 were used to calculate standard deviation (SD) and standard error (SE), respectively.

$$
\begin{gathered}
S D=\sqrt{\frac{\sum(X-\bar{X})^{2}}{(n-1)}} \\
S E_{\bar{X}}=\frac{S D}{\sqrt{n}}
\end{gathered}
$$

Where, $\bar{x}=$ sample mean value; $\mathrm{x}=$ data point $\mathrm{n}=$ sample size 


\section{CHAPTER 5 - CONCLUSION AND FUTURE WORK}

\subsection{Conclusion}

This research project is a part of the studies that our research group is currently conducting for controlling, modifying and tailoring either polymer or BC nanofiber properties to match specific applications in regenerative medicine and drug delivery applications. Results generated from the present work demonstrated the effect of changing the segment composition of polyurethane based bionanocomposite in order to obtain final product with improved mechanical, biodegradation and hydrophilic properties, in addition to non toxic biodegradation products. Green biodegradable polyurethanes composed of PL, PEG, PCL and BDI as nontoxic chain linker were successfully synthesized and characterized. A total of six different TBPUs samples, divided into two extreme, were polymerized and fully characterized using ${ }^{1} \mathrm{H}-\mathrm{NMR}$, FTIR/ATR, GPC, DSC, SEM and contact angle measurements. Three low molecular weight polyurethane of shorter PL segments and higher PEG contents are representing one group of low mechanical strength, which are highly hydrophilic in nature with fast degradation rate (more than ten-fold of PL-homopolymer). These types of polyurethanes will find good applications in encapsulation of drugs for use in DDS and MRI imaging. The other group of polyurethane has higher molecular weights. It consists of longer PL segments and less PEG content. This group of polyurethane shows high mechanical strength along with good hydrophilicity and better biodegradation than Pl-homopolymer. Due to the unique properties of those types of polyurethanes, they can find good application toward soft bone tissue regeneration like cartilage, trabecular and cancellous bones due to their good mechanical properties as well as their improved hydrophilicity and biodegradation which can support cell attachments, regeneration and perforation. One promising member of this group TBPU-3 was utilized to develop five nanocomposites of TBPU-3/BCNW of different composition. Scaffold that was reinforced with $7 \mathrm{w} \%$ of BCNW showed greater tensile strength and elongation at break (between $16.5 \%$ increase in tensile strength and 58\% in $\%$ elongation) throughout the five different polyurethane compositions if it compared with pure polymer and an increase of $330 \%$ in \% elongation if it compared with PL-homopolymer. 


\subsection{Future Recommendations}

1- In this work the effect of reinforced BCNW on the mechanical properties is considered in details for one sample only, i.e. TBPU-3, as a pilot. So it is recommended to further measure and investigate the effect of incorporating nanofibers on the other high strength polymer matrixes TBPU-1 and TBPU-2. This measurement would add another set of mechanical data that might support the properties of harder bones' tissues. In addition, the biodegradation rates of the nanocomposite samples need to be also analyzed.

2- For use in regenerative medicine, it is also recommended to measure the effect of incorporating the hydrophilic PEG segments in polyurethane polymer matrix on the cell attachment/perforation for porous scaffolds that are synthesized from the native and reinforced polyurethane samples. After that, the next step would be introducing the scaffold to an in vitro cell culture to quantify the seeding and attachment of cells on its surface. Furthermore, in vivo animal testing and clinical studies for cytotoxicity and biocompatibility investigations needed to be carried out.

3- Moreover, it's strongly recommended to fabricate drug loaded nanoparticles from the low molecular weight and highly degradable polyurethane samples TBPU-4, TBPU-5 and TBPU-6 which followed by testing their drug release profiles if they are considered for use as drug delivery vehicles. 


\section{APPENDICES}

\section{Appendix A. Gluconacetobacter xylinus (ATCC® ${ }^{800178}{ }^{\mathrm{TM}}$ )}

\section{Description}

Designation: JCM 9730 [BPR2001, FERMBP 4545, LMG 18788]

Deposited Name: Acetobacter xylinus subsp. sucrofermentans Toyosaki et al.

Product Description: Deposited as and referred to as the type strain of Acetobacter xylinus subsp. sucrofermentans. Produces large amounts of cellulose.

\section{Propagation}

\section{Medium}

ATCC® Medium 459: YGC medium

\section{Growth Conditions}

Temperature: $26^{\circ} \mathrm{C}$

Atmosphere: Aerobic

Storage Temp: Frozen at $-80^{\circ} \mathrm{C}$ or colder

Freeze Dried: $2^{\circ} \mathrm{C}$ to $8^{\circ} \mathrm{C}$

\section{Propagation Procedure}

1. Open vial according to enclosed instructions.

2. Using a single tube of \#459 broth (5 to $6 \mathrm{~mL}$ ), withdraw approximately 0.5 to $1.0 \mathrm{~mL}$ with a Pasteur or $1.0 \mathrm{~mL}$ pipette. Rehydrate the entire pellet.

3. Aseptically transfer this aliquot back into the broth tube. Mix well.

4. Use several drops of the suspension to inoculate a \#459 agar slant and/or plate.

5. Incubate the tubes and plate at $26^{\circ} \mathrm{C}$ for 72 hours.

\section{$\underline{\text { References }}$}

References and other information relating to this product are available online at www.atcc.org.

\section{Biosafety Level: 1}

Appropriate safety procedures should always be used with this material. Laboratory safety is discussed in the current publication of the Biosafety in Microbiological and Biomedical Laboratories from the U.S. Department of Health and Human Services Centers for Disease Control and Prevention and National Institutes for Health.

\section{Citation of Strain}

If use of this culture results in a scientific publication, it should be cited in that manuscript in the following manner: Gluconacetobacter xylinus (ATCC® $700178^{\mathrm{TM}}$ ) 


\section{Appendix B. ${ }^{1}$ H-NMR Spectra}

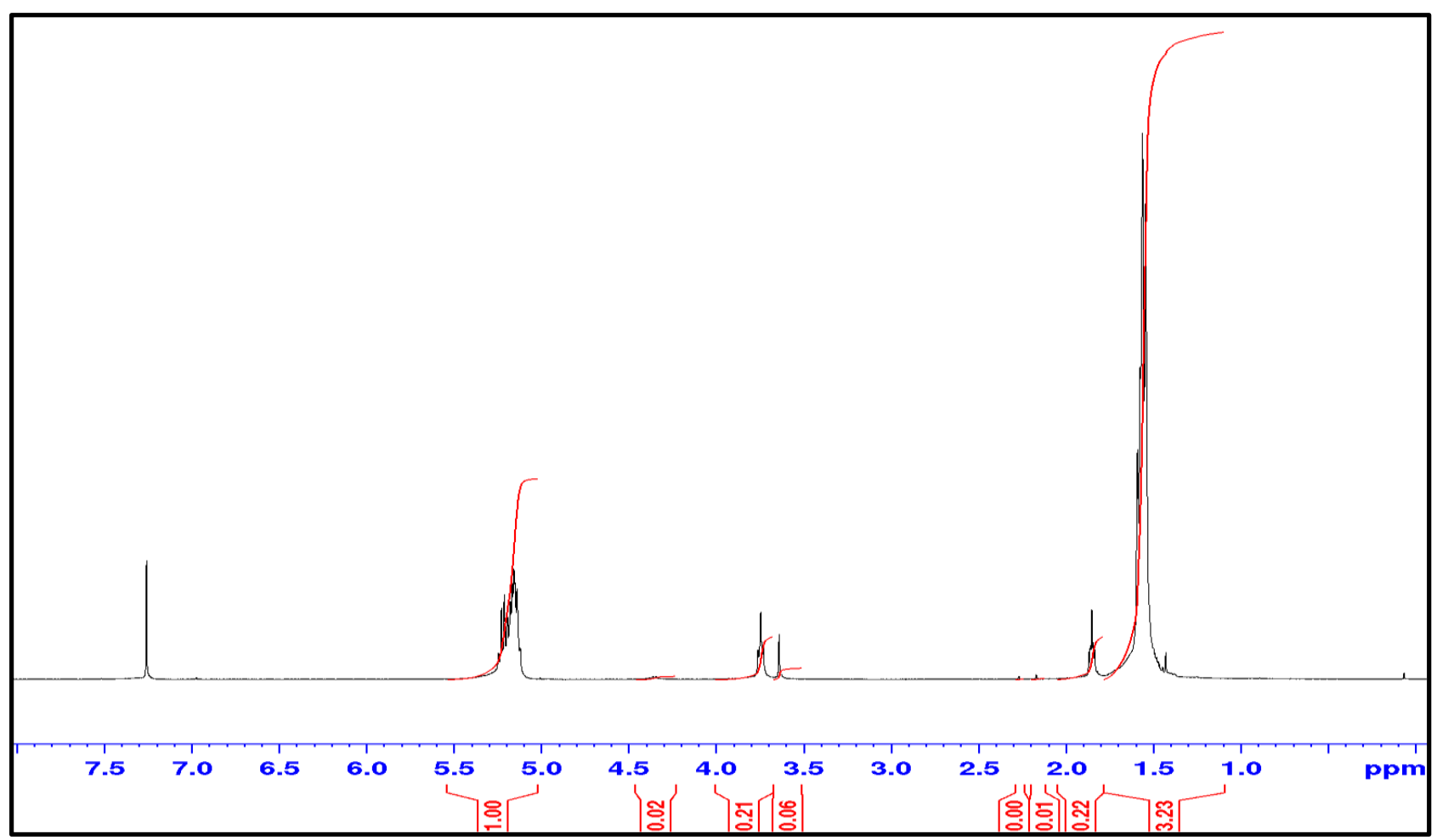

Fig. B $1{ }^{1} \mathrm{H}-\mathrm{NMR}$ spectrum of triblock copolymer TB1 in $\mathrm{CDCl}_{3}$.

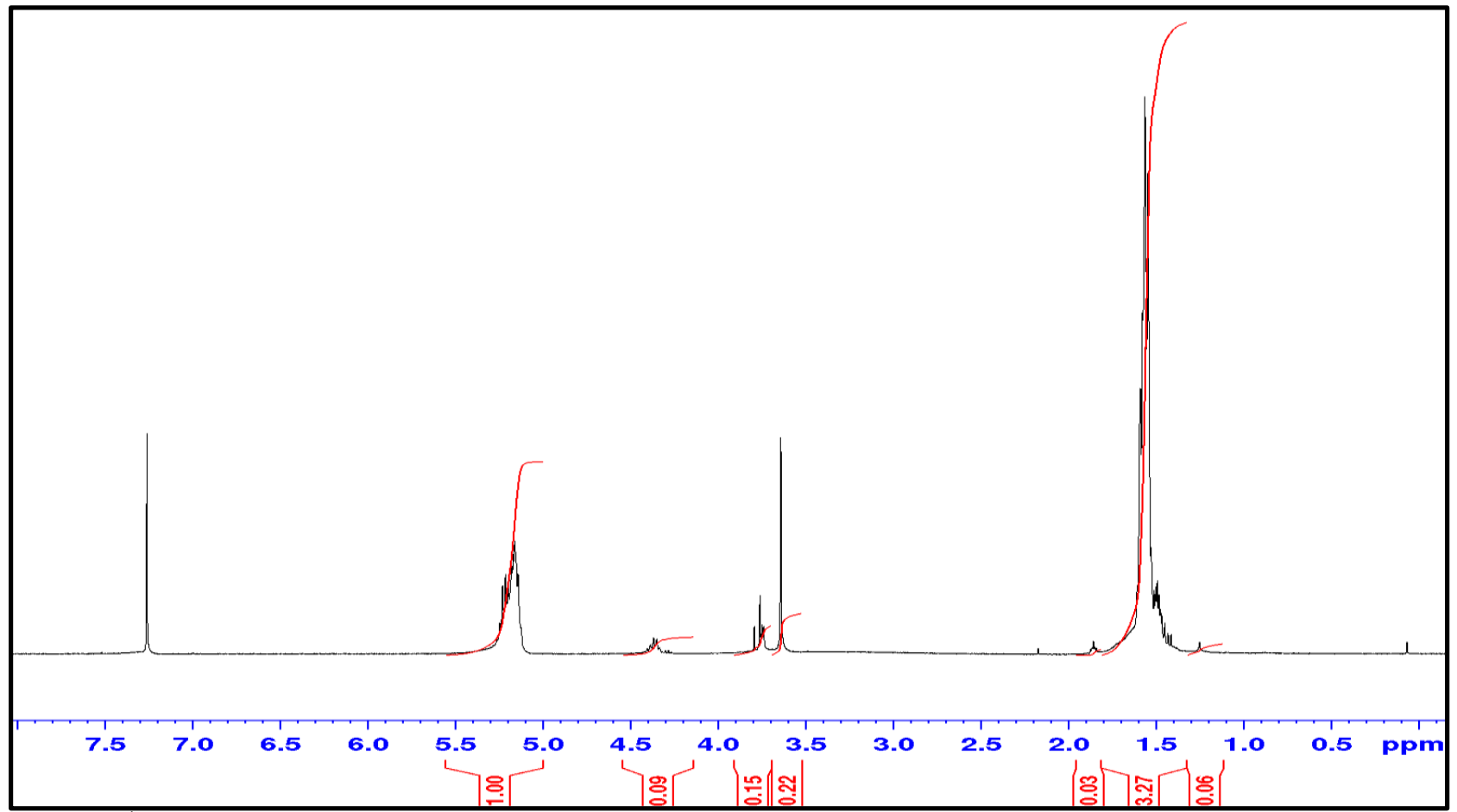

Fig. B2 ${ }^{1} \mathrm{H}-\mathrm{NMR}$ spectrum of triblock copolymer TBPU-1 in $\mathrm{CDCl}_{3}$. 


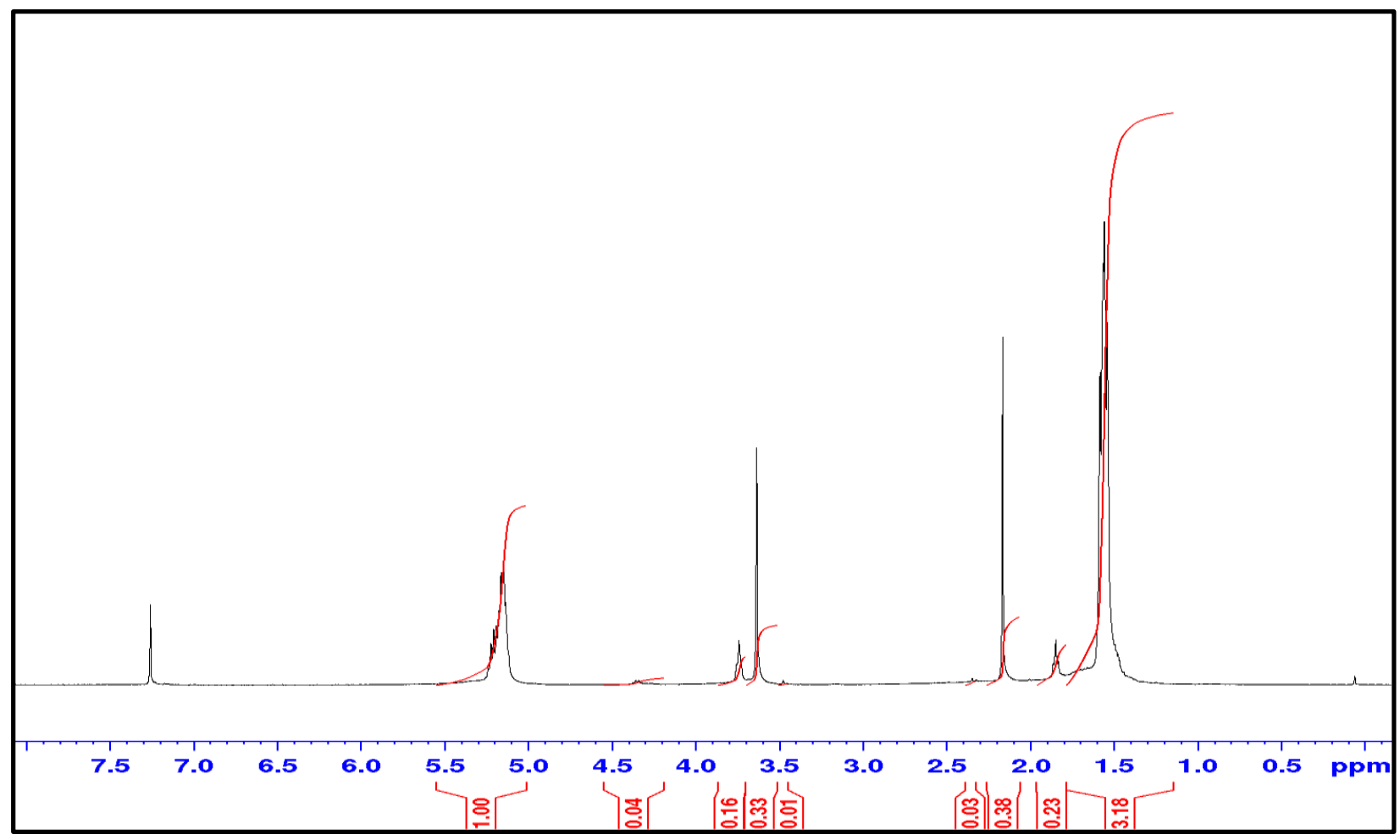

Fig. B3 ${ }^{1} \mathrm{H}-\mathrm{NMR}$ spectrum of triblock copolymer TB2 in $\mathrm{CDCl}_{3}$.

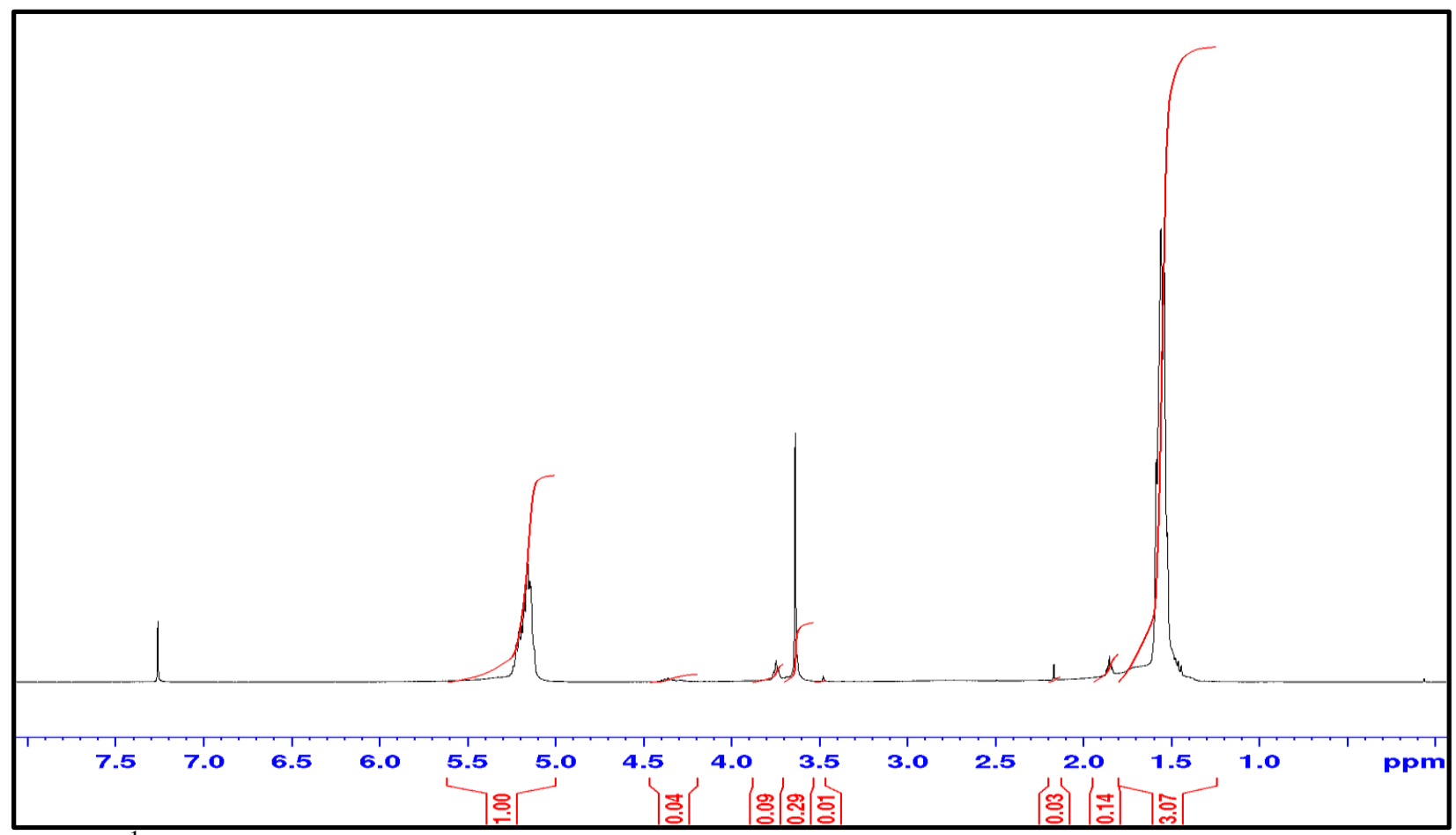

Fig. B4 ${ }^{1} \mathrm{H}-\mathrm{NMR}$ spectrum of triblock copolymer TBPU-2 in $\mathrm{CDCl}_{3}$. 


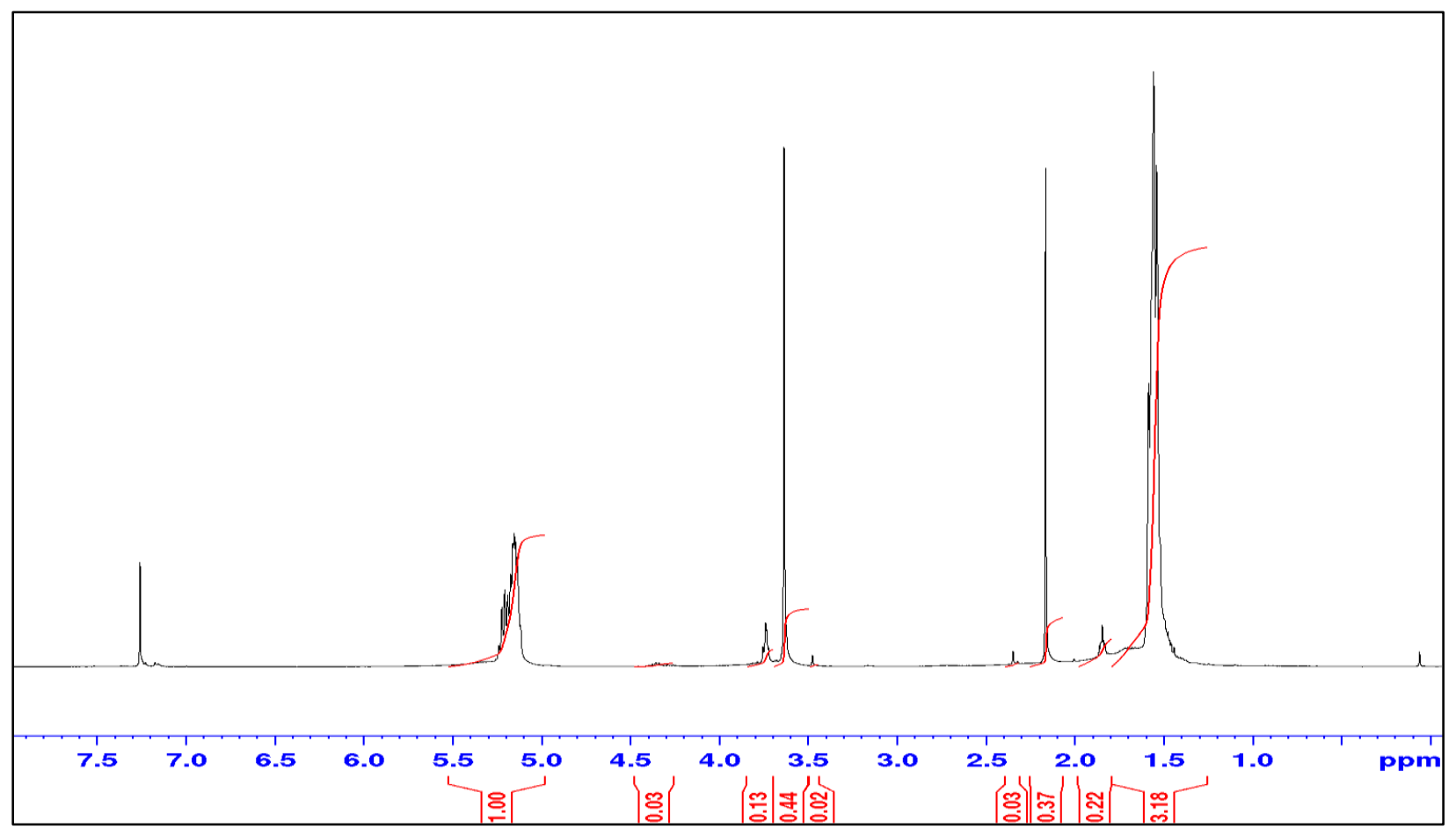

Fig. B5 ${ }^{1} \mathrm{H}-\mathrm{NMR}$ spectrum of triblock copolymer TB3 in $\mathrm{CDCl}_{3}$.

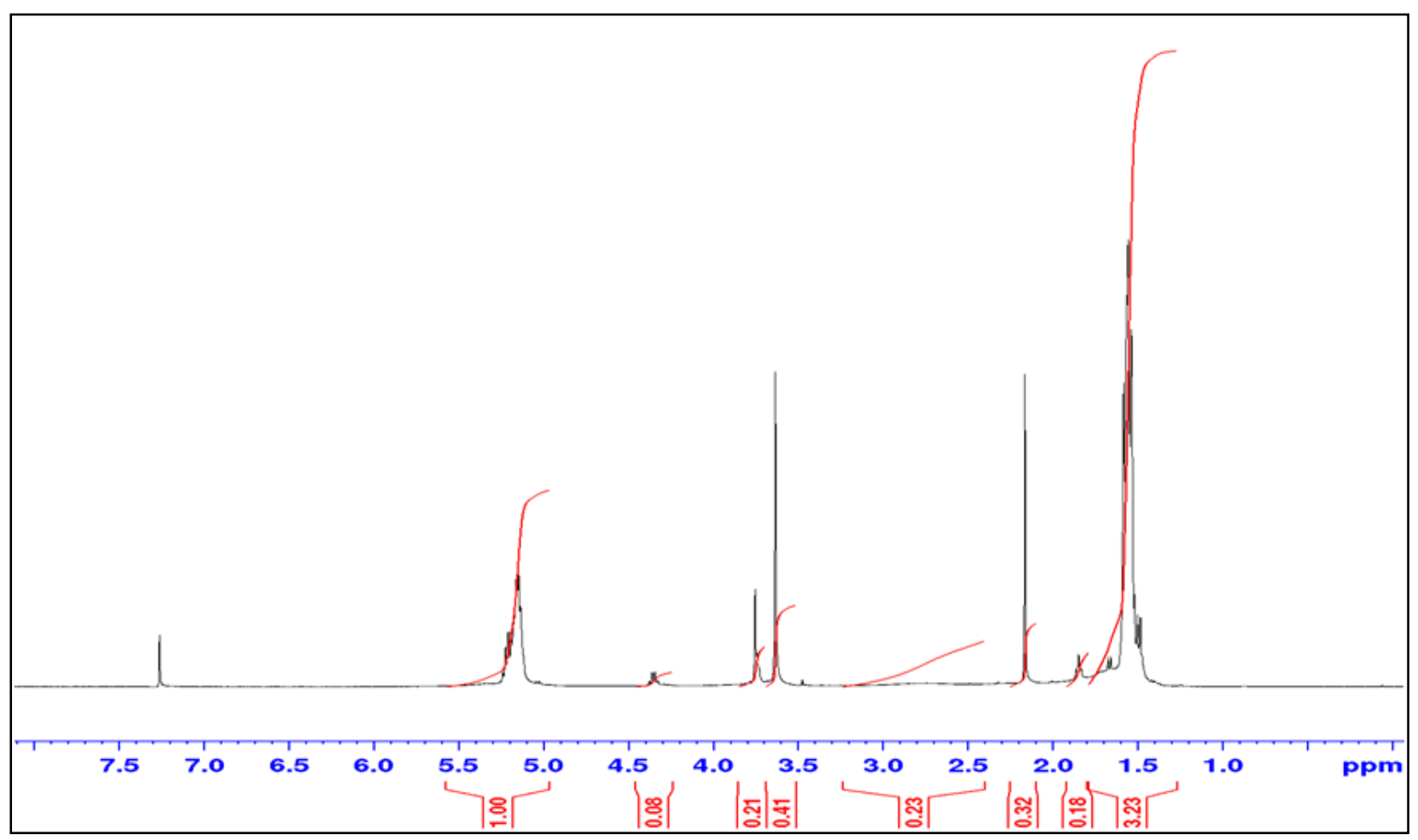

Fig. B6 ${ }^{1} \mathrm{H}-\mathrm{NMR}$ spectrum of triblock copolymer TBPU-3 in $\mathrm{CDCl}_{3}$. 


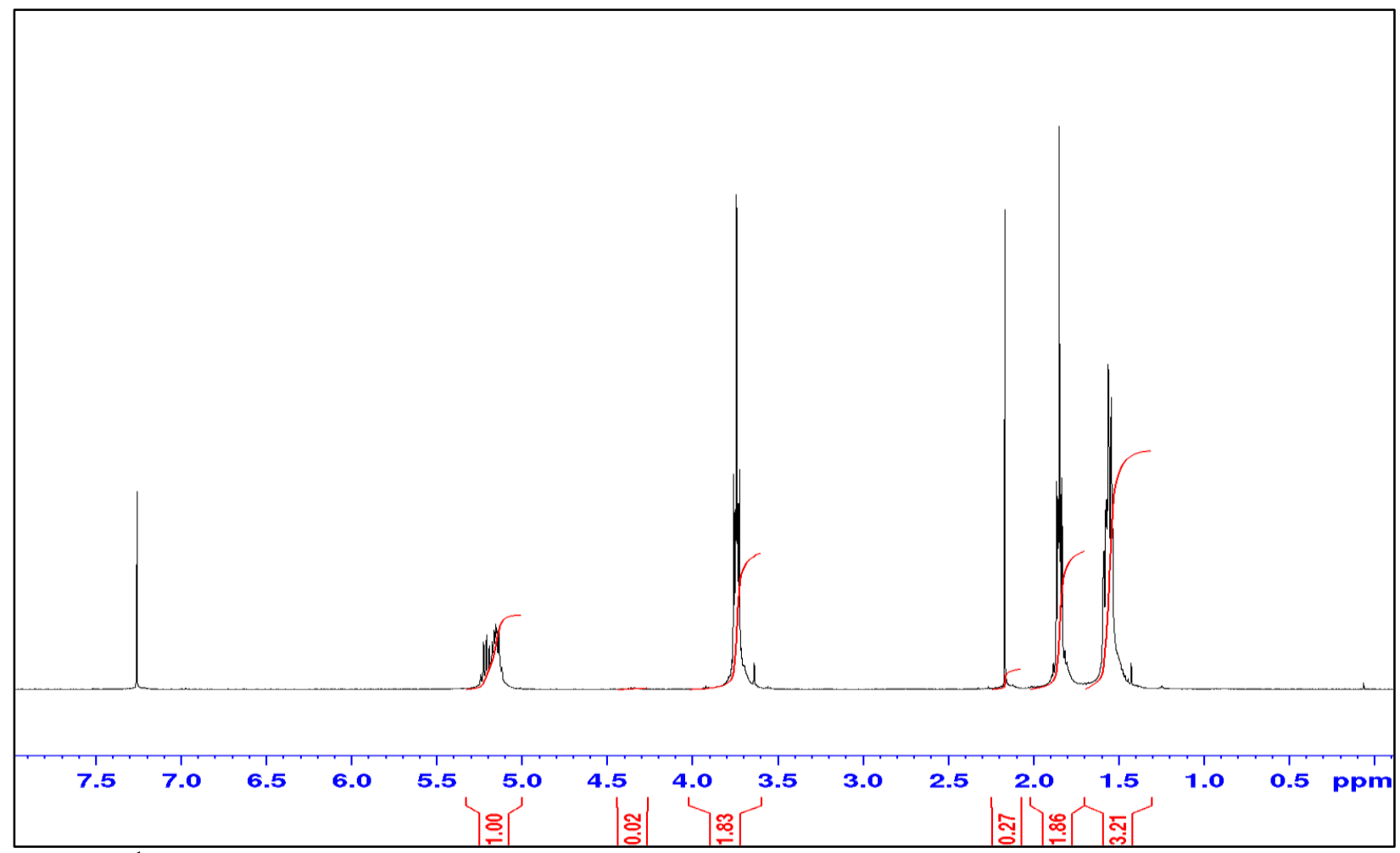

Fig. B $7{ }^{1} \mathrm{H}-\mathrm{NMR}$ spectrum of triblock copolymer TBPU-4 in $\mathrm{CDCl}_{3}$.

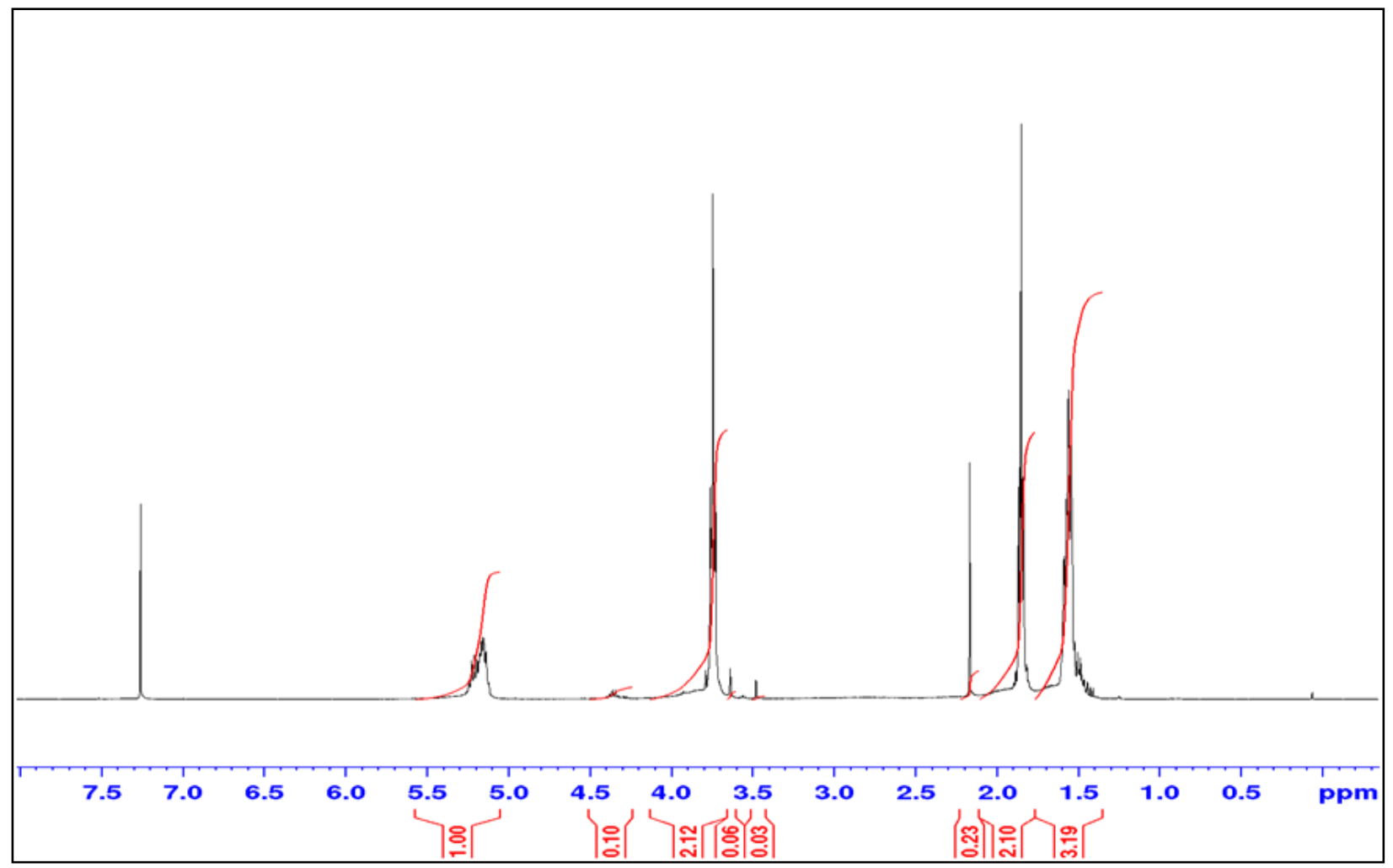

Fig. B8 ${ }^{1} \mathrm{H}-\mathrm{NMR}$ spectrum of triblock copolymer TBPU-5 in $\mathrm{CDCl}_{3}$. 


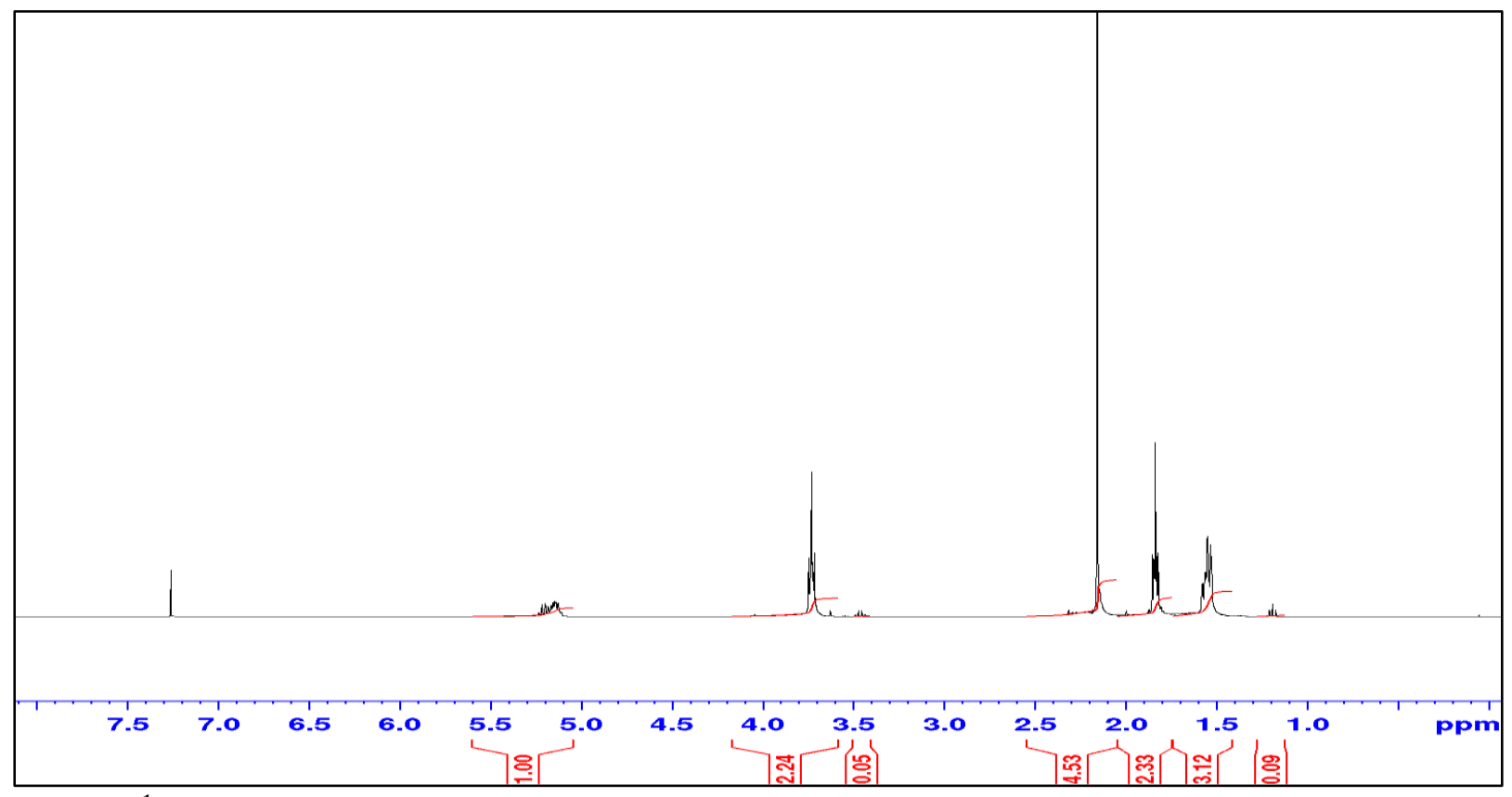

Fig. B9 ${ }^{1} \mathrm{H}-\mathrm{NMR}$ spectrum of triblock copolymer TBPU-6 in $\mathrm{CDCl}_{3}$. 


\section{Appendix C. Row data of some replicated experiments}

C1: Enzymatic degradation of polyurethanes, Fig. 4.8

\begin{tabular}{|c|c|c|c|c|c|c|c|c|}
\hline \multicolumn{5}{|c|}{ TBPU-1 } & \multicolumn{4}{|c|}{ TBPU-2 } \\
\hline time, $h$ & T1 & $\mathbf{T} 2$ & T3 & $\bar{x} \pm(\mathrm{SE})$ & T1 & $\mathbf{T} 2$ & T3 & $\bar{x} \pm(\mathrm{SE})$ \\
\hline 5 & 13.33 & 14.00 & 12.23 & $13.19 \pm 1.88$ & 18.33 & 18.12 & 18.45 & $18.29 \pm 1.18$ \\
\hline 15 & 16.50 & 17.01 & 17.36 & $16.95 \pm 1.18$ & 20.66 & 21.11 & 20.85 & $20.87 \pm 1.12$ \\
\hline 30 & 18.00 & 17.81 & 18.31 & $18.04 \pm 1.26$ & 22.00 & 21.61 & 21.52 & $21.71 \pm 1.40$ \\
\hline 60 & 20.85 & 21.11 & 20.98 & $20.94 \pm 1.09$ & 23.32 & 23.05 & 23.01 & $23.13 \pm 1.20$ \\
\hline 120 & 21.41 & 21.20 & 21.07 & $21.16 \pm 1.03$ & 23.5 & 23.6 & 23.52 & $23.54 \pm 2.40$ \\
\hline \multicolumn{5}{|c|}{ TBPU-3 } & \multicolumn{4}{|c|}{ TBPU-4 } \\
\hline time, $h$ & T1 & $\mathbf{T 2}$ & T3 & $\bar{x} \pm(\mathrm{SE})$ & T1 & $\mathbf{T 2}$ & T3 & $\bar{x} \pm(\mathrm{SE})$ \\
\hline 5 & 19.02 & 19.53 & 19.06 & $19.19 \pm 1.20$ & 43.92 & 44.22 & 43.93 & $44.01 \pm 2.13$ \\
\hline 15 & 22.33 & 22.65 & 22.18 & $22.26 \pm 1.20$ & 57.51 & 56.91 & 57.97 & $57.46 \pm 2.53$ \\
\hline 30 & 23.56 & 24.06 & 23.96 & $23.84 \pm 1.70$ & 61.05 & 60.71 & 61.07 & $60.92 \pm 2.19$ \\
\hline 60 & 26.61 & 27.13 & 25.78 & $26.49 \pm 1.90$ & 74.00 & 73.71 & 73.33 & $73.68 \pm 1.19$ \\
\hline 120 & 27.14 & 26.83 & 26.99 & $26.96 \pm 1.60$ & 75.13 & 75.23 & 76.04 & $75.41 \pm 2.42$ \\
\hline \multicolumn{5}{|c|}{ TBPU-5 } & \multicolumn{4}{|c|}{ TBPU-6 } \\
\hline time, $h$ & T1 & T2 & T3 & $\bar{x} \pm(\mathrm{SE})$ & T1 & $\mathbf{T} 2$ & T3 & $\bar{x} \pm(\mathrm{SE})$ \\
\hline 5 & 60.52 & 60.1 & 62.26 & $60.95 \pm 1.10$ & 81.13 & 82.22 & 79.56 & $80.89 \pm 1.23$ \\
\hline 15 & 7.331 & 70 & 69.74 & $70.25 \pm 3.13$ & 87.22 & 86.91 & 90.06 & $87.69 \pm 2.03$ \\
\hline 30 & 72.91 & 73.3 & 74.45 & $73.55 \pm 2.57$ & 90.07 & 91.25 & 91.97 & $90.99 \pm 1.46$ \\
\hline 60 & 82.35 & 81.43 & 80.95 & $81.32 \pm 1.23$ & 91.21 & 93.00 & 91.34 & $91.78 \pm 1.83$ \\
\hline 120 & 85.42 & 82.44 & 80.76 & $82.05 \pm 4.82$ & 90.33 & 92.05 & 93.59 & $91.86 \pm 0.80$ \\
\hline
\end{tabular}

\begin{tabular}{|c|c|c|c|c|c|c|}
\hline \multicolumn{7}{|l|}{ ANOVA: Single Factor for TBPU-1 system as representative } \\
\hline SUMMARY & & & & & & \\
\hline Groups & & & & & & \\
\hline 13.33 & Count & Sum & Average & Variance & & \\
\hline 16.5 & 2 & 26.23145 & 13.11573 & 1.563885 & & \\
\hline 18 & 2 & 34.35814 & 17.17907 & 0.064132 & & \\
\hline 20.85 & 2 & 36.11396 & 18.05698 & 0.132075 & & \\
\hline 21.4 & 2 & 41.98077 & 20.99038 & 0.000185 & & \\
\hline ANOVA & 2 & 42.06779 & 21.0339 & 0.002298 & & \\
\hline Source of Variation & & & & & & \\
\hline Between Groups & & & & & & \\
\hline Within Groups & SS & $d f$ & MS & $F$ & P-value & F crit \\
\hline Total & 85.30388 & 4 & 21.32597 & 60.49667 & 0.000201 & 5.192168 \\
\hline
\end{tabular}


C2: Tensile properties of the different polymer films, Table 4.7

\begin{tabular}{|c|c|c|c|c|c|c|c|c|c|c|}
\hline \multirow[b]{2}{*}{ Polymer } & \multirow[b]{2}{*}{ Lot name } & \multicolumn{4}{|c|}{ Tensile Strength (MPa) } & \multicolumn{4}{|c|}{ \% Elongation at Break } & \multirow{2}{*}{$\begin{array}{c}\begin{array}{c}\text { Young Modulus } \\
\text { (MPa) }\end{array} \\
\overline{\boldsymbol{x}} \pm(\mathrm{SE})\end{array}$} \\
\hline & & T1 & $\mathbf{T 2}$ & T3 & $\bar{x} \pm(\mathrm{SE})$ & T1 & $\mathbf{T 2}$ & T3 & $\bar{x} \pm(\mathrm{SE})$ & \\
\hline Homopolymer & PL & 34.12 & 36.81 & 35.81 & $35.58 \pm 0.78$ & 3.5 & 3.3 & 3.7 & $3.50 \pm 0.12$ & $3100 \pm 36$ \\
\hline \multirow{3}{*}{ Triblock (TB) } & TB1 & 31.1 & 33.3 & 36.58 & $33.66 \pm 1.67$ & 3.9 & 3.9 & 4.5 & $4.19 \pm 0.20$ & $4555 \pm 56$ \\
\hline & TB2 & 30.3 & 29.5 & 35.45 & $31.75 \pm 1.86$ & 5.4 & 5.1 & 5.04 & $5.18 \pm 0.11$ & $5223 \pm 36$ \\
\hline & TB3 & 28.5 & 29.1 & 32.4 & $30.00 \pm 1.27$ & 7.3 & 6.9 & 7.16 & $7.12 \pm 0.41$ & $6055 \pm 46$ \\
\hline \multirow{3}{*}{$\begin{array}{c}\text { Triblock- } \\
\text { Polyurethane } \\
\text { (TBPU) }\end{array}$} & TBPU-1 & 31.3 & 28.5 & 30.2 & $30.05 \pm 0.77$ & 5.5 & 5.1 & 5.42 & $5.34 \pm 0.12$ & $4100 \pm 66$ \\
\hline & TBPU-2 & 27.2 & 30.3 & 30.16 & $29.22 \pm 1.13$ & 7.3 & 7.6 & 6.76 & $7.22 \pm 0.25$ & $4531 \pm 61$ \\
\hline & TBPU-3 & 29.2 & 26.6 & 25.2 & $27.00 \pm 1.00$ & 10.1 & 9.7 & 8.82 & $9.54 \pm 0.38$ & $5518 \pm 69$ \\
\hline
\end{tabular}

\begin{tabular}{|l|c|c|c|c|c|c|}
\hline ANOVA: Single Factor for (TBPU) system as representative & & & & & \\
\hline & & & & & & \\
\hline SUMMARY & & & & & \\
\hline Groups & Count & Sum & Average & Variance & & \\
\hline 31.3 & 2 & 58.7 & 29.35 & 1.445 & & \\
\hline 27.2 & 2 & 60.46 & 30.23 & 0.0098 & & \\
\hline 29.2 & 2 & 51.8 & 25.9 & 0.98 & & \\
\hline \multicolumn{1}{|c|}{} & & & & & \\
\hline ANOVA & SS & Df & MS & $F$ & P-value & F crit \\
\hline Source of Variation & 20.95053333 & 2 & 10.47527 & 12.90693 & 0.033595 & 9.552094 \\
\hline Between Groups & 2.4348 & 3 & 0.8116 & & & \\
\hline Within Groups & 23.38533333 & 5 & & & & \\
\hline Total & & & & & & \\
\hline
\end{tabular}




\section{Appendix D. Mechanical Testing}

\section{Tensile Strength}

Tensile strength is calculated by dividing the load at break by the original minimum crosssectional area. The result is expressed in megapascals (MPa) and reported to three significant figures.

Tensile strength $=($ load at break $) /($ original width $)$ (original thickness $)$

\section{Percent Elongation}

Percent elongation is calculated by dividing the elongation at the moment of rupture by the initial gauge length and multiplying by 100 . When gauge marks or extensometers are used to define a specific test section, only this length is used in the calculation, otherwise the distance between the grips is used as the initial gauge length. The result is expressed in percent and reported to two significant figures.

$$
\text { Percent elongation }=(\text { elongation at rupture }) \times 100 /(\text { initial gage length })
$$

\section{Young's Modulus}

Young's modulus is calculated by drawing a tangent to the initial linear portion of the stressstrain curve, selecting any point on this tangent, and dividing the tensile stress by the corresponding strain. For purposes of this calculation, the tensile stress shall be calculated by dividing the load by the average original cross section of the test specimen. The result is expressed in gigapascals (GPa) and reported to three significant figures.

$$
\text { Young's modulus }=\frac{\text { load at point on tangent } /(\text { original width })(\text { original thickness })}{\text { elongation at point of tangent }) /(\text { initial gage length })}
$$

\section{Toe Compensation}

In a typical stress-strain curve (see below), there is a toe region, $\mathrm{AC}$, which does not represent a property of the material. It is an artifact caused by a take-up of slack, and alignment or seating of the specimen. In order to obtain correct values of such parameters as modulus, strain, and yield point, this artifact must be compensated for to give the corrected zero point on the strain or extension axis. In the case of a material exhibiting a region of Hookean (linear) behavior as shown below, a continuation of the linear (CD) region of the curve is constructed through the 
zero-stress axis. The intersection (B) is the corrected zero-strain point from which all extensions or strains must be measured, including the yield point, if applicable. The elastic modulus can be determined by dividing the stress at any point along line $\mathrm{CD}$ (or its extension) by the strain at the same point (measured from point B, defined as zero-strain).

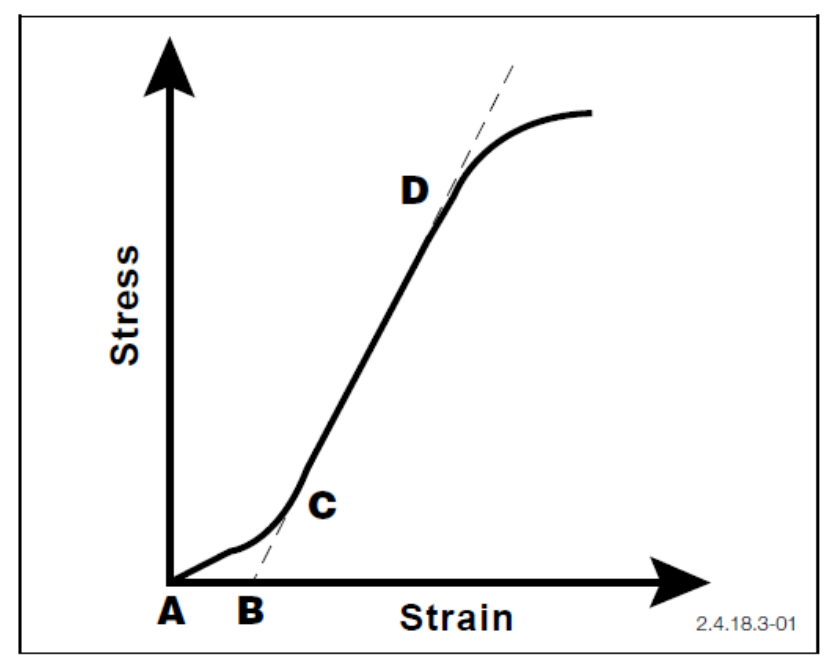

Fig. D1 A typical stress-strain curve. 


\section{REFERENCES}

1. Gunatillake P, Mayadunne R, and Adhikari R. Recent Developments in Biodegradable Synthetic Polymers. Biotechnol. Annu. Rev. 2006; 12: 301-347.

2. Tsuji H. Poly(lactide) stereocomplexes: formation, structure, properties, degradation, and applications. Macromol Biosci. 2005; 5: 569-597.

3. Barnes CP, Sell SA, Boland ED, Simpson DG, Bowlin GL. Nanofiber technology: designing the next generation of tissue engineering scaffolds. Adv Drug Deliv Rev. 2007;59:1413-33.

4. Albertsson A-C, Varma IK. Recent Developments in Ring Opening Polymerization of Lactones for Biomedical Applications. Biomacromolecules. 2003; 6:1466-1486.

5. Andriano KP, Tabata Y, Ikada Y, Heller J. In vitro and in vivo comparison of bulk and surface hydrolysis in absorbable polymer scaffolds for tissue engineering. J Biomed Mater Res. 1999:5:602-612.

6. Gunatillake P, Adhikari R. Biodegradable synthetic polymers for tissue engineering. Eur Cell Mater. 2003; 5: 1-16.

7. Agrawal CM, Athanasiou KA. Technique to control $\mathrm{pH}$ in vicinity of biodegrading PLA-PGA implants. J Biomed Mater Res. 1997; 38: 105-14.

8. Ara M, Watanabe M, Imai Y. Effect of blending calcium compounds on hydrolytic degradation of poly(DL-lactic acid-co-glycolic acid). Biomaterials. 2002; 23 :2479-2483.

9. Jaganjac M, Milkovi L, Cipak A, Mozeti M, Recek N. Cell adhesion on hydrophobic polymer surfaces. Materials and technology. 2012; 461: 53-56.

10. Lamba NMK, Woodhouse KA, Cooper SL. Polyurethanes in Biomedical Applications, CRC Press, New York, 1998, pp. 205.

11. Loh XJ, Tan KK, Li X, Li J. The in vitro hydrolysis of poly(ester urethane)s consisting of poly[(R)-3-hydroxybutyrate] and poly(ethylene glycol). Biomaterials. 2006; 27: 1841.

12. Guan J, Fujimoto KL, Sacks MS, Wagner WR. Preparation and characterization of highly porous, biodegradable polyurethane scaffolds for soft tissue applications. Biomaterials. 2005; 26: 3961 .

13. Cardy RH.Carcinogenicity and chronic toxicity of 2,4-toluenediamine in F344 rats. J. Natl. Cancer I, 1979; 62:1107. 
14. Tuominen J, Kylmä J, Kapanen A, Venelampi O, Itävaara M, and Seppälä J. Biodegradation of lactic acid based polymers under controlled composting conditions and evaluation of the ecotoxicological impact, Biomacromolecules, 2002; 3: 445-455.

15. Zhang JY, Beckman EJ, Piesco NP, Agarwal S. A new peptide-based urethane polymer: synthesis, biodegradation, and potential to support cell growth in vitro. Biomaterials. 2000; 21:1247.

16. Skarja GA, Woodhouse KA. Structure-property relationships of degradable polyurethane elastomers containing an amino acid-based chain extender. J Appl Polym Sci. 2000; 75: $1522-1534$.

17. Skarja GA, Woodhouse KA. In vitro degradation and erosion of degradable, segmented polyurethanes containing an amino acid-based chain extender. J Biomater Sci Polym Ed. 2001; 12: 851-873.

18. Asplund JO, Bowden T, Mathisen T, Hilborn J. Synthesis of highly elastic biodegradable poly(urethane urea). Biomacromolecules, 2007; 8:905-11.

19. Asplund B, Aulin C, Bowden T, Eriksson N, Mathisen T, Bjursten LM, Hilborn J. Journal of Biomedical Materials Research Part B: Applied Biomaterials. 2008;86: 45-55.

20. Sivak WN, Pollack IF, Petoud S, Zamboni WC, Zhang J, Beckman EJ. LDI-glycerol polyurethane implants exhibit controlled release of DB-67 and anti-tumor activity in vitro against malignant gliomas. Acta Biomater. 2008; 4: 852.

21. Sivak WN, Pollack IF, Petoud S, Zamboni WC, Zhang J, Beckman EJ. Catalyst-dependent drug loading of LDI-glycerol polyurethane foams leads to differing controlled release profiles. Acta Biomater. 2008; 4: 1263.

22. Ding MM, Zhou LJ, Fu XT, Tan H, Li JH, Fu Q. Biodegradable gemini multiblock poly ( $€-$ caprolactone urethane)s toward controllable micellization. Soft Matter. 2010; 9: 2087-2092.

23. Lu J, Ma SL, Sun JY, Xia CC, Liu C, Wang ZY, Zhao XN, Gao FB, Gong Q, Song B, Shuai XT, Ai H , Gu ZW. Biomaterials, 2009; 30: 2919.

24. Guo XD, Tan JPK, Kim SH, Zhang LJ, Zhang Y, Hedrick JL, Yang YY, Qian Y. Assembled Paclitaxel Structures: Templates for Hierarchical Block Copolymer Assemblies and Sustained Drug Release. Biomaterials, 2009; 30: 6556.

25. De Groot JH, de Vrijer R, Wildeboer BS, Spaans SC, Pennings AJ, New biomedical polyurethane ureas with high tear strengths. Polym. Bull. 1997; 38 :211-218. 
26. Spaans CJ, de Groot JH, Dekens FG, Pennings AJ. High molecular weight polyurethanes and a polyurethane urea based on 1,4-butanediisocyanate. Polym. Bull. 1998; 41: 131-138.

27. Singh V, Joung D, Zhai L, Das S, Khondaker SI, Seal S. Graphene based materials: Past, present and future. Prog. Mater. Sci. 2011; 56: 1178-1271.

28. Chiang M-F, Wu TM. Synthesis and characterization of biodegradable poly(l-lactide)/layered double hydroxide nanocomposites. Compos. Sci. Technol. 2010; 70: 110-115.

29. Jorfi M, Foster EJ. Recent advances in nanocellulose for biomedical applications. A Review. Journal of Applied Polymer Science, 2015; 132: 41719.

30. Wu X, Moon RJ, Martini A. Crystalline cellulose elastic modulus predicted by atomistic models of uniform deformation and nanoscale indentation. Cellulose, 2013; 20: 43-55.

31. Auras R, Harte B, Selke S. An overview of polylactides as packaging materials. Macromol Biosci. 2004; 4: 835-864.

32. Amine H, Adrien L, H`el `ene N, Xavier G, Jean C, Benjamin N. PLA-based biodegradable and tunable soft elastomers for biomedical applications. Biomed. Mater. 2011; 6: 065006.

33. Zhang KY, Ran, XH, Wang XM, Han CY, Han LJ, Wen X, Zhuang YG, Dong LS. Improvement in Toughness and Crystallization of Poly(L-Lactic Acid) by Melt Blending with Poly(Epichlorohydrin-Co-Ethylene Oxide). Polymer Engineering \& Science. 2011;51: 2370-2380.

34. Zhu GQ, Wang FG, Tan HS, Gao QC, Liu YY, Polym-Plast Technol. 2012; 51:1562-1566.

35. Na YH, He Y, Shuai X, Kikkawa Y, Doi Y and Inoue Y. Compatibilization Effect of Poly( $\varepsilon-$ Caprolactone)-b-Poly(Ethylene Glycol) Block Copolymers and Phase Morphology Analysis in Immiscible Poly(Lactide)/ Poly( $\varepsilon$-Caprolactone) Blends. Biomacromolecules, 2002; 3: $1179-1186$.

36. Brostrom J, Boss A and Chronakis IS. Biodegradable films of partly branched poly(1lactide)-co-poly(epsilon-caprolactone) copolymer: Modulation of phase morphology, plasticization properties and thermal depolymerisation. Biomacromolecules. 2004;5:1124-34.

37. Choi Y, Kim SY, Moon MH, Kim SH, Lee KS , Byun Y. Poly(ethylene glycol)-poly(Llactide) diblock copolymer prevents aggregation of poly(L-lactide) microspheres during ethylene oxide gas sterilization. Biomaterials. 2001; 22: 995-1004. 
38. Baudis S, Ligon SC, Seidler K, Weigel G, Grasl C, Bergmeister H, Schima, R. Liska . HardBlock Degradable Thermoplastic Urethane-Elastomers for Electrospun Vascular Prostheses. J Polym Sci A Polym Chem. 2012; 50: 1272-1280.

39. Chen S-H, Tsao C-T, Chou H-C, Chang C-H, Hsu C-T, Chuang C-N K. Wang, K.H. Hsieh . Synthesis of poly(lactic acid)-based polyurethanes. Polym Int. 2012; 62: 1159-1168.

40. Khan F, Valere S, Fuhrmann S, Arrighi V and Bradley M. Synthesis and cellular compatibility of multi-block biodegradable poly(?-caprolactone)-based polyurethanes. Journal of Materials Chemistry B. 2013; 20: 2590-2600.

41. Drumright RE, Gruber PR, Henton DE. Polylactic acid technology. Adv. Mater., 2000; 12: 1841-1846.

42. Bendix D. Chemical synthesis of polylactide and its copolymers for medical applications. Polym. Degrad. Stab, 1998; 59:129-135.

43. Jacobsen S, Degée Ph, Fritz HG, Dubois Ph, Jérome R. Polylactide (PLA)- A new way of production. Polym. Eng. Sci. 1999; 39: 1311-1319.

44. Hartmann MH. High molecular weight polylactic acid polymers. In Biopolymers from renewable resources, Kaplan, D. L. (ed.), Springer, Germany 1998, pp. 367-411.

45. Kricheldorf HR, Kreiser-Saunders I, Stricker A. Polylactones 48. SnOct2-initiated polymerisations of lactide: A mechanistic study. Macromolecules. 2000; 33: 702-709.

46. Löfgren A, Albertsson A-C, Dubois P, Jerome R. Recent advanceces in ring-opening polymerisation of lactones and related compounds. J. M. S.-Rev. Macromol. Chem. Phys., 1995;35: 379-418.

47. Carothers W, Dorough G, Van Natta F. Studies on polymerisation and ring formation. X. The reversible polymerisation of six-membered cyclic esters. J. Am. Chem. Soc.1932; 54:761-72.

48. Mecerreyes D, Je'ro^me R, DuboisP. Novel macromolecular architectures based on aliphatic polyesters: Relevance of the "coordination-insertion" ring-opening polymerization. Adv. Polym. Sci., 1999; 147: 1-59.

49. Lo“fgren A, Albertsson A-C, Dubois P, Je'rome R. Recent advances in ringopening polymerization of lactones and related compounds. J. Macromol. Sci.-Rev. Macromol. Chem. Phys. 1995; 35: 379-418.

50. Grijpma DW, Pennings AJ. Polymerization temperature effects on the properties of L-lactide and g-caprolactone copolymers. Polym. Bull. 1991; 25: 335-341. 
51. Prego G, Cella GD, Bastioli C. Effect of molecular weight and crystallinity on poly(lactic acid) mechanical properties. J. Appl. Polym. Sci., 1996; 59: 37-43.

52. Duda A, Penczek S, Kowalski A. Libiszowski polymerization of caprolactone and L, Ldilactide initiated with stannous octoate and stannous butoxide-a comparison. Macromol. Symp. 2000; 153: 41-53.

53. Korhonen H, Helminen A, Seppala JV. Synthesis of polylactide in the presence of coinitiators with different number of hydroxyl groups. Polymer, 2001: 42: 7541-7549.

54. Kricheldorf HR, Serra A. Polylactones. 6: Influence of various metal salts on the optical purity of poly(L-lactide). Polym. Bull., 1985;14: 497-502.

55. Schwach G, Coudane J, Engel R, Vert M. More about the polymerization of lactides in the presence of stannous octoate. Journal of Polymer Science Part A: Polymer Chemistry. 1997; $35: 3431-3440$.

56. Han DK, Hubbell JA. Lactide-based poly(ethylene glycol) polymer networks for scaffolds in tissue engineering. Macromolecules. 1996;29: 5233-5235.

57. Moon SI, Kimura Y. Melt polycondensation of L-lactic acid to poly(L-lactic acid) with Sn(II) catalysts combined with various metal alkoxides. Polym Int., 2003;52:299-303.

58. Korhonen H, Helminen A, Seppala JV. Synthesis of polylactide in the presence of coinitiators with different number of hydroxyl groups. Polymer, 2001;42: 7541-7549.

59. Zhang X, MacDonald DA, Goosen MF, McAuley KB. Mechanism of lactide polymerization in the presence of stannous octoate: The effect of hydroxyl and carboxylic acidsubstances. J. Polym. Sci. Part A: Poly. Chem. 1994;32: 2965-2970.

60. Hyon SH, Jamshidi K, Ikada Y. Synthesis of polylactides with different molecular weights. Biomaterials, 1997;18: 1503-1508.

61. Jacobsen S, Fritz HG, Degee P, Dubois P, Jerome R. New developments on the ring-opening polymerization of polylactide. Industrial Crops and Products, 2000;11: 265-275.

62. Rafier G, Lang J, Jobmann M. Bechthhold I. Process for manufacturing homoand copolyesters of lactic acid. U.S. Patent 6, 2003, 657,042.

63. Moller M, Nederberg F, Lim LS, Kange R, Hawker CJ, Hedrick JL, Gu Y, Shah R, Abbott L. Stannous(II) trifloromethane sulfonate: a versatile catalyst for the controlled ring-opening polymerization of lactides: formation of stereo-regular surfaces from polylactide brushes. Journal of Polymer Sciene: Part A: Polymer Chemistry, 2001; 39: 3529-3538. 
64. Lee MW, Tan HT, Chandrasekaran M, Ooi CP. synthesis and characterization of PLLA by melt polycondensation using binary catalyst system. SIMTech Rep., 2005; 6:40-4.

65. AbdelFattah TM, Pinnavata TJ. Substituted mesoporous silica molecular sieve (Si-HMS): Synthesis and properties as a heterogeneous catalyst for lactide ring-opening polymerization. Chem. Commun., 1996; 5: 665-666.

66. Ajioka M, Enomoto K, Suzuki K, Yamaguchi A. Basic properties of polylactic acid produced by the direct condensation of lactic acid. Bull.Chem. Soc. Jpn., 1995;68: 2125-2131.

67. Metters AT, Anseth KS, Bowman CN. Fundamental studies of a novel, biodegradable PEGb-PLA hydrogel. Polymer, 2000; 41: 3993-4004.

68. Wang S, Cui W, Bei J. Bulk and surface modifications of polylactide. Analytical and Bioanalytical Chemistry, 2005; 381: 547-556.

69. Zhang L. Camptothecin derivative-loaded poly(caprolactone-co-lactide)-b-PEG-bpoly(caprolactone-co-lactide) nanoparticles and their biodistribution in mice. Journal of controlled release, 2004; 96: 135-148.

70. Riley T. Physicochemical evaluation of nanoparticles assembled from poly(lactic acid)poly(ethylene glycol) (PLA-PEG) block copolymers as drug delivery vehicles. Langmuir, 2001; 17: 3168-3174.

71. Li S, Vert M. Synthesis, characterization, and stereocomplex-induced gelation of block copolymers prepared by ring-opening polymerization of $\mathrm{L}$ (D)-lactide in the presence of poly(ethylene glycol). Macromolecules, 2003; 36: 8008-8014.

72. Fu B. Preparation of lactic acid based polyurethanes modified by castor oil. Advanced Materials Research, 2008; 47: 1458-1461.

73. Matsumoto J, Nakada Y, Sakurai K, Nakamura T, Takahashi Y. Preparation of nanoparticles consisted of poly(L-lactide)-poly(ethylene glycol)-poly(L-lactide) and their evaluation in vitro. International Journal of Pharmaceutics, 1999 ; 185: 93-101.

74. Lang M, Bei J, Wang S. Synthesis and characterization of polycaprolactone/poly(ethylene oxide)/polylactide tri-component copolymers. J. Biomater. Sci. Polymer Edn., 1999 ;10: 501 512.

75. Lemmouchi Y, Perry MC, Amass AJ, Chakraborty K, Schue F. Novel Synthesis of Biodegradable Poly(lactide-co-ethylene glycol) Block Copolymers. Journal of Polymer Science: Part A: Polymer Chemistry, (2007). DOI 10.1002/pola. 
76. Wan Y, Chen W, Yang J, Bei J, Wang S. Biodegradable poly(l-lactide)-poly(ethylene glycol) multiblock copolymer:synthesis and evaluation of cell affinity. Biomaterials, 2003; 24 : 2195-2203.

77.Wang Z-Y, Zhao Y-M, Wang F. Syntheses of Poly(lactic acid)-Poly(ethylene glycol) Serial Biodegradable Polymer Materials via Direct Melt Polycondensation and Their Characterization. Journal of Applied Polymer Science, 2006; 102: 577-587.

78. Huh K M, Bae Y H. Synthesis and characterization of poly(ethylene glycol)/poly(l-lactic acid) alternating multiblock copolymers. Polymer 1999; 40: 6147-6155.

79. Yasugia K, Nagasakia Y, Katoa M, Kataokab K. Preparation and characterization of polymer micelles from poly(ethylene glycol)-poly(D,L-lactide) block copolymers as potential drug carrier. Journal of Controlled Release 1999; 62: 89-100.

80. Bonsignore P. Production of high molecular weight polylactic acid, US5470944, 1995.

81. Inata H, Matsumura S. Chain extender for polyester. I. Addition-type chain extenders reactive with carboxyl end groups of polyesters. J. Appl. Polym. Sci., 1985; 30: 3325-3337.

82. Loontjens T, Pauwels K, Derks F, Neilen M, Sham C K, Serné M. The action of chain extender in nylon-6, PET, and model compounds. J. Appl. Polym. Sci., 1997; 65:1813-1819.

83. Inata $\mathrm{H}$, Matsumura $\mathrm{S}$. Chain extenders for polyester. II. Reactivities of carboxyladditiontype chain extenders; bis cyclic-imino-ethers. J. Appl. Polym. Sci.1986;32:51935202.

84. Inata H, Matsumura S. Chain extender for polyester. V. Reactivities of hydroxyl-additiontype chain extender; 2,2'-bis(4H-3,1-benzoxazin-4-one), J. Appl. Polym. Sci., 1987;34: 2609-2617.

85. Inata H, Matsumura S. Chain extenders for polyesters. III. Addition-type nitrogen-containing chain extenders reactive with hydroxyl end groups of polyesters. J. Appl. Polym. Sci., 1986;32:4581-4594.

86. Inata H, Matsumura S. Chain extender for polyester. IV. Properties of the polyesters chainextended by 2,2’-bis(2-oxazoline). J. Appl. Polym. Sci., 1987; 33 : 3069-3079.

87. Hiltunen K. Synthesis and characterization of lactic acid based poly(ester-urethanes). Acta Polytech. Scand. Chem. Technol. Ser., 1997; 251: 1-56.

88. Kylmä J. Lactic Acid Based Poly(ester-urethane) Modification via copolymerization, chain linking and blending, Acta Polytech. Scand. Chem. Technol. Ser., 2001; 282: 1-47. 
89. Wu J, Wu C, Kuo M C, Tsai Y, J. Characterization and Properties of Reactive Poly (Lactic Acid)/Ethylene-Vinyl Alcohol Copolymer Blends with Chain-Extender. Polym. Environ., $2016 ; 24: 129-138$.

90. X.-Q. Li, B. Wang, H.-Y. Ji, Y. Li, Catal. Sci. Technol. 2016; 1:1-22.

91. Nagarajan V, Mohanty K A, Misra M. Perspective on polylactic acid (PLA) based sustainable materials for durable applications: Focus on toughness and heat resistance. ACS Sustainable Chemistry \& Engineering. 2016; 4: 2899-2916.

92. Seppälä J, Härkönen M, Hiltunen K, Malin M. Biodegradable Thermoplastic Poly(esterurethane), a presentation at MakroAkron '94, 35th IUPAC International Symposium on Macromolecules, Akron, July 11-15, 1994.

93. Härkönen M, Hiltunen K, Malin M, Seppälä J. Properties and polymerization of biodegradable thermoplastic poly(ester-urethane). J.M.S.-Pure Appl. Chem. 1995;32: 857-62.

94. Hiltunen K, Härkönen M, Seppälä J, Väänänen T. The synthesis and characterization of lactic acid based telehelic polymers. Macromolecules. 1996 ; 29: 8677-8682.

95. Hiltunen K, Seppälä J, Härkönen M. Lactic acid based poly(ester-urethanes). Use of hydroxyl terminated prepolymer in urethane synthesis. J. Appl. Polym. Sci., 1997; 63:10911100.

96. Kylmä J, Härkönen M, Seppälä J. The modification of lactic acid based poly(ester-urethane) by copolymerization. J. Appl. Polym. Sci., 1997; 63: 1865-1872.

97. Kylmä J, Seppälä JV. Synthesis and characterization of a biodegradable thermoplastic poly(ester-urethane) elastomer. Macromolecules, 1997;30: 2876-2882.

98. Hiltunen K, Seppälä JV. The use of different diols in the synthesis of low molecular weight lactic acid based telechelic prepolymers. J. Appl. Polym. Sci., 1998; 67: 1017-1023.

99. Seppälä JV, Korhonen H, Kylmä J, Tuominen J. General methodology for chemical synthesis of polyesters, in Biopolymers Vol 3b Polyesters II - Properties and chemical synthesis. Doi, Y. and Steinbüchel, A (ed.), Wiley-VCH, Germany 2002, pp. 327-369.

100. Pavelkova A, Kucharczyk P, Stloukal P, Koutny M, Sedlarik V. Novel poly(lactic acid)poly(ethylene oxide) chain-linked copolymer and its application in nano-encapsulation. Polym. Adv. Technol., 2014; 25: 595-604. 
101. Ali F B, Kang D J, Kim MP, Cho C-H, Kim BJ. Synthesis of biodegradable and flexible, polylactic acid based, thermoplastic polyurethane with high gas barrier properties. Polym Int., 2014; 63: 1620-1626.

102. Dieterich D, Grigat E, Hahn W. Chemical and physical-chemical principles of polyurethane chemistry, in Polyurethane Handbook: Chemistry - Raw Materials - Processing Applications-Properties, Oertel, G. (ed.), Hanser Verlag, Munich 1985, p 7-41

103. Szycher M. Isocyanate Chemistry, in Szycher's Handbook of Polyurethane, CRC Press LLC, Florida 1999, p 4-1-40.

104. Lenz RW. Biodegradable polymers, in Biopolymers I. Peppas, N.A. and Langer, R.S. (Ed), Springer-Verlag Berlin Heidelberg 1993, pp 1-40.

105. Schwach G, Coudane J, Engel R, Vert M. Influence of polymerisation conditions on the hydrolytic degradation of poly(DL-lactide) polymerised in the presence of stannous octoate or zinc-metal. Biomaterials, 2002; 23: 993-1002.

106. Gorna K, Gogolewski S. In vitro degradation of novel medical biodegradable aliphatic polyurethanes based on $\varepsilon$-caprolactone and Pluronics® with various hydrophilities. Polym. Degrad. Stab, 2002; 75: 113-122.

107. Rehman I, Andrews EH, Smith R. In vitro degradation of poly(ester-urethanes) for biomedical applications. J. Mater. Sci.- Mater. Med., 1996; 7: 17-20.

108. Hyon S-H, Jamshidi K, Ikada Y. Effects of residual monomer on the degradation of DLlactide polymer. Polym. Int., 1998; 46:196-202.

109. Rich J, Tuominen J, Kylmä J, Seppälä J, Nazhat SN, Tanner KE. Lactic acid based PEU/HA and PEU/BCP composites: Dynamic mechanical characterization over hydrolysis. J. Biomed. Mater. Res., (Appl. Biomater.) 2002;63:346-353.

110. Hiltunen K, Seppälä JV, Itävaara M, Härkönen M. The biodegradation of lactic acid based poly(ester-urethanes). J. Environ. Polym. Degrad., 1997; 5: 167-173.

111. Linhardt RJ, Wang HT, Flanagan DR, Schmitt HT, Palmer H. Biodegradable poly(esters) for the controlled delivery of vaccines. Polym. Mater. Sci. Eng., 1990; 63: 39-42.

112. Pitt CG, Gratzl MM, Kimmel GL, Surles J, Schindler A. Aliphatic polyesters II. The degradation of poly(DL-lactide), poly( $\varepsilon$-caprolactone), and their copolymers in vivo. Biomaterials, 1981; 2: 215-220. 
113. Iqbal MH, Kyazze G, Tron $\mathrm{T}$, Keshavarz $\mathrm{T}$. Laccase-assisted grafting of poly(3hydroxybutyrate) onto the bacterial cellulose as backbone polymer: development and characterisation. Carbohydr. Polym., 2014; 113: 131-137.

114. Lee KY, Tammelin T, Schulfter K, Kiiskinen H, Samela J, Bismarck A. High performance Cellulose nanocomposites: comparing the reinforcing ability of bacterial cellulose and nanofibrillated cellulose. ACS Appl Mater Interfaces. 2012;4:4078-86.

115. Yang HS, Kim HJ, Son J, Park HJ, Lee BJ, Hwang TS. Ricehusk flour filled polypropylene composites: Mechanical and morphological study. Composite Structures, 2004; 63: 305-312.

116. Iqbal HMN, Kyazze G, Keshavarz T. Advances in the valorization of lignocellulosic materials by biotechnology: An overview. BioResources. 2013;8: 3157-3176.

117. Rockville MD: FDA, 2012.U.S. Department of Health and Human Services. Pyrogen and endotoxins testing: Questions and answers. In: Guidance for industry.

118. Thielemans W, Warbey CR, Walsh DA. Perm selective nanostructured membranes based on cellulose nanowhiskers. Green Chem, 2009; 11: 531-537.

119. Sacui IA, Nieuwendaal RC, Burnett DJ, Stranick SJ, Jorfi M, Weder C, et al. Comparison of the Properties of Cellulose Nanocrystals and Cellulose Nanofibrils Isolated from Bacteria, Tunicate, and Wood Processed Using Acid, Enzymatic, Mechanical, and Oxidative Methods. ACS Appl. Mater. Interfaces. 2014; 6: 6127-138.

120. Spoljaric S, Salminen A, Luong ND, Seppälä J. Ductile nanocellulose-based films with high stretchability and tear resistance. European Polymer Journal. 2015; 69:328-340.

121. Wu X, Moon RJ, Martini A. Crystalline cellulose elastic modulus predicted by atomistic models of uniform deformation and nanoscale indentation. Cellulose, 2013; 20: 43-55.

122. Capadona JR, Shanmuganathan K, Trittschuh S, Seidel S, Rowan SJ, Weder C. Polymer nanocomposites with microcrystalline cellulose. Biomacromolecules, 2009; 10:712-16.

123. López SH, Santiago EV, Mora MM, Mancilla JRF, Contreras EAZ. Cellulose-Based Polymer Composite with Carbon Black for Tetrahydrofuran Sensing. International Journal of Polymer Science. 2013; ID 381653.

124. Ojijo V, Ray SS, Sadiku R. Toughening of biodegradable polylactide/poly(butylene succinate-co-adipate) blends via in situ reactive compatibilization. ACS Appl Mater Interfaces, 2013; 5:4266-4276. 
125. Miao C, Hamad WY. Cellulose reinforced polymer composites and nanocomposites: a critical review. Cellulose, 2013; 20: 2221-2262.

126. Azizi Samir MAS, Alloin F, Sanchez JY, Dufresne A. Nanocomposite polymer electrolytes based on poly(oxyethylene) and cellulose whiskers. Polymers: Cie^ncia e Tecnologia, 2005; 15:109-113.

127. Halpin JC, Kardos JL. Moduli of crystalline polymers emploing composites theory. J. Appl. Phys., 1972; 43: 2235-41.

128. Ouali N, Cavaille JY, Perez J. Elastic, viscoelastic and plastic behavior of multiphase polymer blends. Plast. Rubber Comp. Process. Appl., 1991;16:55-60.

129. Mi H-Y, Salick MR, Jing X, Jacques BR, Crone WC, Peng X-F, Turng L-S. Characterization of thermoplastic polyurethane/polylactic acid (TPU/PLA) tissue engineering scaffolds fabricated by microcellular injection molding. Mater. Sci. Eng., 2013; 33: 47674776.

130. Kouya T, Tada S-I, Minbu H, Nakajima Y, Horimizu M, Kawase T, Lloyd DR, Tanaka T. Microporous membranes of PLLA/PCL blends for periosteal tissue scaffold. Mater. Lett., 2013; 95: 103-106.

131. Kylma J, Seppala JV. Synthesis and Characterization of a Biodegradable Thermoplastic Poly(ester-urethane) Elastomer Macromolecules, 1997; 30: 2876-2882 .

132. Zhong Q, Ren J and Wang QF. Preparation and characterization of polylactide-blockpoly(butylene adipate) polyurethane thermoplastic elastomer.Polym Eng Sci.2011;51:908-16.

133. Manavitehrani I, Fathi A, Badr H, Daly S, Shirazi A N, Dehghani F. Biomedical Applications of Biodegradable Polyesters. A Review. Polymers, 2016; 8: 20.

134. Ping Qu, Yuan Gao, Guo-feng Wu, Li-ping Zhang. Nanocomposites of poly(lactic acid) reinforced with cellulose nanofibrils. BioResources, 2010; 5: 1811-1823.

135. Oksman K, Mathew AP, Bondeson D, Kvien I. Manufacturing process of cellulose whiskers/polylactic acid nanocomposites. Compos. Sci. Technol., 2006; 66: 2776-2784.

136. Arrieta MP, Castro-López Mde M, Rayón E, Barral-Losada LF, López-Vilariño JM, López J. Plasticized poly(lactic acid)-poly(hydroxybutyrate) (PLA-PHB) blends incorporated with catechin intended for active food-packaging applications. J Agric Food Chem., 2014; 62 : 10170-10180. 
137. Mitragotri S., Lahann J. Physical approaches to biomaterial design. Nature Materials. 2009; 8: 15-23. DOI: $10.1038 /$ nmat2344.

138. Saito N, Takaoka K. New synthetic biodegradable polymers as BMP carriers for bone tissue engineering. Biomaterials, 2003; 24: 2287-2293.

139. Hamad K, Kaseem M, Yang HW, Deri F, Ko1 YG. Properties and medical applications of polylactic acid: A review. eXPRESS Polymer Letters, 2015;9: 435-455.

140. Li G, Wang Z-X, Fu W-J, Hong B-F, Wang X-X, Cao L, Xu F-Q, Song Q, Cui F-Z, Zhang $\mathrm{X}$. Introduction to biodegradable polylactic acid ureteral stent application for treatment of ureteral war injury. BJU International, 2011;108: 901-906.

141. Leroux J-C, Allémann E, De Jaeghere F, Doelker E, Gurny R. Biodegradable nanoparticles From sustained release formulations to improved site specific drug delivery. Journal of Controlled Release, 1996; 39: 339-350.

142. Fishbein I, Chorny M, Rabinovich L, Banai S, Gati I, Golomb G. Nanoparticulate delivery system of a tyrphostin for the treatment of restenosis. Journal of Controlled Release. 2000; 65:221-229.

143. Matsumoto J, Nakada Y, Sakurai K, Nakamura T, Takahashi Y. Preparation of nanoparticles consisted of poly(L-lactide)-poly(ethylene glycol)-poly(L-lactide) and their evaluation in vitro. International Journal of Pharmacy. 1999; 185: 93-101.

144. Xing J, Zhang D, Tan T. Studies on the oridoninloaded poly(D,L-lactic acid) nanoparticles in vitro and in vivo. International Journal of Biological Macromolecules, 2007;40: 153-158.

145. Rancan F, Papakostas D, Hadam S, Hackbarth S, Delair T, Primard C, Verrier B, Sterry W, Blume-Peytavi U, Vogt A. Investigation of polylactic acid (PLA) nanoparticles as drug delivery systems for local dermatotherapy. Pharmaceutical Research, 2009; 26: 2027-2036.

146. Gao H, Wang YN, Fan YG, Ma JB. Synthesis of a biodegradable tadpole-shaped polymer via the coupling reaction of polylactide onto mono(6-(2-aminoethyl)amino-6-deoxy)-\%cyclodextrin and its properties as the new carrier of protein delivery system. Journal of Controlled Release, 2005; 107: 158-173.

147. Vila A. PLA-PEG particles as nasal protein carriers: The influence of the particle size. International Journal of Pharmaceutics, 2005; 292: 43-52.

148. $\mathrm{Hu}$ K. Lactoferrin-conjugated PEG-PLA nanoparticles with improved brain delivery: In vitro and in vivo evaluations. Journal of Controlled Release. 2009;134: 55-61. 
149. Zhang Z, Feng SS. Nanoparticles of poly(lactide)/vitamin E TPGS copolymer for cancer chemotherapy: Synthesis, formulation, characterization and in vitro drug release. Biomaterials. 2006;27: 262-270.

150. Venkatraman SS. Micelle-like nanoparticles of PLA-PEG-PLA triblock copolymer as chemotherapeutic carrier. International Journal of Pharmaceutics, 2005;298: 219-232.

151. Wu XL. Tumor-targeting peptide conjugated $\mathrm{pH}$-responsive micelles as a potential drug carrier for cancer therapy. Bioconjugate Chemistry, 2010; 21: 208-213.

152. Liu C, Yu W, Chen Z, Zhang J, Zhang N. Enhanced gene transfection efficiency in CD13positive vascular endothelial cells with targeted poly(lactic acid)-poly(ethylene glycol) nanoparticles through caveolae-mediated endocytosis. Journal of Controlled Release, 2011;151:162-75.

153. Shalaby KS, Soliman ME, Casettari L, Bonacucina G, Cespi M, Palmieri GF, Sammour OA, El Shamy A. Determination of factors controlling the particle size and entrapment efficiency of noscapine in PEG/PLA nanoparticles using artificial neural networks. International Journal of Nanomedicine, 2014;9:4953-4964.

154. Matsusue Y, Nakamura T, Suzki S, Iwasaki R. Biodegradable pin fixation of osteochondral fragments of the knee. Clinical Orthopaedics and Related Research. 1996; 322:166-173.

155. Bucholz RW, Henry S, Henley MB. Fixation with bioabsorbable screws for the treatment of fractures of the ankle. Journal of Bone and Joint Surgery, 1994; 76: 319-324.

156. Casteleyn PP, Handelberg F, Haentjens P. Biodegradable rods versus Kirschner wire fixation of wrist fractures. A randomised trial. Journal Bone and Joint Surgery. $1992 ; 74$ : 858-861.

157. Hope PG, Williamson DM, Coates CJ, Cole WG. Biodegradable pin fixation of elbow fractures in children: A randomized trial. Journal Bone and Joint Surgery, 1991;73: 965968.

158. Haers PE, Suuronen R, Lindqvist C, Sailer H. Biodegradable polylactide plates and screws in orthognathic surgery: Technical note. Journal of Cranio Maxillofacial Surgery. 1998;26: 87-91.

159. A Sani, Y Dahman. Improvements in the production of bacterial synthesized biocellulose nanofibres using different culture methods. J Chem Technol Biotechnol 2010; 85: 151-164. DOI 10.1002/jctb.2300. 
160. Hirai A, Inui O, Horii F, Tsuji M. Phase separation behavior in aqueous suspensions of bacterial cellulose nanocrystals prepared by sulfuric acid treatment.Langmuir, 2009;25: 497-502.

161. Leenslag JW, Pennings AJ. Synthesis of high-molecular-weight poly(L-lactide) initiated with tin 2-ethylhexanoate. Makromol. Chem., 1987; 188: 1809-1814.

162. Fortunati E, Rinaldi S, Peltzer M, Bloise N, Visai L, Armentano I, Jiménez A, Latterini L, Kenny J. Nano-Biocomposite Films with Modified Cellulose Nanocrystals and Synthesized Silver Nanoparticles. Carbohydr. Polym. 2014;101: 1122-1133.

163. Izunobi J, Higginbotham CL. Polymer Molecular Weight Analysis by ${ }^{1} \mathrm{H}-\mathrm{NMR}$ Spectroscopy. J. Chem. Educ., 2011; 88: 1098-1104.

164. Painter PC, Coleman MM. Fundamentals of Polymer Science: An Introductory Text, 2nd ed.; Technomic: Lancaster, PA, 1997; pp 339394.

165. Wang H L, Zhang Y, Tian M, Zhai LF, Wei Z, Shi TJ. Preparation and degradability of poly(lactic acid)-poly(ethylene glycol)-poly(lactic acid)/SiO${ }_{2}$ hybrid material J.Appl. Polym. Sci., 2008; 110: 3985 -3989.

166. LANG M, BEI J, WANG S. Synthesis and characterization of polycaprolactone/ poly(ethylene oxide)/ polylactide tri-component copolymers. J. Biomater. Sci. Polymer Edn., 1999; 10: 501-12.

167. Ali F B, Kang DJ, Kim MP, Cho C-H, Kim BJ. Synthesis of biodegradable and flexible, polylactic acid based, thermoplastic polyurethane with high gas barrier properties. Polym Int., 2014; 63: 1620-1626.

168. Rashkov I, Manolova N, Li SM, Espartero JL, Vert M. Synthesis, Characterization, and Hydrolytic Degradation of PLA/PEO/PLA Triblock Copolymers with Short Poly(L-lactic acid) Chains. Macromolecules, 1996; 29:50-56.

169. Li SM, Rashkov I, Espartero JL, Manolva N, Vert M. Synthesis, Characterization, and Hydrolytic Degradation of PLA/PEO/PLA Triblock Copolymers with Long Poly(L-lactic acid) Blocks.Macromolecules, 1996; 29:57-62.

170. Youxin L, Kissel T. Synthesis and properties of biodegradable ABA triblock copolymers consisting of poly(L-lactic acid) or poly(L-lactic-co-glycolic acid) A-blocks attached to central poly(oxyethylene) B-blocks. J. Control. Release, 1993;27:247-257. 
171. Hugo E. Gottlieb, Vadim Kotlyar, Abraham Nudelman. NMR Chemical Shifts of Common Laboratory Solvents as Trace Impurities .J. Org. Chem., 1997; 62: 7512-7515.

172. Kulkarni RK, Pani KC, Neuman C, Leonard F. Biodegradable polylactic acid Biomed. Mater. Res., 1971; 5: 169.

173. Luo BH, Zhou C R, Chen YK, Li LH, Jiao YP. Chin J Funct Polym. 2005;18:299.

174. Wang ZY, Zhao YM, Wang F, Wang J. Syntheses of poly(lactic acid-co-glycolic acid) serial biodegradable polymer materials via direct melt polycondensation and their characterization. J Appl. Polym. Sci., 2006; 99: 244-252.

175. Zhang CH, Zhao KJ, Hu TY, Cui XF, Brown N, Boland T. Loading dependent swelling and release properties of novel biodegradable, elastic and environmental stimuli-sensitive polyurethanes. J Control Release. 2008;131:128-36.

176. H. Fukuzaki, M. Yoshida, M. Kumakura, T. Mashimo, H. Yuasa, K. Imai and Y. Hidetoshi, Polymer. 1990, 31, 2006.

177. Wibullucksanakul S, Hashimoto K, Okada M. Hydrolysis and release behavior of hydrolyzable poly(etherurethane) gels derived from saccharide-, L-lysine-derivatives, and poly(propylene glycol). Macromol. Chem. Phys., 1997; 198: 305-319.

178. Umare SS, Chandure AS. Synthesis, characterization and biodegradation studies of poly (ester urethane) s.Chemical Engineering Journal. 2008;142:65-77.

179. Sabir MI, Xu X, Li L. A review on biodegradable polymeric materials for bone tissue engineering applications. J Mater Sci., 2009; 44: 5713-5724.

180. Li HY, Chang J. pH-compensation effect of bioactive inorganic fillers on the degradation of PLGA. Compos. Sci Technol. 2005;65:2226-2232

181. Ding M, Li JH, Fu XT, Zhou J, Tan H, Gu Q, Fu Q. Synthesis, Degradation, and Cytotoxicity of Multiblock Poly( $\varepsilon$-caprolactone urethane)s Containing Gemini Quaternary Ammonium Cationic Groups . Biomacromolecules, 2009; 10: 2857-2865. 